U. S. DEPARTMENT OF COMMERCE NATIONAL BUREAU OF STANDARDS

\title{
DESIGN AND CONSTRUCTION OF BUILDING EXITS
}





\section{U. S. DEPARTMENT OF COMMERCE}

DANIEL C. ROPER, Secretary

NATIONAL BUREAU OF STANDARDS

LYMAN J. BRIGGS, Director

\section{DESIGN AND CONSTRUCTION OF BUILDING EXITS}

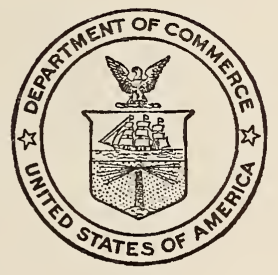

UNITED STATES

GOVERNMENT PRINTING OFFICE

WASHINGTON : 1935 



\section{DESIGN AND CONSTRUCTION OF BUILDING EXITS}

\section{ABSTRACT}

The deplorable loss of life that occurs annually in building fires can be reduced by providing suitable exits. Building-code requirements vary widely as to how many exits are needed, what sizes they should be, and how the details concerning them should be worked out. To aid those interested in the problem, surveys of current practice in providing exits and of the rates at which people can effect their escape through different kinds of exits have been made. The methods employed in the surveys and the results are presented here in detail. To supplement the information thus obtained, opinions have been solicited from numerous architects, building officials, fire-protection experts, and others. Five methods of calculating exit width in current use are discussed. As a useful reference when local requirements are under consideration, suggested requirements are presented, together with notes on the reasoning employed in connection with them.

\section{CONTENTS}

I. Introduction

II. Importance of fire losses.

1. Property loss

2. Life loss

3. Causes of loss of life by fire

III. Building exits survey

1. Procedure

2. Sources of information

3. Field investigations.

4. Tabulation of data collected.

5. Population studies...

6. Location and number of exits

7. Stairway widths

8. Proportion of treads and risers

9. Stairway enclosures

10. Exit outlets

11. Special forms of exits.

12. Exit designation

13. Exit maintenance

IV. Survey of traffic movement in exits

1. Procedure

2. Sources of information

3. Conclusions of previous traffic counts

4. Field work

5. Methods used in making counts

6. Conditions affecting traffic counts made.

7. Tabulation of counts on stairway discharge

8. Characteristics of stairway discharge

9. Ramps.....

10. Doorways.

v. Method of calculating exit width

1. Capacity method.

2. Flow method

3. Combined method

4. Probability method.

5. Floor-area method

6. Development of a satisfactory method

7. Credit for elevators. 
APPENDIX

VI. Means of egress

1. Recommendations. 46

2. Definitions

3. Classifications

Sec. 3-1. Classification of buildings by occupancy

$3-2$. Classification of buildings by type of construction.-... 48

7-1. Application of chapter.

$7-1-1$. New buildings

7-1-2. Existing buildings..... 50

7-1-3. Alterations

7-2. Kinds of exits

7-3. Minimum number of exits 51

$7-3-1$. Room doorways

7-3-2. Ground-floor exits..... 52

7-3-3. Floor-area exits

7-3-4. Exits for institutional occupancies

$7-3-5$. Exits for places of assembly ...

7-3-5-1. Rooms

$7-3-5-2$. Buildings

$7-3-5-3$. Separation of theater stairways

7-3-6. Boiler-room exits

7-4. Location of exits

7-4-1. Distance to exits

7-4-2. Distribution of exits.

7-4-3. Outlets from exits

7-5. Relation of population to exits

7-5-1. Determination of population. 57

7-5-2. Population limited

7-6. Stairways

7-6-1. Width

7-6-1-1. Minimum width..... 59

7-6-1-2. Aggregate width

7-6-1-3. Changes in stairway width

7-6-1-4. Exit stairways serving floor area below grade

7-6-2. Construction... 64

7-6-2-1. Materials

$7-6-2-2$. Treads and risers.

7-6-2-3. Required landings. 65

7-6-2-4. Changes in floor level

7-6-2-5. Handrails

7-6-3. Enclosures.-.

7-6-3-1. Construction. 66

$7-6-3-2$. Openings

7-6-4. Moving stairs.-1

7-7. Ramps.

7-8. Doorways. 67

7-8-1. Width

7-8-2. Hanging of doors

7-8-3. Revolving doors.. 69

7-8-4. Door fastenings... 70

7-9. Exit passageways 70

7-9-1. Width

7-9-2. Enclosures. 70

$7-9-2-1$. Construction. 70

7-9-2-2. Openings.

7-9-3. Inclined exit passageways 71

7-10. Hallways _._. 71

7-11. Horizontal exits 72

7-12. Modifications in required exit widths 73

7-13. Exit designation 73

7-13-1. Exit signs

7-13-2. Lighting

7-14. Maintenance

INDEX TO RECOMMENDATIONS. 75 
1. Causes of loss of life from fires

2. Deaths by fire in buildings in New York City, 1920 to 1931 , inclusive

3. Deaths per fire

4. Causes of loss of life in hotel fires

5. Relation of garage and tenement fires to total in New York City

6. Summary of exit measurements for office buildings_._.

7. Summary of exit measurements for store buildings

8 . Summary of exit measurements for factory buildings.

9. Summary of exit measurements for school buildings___._._.

10. Summary of exit measurements for apartment buildings_._.

11. Summary of exit measurements for hotels

12. Summary of exit measurements for hospitals

13. Summary of exit measurements for dormitories, churches, and city halls

14. Summary of exit measurements for theaters

15. Average of exit measurements

16. Summary of some previous traffic movement observations

17. Survey of exits in school buildings in Rochester, N. Y

18. Capacity tests on revolving doors of certain buildings in New York City -

19. Summary of observations of traffic movement on stairways

20. Summary of observations of traffic movement on ramps........

21. Summary of observations of traffic movement through gates and doorways_...

\section{ILLUSTRATIONS}

1. Doorways placed "as remote as practicable"

2. Doorway location for connecting rooms occupied by 100 or more persons

3. Discharge from a theater into a court, thence through a passageway to the street

4. Distribution of stairways in a building where services are in a central core

5. Example for computation of amount of service area alloted to mixed occupancies.

6. Relation between exit width and population per floor

7. Relation between exit width and floor area.

8. Results of exits survey compared with curve adopted for office buildings.

9. Results of exits survey compared with curve adopted for stores

10. Results of exits survey compared with curve adopted for factories.--

11. Results of exits survey compared with curve adopted for schools...--

12. Results of exits survey compared with curve adopted for apartments.

13. Results of exits survey compared with curve adopted for hotels and dormitories

14. Results of exits survey compared with curve adopted for hospitals and institutions _... . .

15. Results of exits survey compared with curve adopted for places of assembly

16. Example for computation of doorway widths

17. Example for computation of exit passageway widths

18. Level landings required on inclined passageways

19. Various types of horizontal exits 



\section{INTRODUCTION}

If buildings are to be safe for human occupancy adequate exits are essential. State governments have a legal right to require that exits shall be suitable in number, size, and location. This power is generally exercised through local building codes. Inspection of representative codes discloses that the degree of safety assured occupants of buildings varies widely. There is no apparent reason why more emphasis should be placed on the subject in one locality than in another. That such a condition exists seems to be due partly to the development of regulations independently in different parts of the country, partly to the existence of varying ideas on what constitutes reasonable provision for safety, and partly to a lack of information on fundamentals.

Some five methods of determining the necessary stairways for a given building are in current use. These methods all contain desirable features, but they tend to become confusing to anyone not a student of exit design and practice and they have been reported to cause difficulties for architects, engineers, building officials, and others. While some maintain that many existing codes are too severe, reducing unreasonably the rentable area of buildings, numerous deaths by fire testify to the need of extreme care in lowering present requirements.

Fire protection is closely associated with provision for building exits. This was recognized by the Department of Commerce Building Code Committee in preparing its report, Recommended Minimum Requirements for Fire Resistance in Buildings, issued in 1931. The committee, which has now been discontinued, was responsible for seven reports dealing with various aspects of building regulation that have been widely used in preparing and revising building codes. Its membership at the time of its dissolution was as follows:

WILLIAM K. HATT, chairman; professor of civil engineering and director, Laboratory for Testing Materials, Purdue University; member, American Society of Civil Engineers, American Concrete Institute, and American Society for Testing Materials.

Albert KaHN, architect, Detroit, Mich.; fellow, American Institute of Architects.

RUDOLPH P. Miller, consulting engineer, New York, N. Y.; past president, Building Officials' Conference; member, American Society of Civil Engineers, American Institute of Consulting Engineers, and American Society for Testing Materials.

John A. Newlin, in charge of section of timber mechanics, Forest Products Laboratory, Forest Service, U. S. Department of Agriculture, Madison, Wis.; member, American Society for Testing Materials, and American Society. of Civil Engineers.

William Arthur Payne, vice president, Charles T. Wills, Inc., Building Construction, New York, N. Y.; vice president, New York Building Congress.

H. L. WhitTemore, chief, engineering mechanics section, National Bureau of Standards; manager, American Society of Mechanical Engineers; member, American Society for Testing Materials, American Association of Engineers, and American Welding Society.

Joseph P. Worcester, consulting engineer, Boston, Mass.; member, American Society of Civil Engineers, and American Institute of Consulting Engineers. 
Upon the completion of its report on fire-resistance requirements, the committee undertook a study of exit requirements with the object of developing provisions suitable for building codes. It was planned that the two sets of requirements should be used together. In conducting the study, existing requirements were compared and tentative provisions were drafted to serve as a basis for discussion. These were sent out to a large number of architects, engineers, building officials, and other groups, with a request for expression of opinion. The replies indicated wide divergency of views and the need for a greater amount of data upon which conclusions could be based.

Early in its work on exits the committee arranged to cooperate with the Committee on Safety to Life of the National Fire Protection Association, which is also the Sectional Committee on Building Exits of the American Standards Association. The latter committee had considered the problem over a long period. Its representatives participated in joint conferences and were generous in sharing the results of their studies.

Appreciating the need for more information the joint conference instituted surveys of existing exit facilities in buildings, and of the rate of flow of people through various types of exits. This work was conducted by John H. Courtney and Harry B. Houghton, associate engineers at the National Bureau of Standards, and George N. Thompson, secretary to the committee. The results are embodied in this report. To these are added proposed requirements which were in process of development when the Building Code Committee was discontinued.

To a greater extent than with some other features of building regulations, exit requirements must rest on composite judgment. The scarcity of fundamental data, the uncertainty of how both fire and human beings will act under varying conditions, and the great variety of occupancies to be dealt with, all tend to create a problem where divergency of opinion is possible. Experience, good judgment, and skillful interpretation of such facts as are available become the guides for arriving at reasonable and acceptable conclusions.

\section{IMPORTANCE OF FIRE LOSSES}

\section{PROPERTY LOSS}

The burning of buildings and their contents results in property loss and, much too frequently, in life loss. The property loss was estimated at approximately $\$ 500,000,000$ for the year 1930 , but dropped to about $\$ 270,000,000$ for 1933 . This discussion is not concerned with the property loss, important though it may be, but is concerned with the life loss because of its relation to the subject of exits.

\section{LIFE LOSS}

The loss-of-life statistics, unfortunately, are in no sense as complete as the property-loss figures. Such information as may be gathered from various sources, however, indicates that the death toll resulting from fire is an impressive one. The figures obtained by the United 
States Bureau of the Census indicate an average annual loss of life from fire and burns of nearly 7,500 persons. ${ }^{1}$ Figures from other sources often quoted are even higher, ranging between ten and fifteen thousand lives annually, although the evidence to substantiate these higher figures is lacking. In both cases, the loss of life results from a great variety of causes, some only remotely connected with fire. Nevertheless, the losses are of sufficient proportions to justify a diligent search into the underlying causes of such an apparently needless waste of human life.

The principal difficulty with the statistics commonly quoted in connection with loss of life by fire is that they are too inclusive. Thus all manner of deaths which are in any way, regardless of how remotely, connected with fire are compiled under the general heading of loss of life by fire, and the public, which has become accustomed to associate fires with burning buildings, conjures up a picture of a vast number of burning buildings in which these ten or fifteen thousand lives are lost annually. It fails from lack of complete information to take into account the fact that a great many of these deaths result from burns and scalds received from industrial processes; forest fires; explosions of vapors, gases, dust, and powder; bonfires; cleaning fluids; matches; and many other sources which have no connection with burning buildings, and, in many cases, which do not result in fires, in the commonly accepted usage of the term, at all.

The impression thus gained has undoubtedly been of assistance in the promotion of campaigns for safety to life and protection against fire and in that connection the misinterpretation of the statistics has not been important. But where they have resulted in drastic and unnecessarily restrictive requirements in building codes, it would appear desirable that they be broken down and the causes of loss of life by fire determined as accurately as possible in order to correct the impression that loss of life by fire means burned to death in a burning building, or that simply providing a number of stairways or fire escapes on buildings will eliminate this loss of life. This is not to minimize the importance of the statistics but rather, for the purpose of this report, to so adjust the data that a more proper relation between lives lost by fire, lives lost by fire in burning buildings, and the influence of exits on the number of lives lost in burning buildings can be established.

Probably the most nearly complete data on loss of life from fire are those collected by the United States Bureau of the Census. In the Census reports deaths resulting from fire are segregated into two classes: "Conflagration", which includes deaths from fires in buildings, forest fires, deaths under similar conditions, and "Burns", which includes deaths due to ignition of clothing or bodily burns without anything else necessarily being set on fire. For the 5-year period, 1916 to 1920, inclusive, the Census report shows an estimated average of 1,465 deaths annually for the conflagration classification. For the 9 -year period, 1921 to 1929 , inclusive, the deaths for this classification averaged 1,620 yearly, an increase which corresponds very closely to the increase in population for these two periods. In more recent years there has been a slight decline, the figure for 1933 standing at 1,521. It is difficult to estimate with any degree of exactness

1 Safety for the Household, Cir. BS C397, table 5, p. 9 (1932).

$1158-35-2$ 
the number of deaths in this classification occurring in burning buildings, but it is obviously somewhat less than the average figures cited. That there is a seasonal trend in the figures is indicated by the following monthly distribution for the year 1933 of deaths by conflagration, Continental United States (source, U. S. Bureau of the Census):

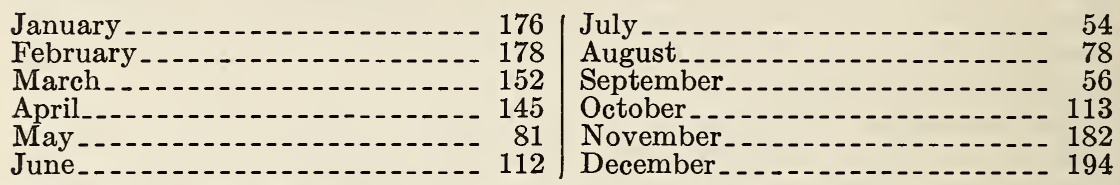

This is to be expected in view of the greater use of heating appliances in the winter months, although it might easily be upset by some major theater disaster having no relation to heating needs.

For the 5-year period, 1912 to 1916 , inclusive, the State of Illinois reported 1,511 deaths from fire and burns, 215 of which are listed under the causes as burned in burning buildings. ${ }^{2}$

\section{CAUSES OF LOSS OF LIFE BY FIRE}

The statistics covering the causes of loss of life by fire in buildings are admittedly meagre, due to the fact that no central agency is charged with the duty of compiling such a record. It is largely through the efforts of certain State officials and such organizations as the National Fire Protection Association that information of this character is available at all. It seems to be a well-established opinion that certain occupancies suffer greater loss of life by fire than others, but there is little data to support such a contention. The late Ira H. Woolson, consulting engineer, National Board of Fire Underwriters, and first chairman of the Department of Commerce Building Code Committee, stated in a paper presented before the Building Officials' Conference of America, in 1927, that fires occur at the rate of something like one a minute, day and night, in the United States. $^{3}$ Fortunately not all of these fires result in loss of life, but it seems almost impossible with such a frequency of occurrence that any one occupancy class could avoid life loss at one time or another.

Table 1 has been prepared from data published by the National Fire Protection Association. ${ }^{4}$ It does not purport to be a complete record for the entire country for any given period, but is of considerable interest as a representative list of causes. This table lists the causes of 3,207 deaths from 544 fires involving 104 different occupancies. Dwelling fires are not included because the statistical data relative to loss of life in dwellings are not readily available.

2 Safety for the Household, Cir. BS C397, table 7, p. 11 (1932).

3 Work of the Nat. Board of Fire Underwriters, Proc. 13th Annual Meeting of Bldg. Officials' Conference Am. p. 52 (1927).

${ }_{4}^{4}$ Quart. Nat. Fire Protect. Assn. (January 1925). 
TABLE 1.-Causes of loss of life from fires

[Excluding dwelling fires]

\begin{tabular}{|c|c|c|c|c|c|}
\hline \multirow[b]{2}{*}{ Cause } & \multicolumn{5}{|c|}{ Occupancy } \\
\hline & $\begin{array}{l}\text { Manufac- } \\
\text { turing } \\
\text { building }\end{array}$ & $\begin{array}{c}\text { Public } \\
\text { assembly }\end{array}$ & $\begin{array}{l}\text { Residence } \\
\text { building }\end{array}$ & $\begin{array}{l}\text { Miscella- } \\
\text { neous }\end{array}$ & Total \\
\hline $\begin{array}{l}\text { Inadequate exits } \\
\text { Rapid spread of fire } \\
\text { Jumped from burning buildings } \\
\text { Trapped in burning buildings } \\
\text { Overcome by smoke } \\
\text { Suffocation while asleep } \\
\text { Children alone } \\
\text { Panic unexplained } \\
\text { Iroquois Theater fire }\end{array}$ & $\begin{array}{r}152 \\
75 \\
57 \\
20 \\
24 \\
3 \\
5\end{array}$ & \begin{tabular}{r}
306 \\
30 \\
6 \\
2 \\
3 \\
\hdashline-1 \\
-15
\end{tabular} & $\begin{array}{r}32 \\
217 \\
26 \\
27 \\
48 \\
67 \\
6 \\
-\end{array}$ & $\begin{array}{r}4 \\
12 \\
7 \\
27 \\
9 \\
2 \\
- \\
-\end{array}$ & $\begin{array}{r}494 \\
334 \\
96 \\
76 \\
84 \\
72 \\
6 \\
5 \\
571\end{array}$ \\
\hline $\begin{array}{l}\text { Subtotal } \\
\text { Manufacturing processes (explosions) } \\
\text { Burns and ignition of clothing } \\
\text { Fire fighting and salvage } \\
\text { Miscellaneous (forest fires, building collapse, } \\
\text { etc.) } \\
\text { No data. }\end{array}$ & $\begin{array}{r}336 \\
541 \\
8 \\
44 \\
\\
41 \\
18\end{array}$ & $\begin{array}{r}918 \\
7 \\
2 \\
25\end{array}$ & $\begin{array}{r}423 \\
24 \\
23 \\
18\end{array}$ & $\begin{array}{r}61 \\
353 \\
31 \\
76 \\
98 \\
74\end{array}$ & $\begin{array}{r}1,738 \\
925 \\
64 \\
163 \\
139 \\
178\end{array}$ \\
\hline Grand total & 988 & 979 & 547 & 693 & 3,207 \\
\hline
\end{tabular}

From the reports of the New York City Fire Department, Rudolph P. Miller, a member of the U.S. Department of Commerce Building Code Committee, prepared an analysis of deaths resulting from fires in New York City for the years 1920 to 1931, inclusive. The total number of deaths by fire recorded was 1,453 , with a yearly average of 121. Injuries totaled 3,384 , with a yearly average of 282 . The total number of deaths by fire in buildings was 1,389 , divided among occupancy classifications as shown in table 2.

TABLE 2.-Deaths by fire in buildings in New York City, 1920 to 1931, inclusive (From reports of New York City Fire Department)

\begin{tabular}{|c|c|c|}
\hline Class of occupancy & $\begin{array}{l}\text { Number } \\
\text { of deaths }\end{array}$ & $\begin{array}{c}\text { Percentage } \\
\text { of deaths }\end{array}$ \\
\hline $\begin{array}{l}\text { Residence buildings: } \\
\text { Dwellings. } \\
\text { Furnished-room houses, } \\
\text { Multiple dwellings (3 or more families) } \\
\text { Hotels, including lodging houses } \\
\text { Clubs }\end{array}$ & $\begin{array}{r}292 \\
85 \\
800 \\
14 \\
4\end{array}$ & $\begin{array}{r}21.0 \\
6.1 \\
57.0 \\
1.0 \\
0.3\end{array}$ \\
\hline Total & 1,195 & 86.0 \\
\hline $\begin{array}{l}\text { Institutional buildings: } \\
\text { Asylum (1 insane asylum)... } \\
\text { Hospitals.... }\end{array}$ & $\begin{array}{r}25 \\
5 \\
\end{array}$ & $\begin{array}{l}1.8 \\
0.3\end{array}$ \\
\hline Total & 30 & $\overline{2.1}$ \\
\hline Public building & 1 & 0.1 \\
\hline $\begin{array}{l}\text { Business buildings: } \\
\text { Factories, including brewery and auto repair shop. } \\
\text { Moving-picture studio (1 case) } \\
\text { Stores-ow } \\
\text { Warehouses } \\
\text { Sheds, including piers }\end{array}$ & $\begin{array}{r}80 \\
10 \\
5 \\
13 \\
11\end{array}$ & $\begin{array}{l}5.8 \\
0.7 \\
0.4 \\
0.9 \\
0.8\end{array}$ \\
\hline Total & 119 & 8.6 \\
\hline $\begin{array}{l}\text { Garages, etc.: } \\
\text { Garages-public and private-1 } \\
\text { Stables, including barns. } \\
\text { Car barn }\end{array}$ & $\begin{array}{r}28 \\
7 \\
1 \\
\end{array}$ & $\begin{array}{l}2.0 \\
0.5 \\
0.1\end{array}$ \\
\hline Total.............. & 36 & 2.6 \\
\hline $\begin{array}{l}\text { Buildings in course of construction } \\
\text { Unoccupied buildings }\end{array}$ & $\begin{array}{l}3 \\
5\end{array}$ & $\begin{array}{l}0.2 \\
0.4 \\
\end{array}$ \\
\hline Grand total. & 1,389 & 100.0 \\
\hline
\end{tabular}


The 64 deaths, making up the difference between the deaths resulting from fires in buildings and the total deaths from fire, are reported as having occurred in or in connection with ships, launches, barges, scows, motorboats, automobiles on street, airplanes, railroad car, ferry-house, subway, elevated railway, auto service station, watchmen's shanties, storage yard, yard, street, manhole in street, or a bonfire.

Class 1, public, as established in the report, Recommended Minimum Requirements for Fire Resistance in Buildings, ${ }^{5}$ including city halls, churches, schools, theaters, and recreational buildings and structures, is charged with a large total loss of life. The nature of the occupancy with its dense population and susceptibility to panics accounts to a considerable extent for the large total.

Theaters have probably the most complete record of loss of any single occupancy due to the fact that loss of life when it does occur in theaters is of such size as to receive unusual publicity and consequently becomes a matter of easy record. The National Fire Protection Association has published a record ${ }^{6}$ of lives lost in theater fires during the period 1797 to 1930 in the United States, Europe, and Asia. The records are not complete, particularly in regard to fires in Europe and Asia, but they provide an indication of the extent of the life loss in theater fires. The total deaths for the 133-year period is approximately 12,000, and of this total the United States is charged with 1,671 .

It was reported some years ago that fires were occurring in theaters at the rate of 2 per day. It should be borne in mind that the life loss in theaters cannot be measured by the number of fires nor by the intensity or destructive effects of the fire. There are records of heavy loss of life in theaters in which there has been little if any fire, the deaths being due entirely to the development of panic conditions followed by a rush for the exits. An idea of the dense occupancy of theaters and the possibilities for the development of panic conditions may be gained from the reported seating capacity of the theaters of the Borough of Manhattan, New York City. For the year 1930 there were reported to be 301 theaters and moving-picture theaters in this borough alone with a total seating capacity for 356,623 persons. ${ }^{7}$

An analysis of the causes of 2,426 deaths in 50 theater fires is given below: 8

\section{Cause}

Deaths

Inadequate exits and panic. 1,127

Rapid spread of fire cut off exits

Jumped to death from windows

Burned by inflammable film

Burned by open flame.

Fire fighting

No definite data

Total_...

The record of individual theater fires presents a long list of deaths due to improperly designed and inadequate exits, poor maintenance,

\footnotetext{
5 BS BH14 (1931).

6 Theater Fires, Nat. Fire Protect. Assn. (1930).

7 Bureau of Buildings, Borough of Manhattan, City of New York, Annual Report (1930).

8 Theater Fires, Nat. Fire Protect. Assn.
} 
defective construction, violations of ordinance, and panic. The exits have played an important part among the causes of deaths and emphasize the necessity for careful design and proper maintenance of these facilities.

Next in importance to theaters in this class in the number of lives lost are the schools. The National Fire Protection Association lists a total of 423 lives lost in but 30 fires, ${ }^{9}$ a high average loss per fire compared with other occupancies. This average is much higher than would be expected in buildings of daytime occupancy and supposedly having the advantage of frequent fire drills. However, an examination of the records of individual fires discloses heavy loss in a few fires, 4 fires causing the death of 284 people. The general average for the recorded school fires is, therefore, considerably less than indicated by the 30 fires mentioned before. As in theaters, the exits in schools have figured very prominently as a cause of loss of life. The necessity for a free and unobstructed path of exit has been strikingly illustrated by several fires, as has also the necessity for proper distribution of exits. One school is reported to have been emptied many times in a minute and a half during fire drills, yet 22 lives were lost when the school burned because the fire drills had never been varied to provide for the contingency of an exit being blocked. ${ }^{10}$

The following tabulation, prepared from data published by the National Fire Protection Association, gives the causes of loss of life in 30 school fires. ${ }^{11}$

Inadequate exits

Exit doors open in, barred windows

Exits cut off by fire._.

Subtotal

Suffocated while asleep

Burns and ignition of clothing

Fire fighting and salvage. 21

Special hazards

Miscellaneous, no data... 45

Total

The impression is gained from a study of older buildings that those in which people enter of their own free will, such as office buildings, stores, etc., have been usually of a better type of construction than those buildings which they are forced to enter without their consent, such as schools and certain institutional buildings. This impression seems to be confirmed by the records of many school fires.

Incomplete records of church fires do not reveal any loss of life in this country which might be charged to the fact that the buildings were used as places of assembly, in spite of the frequency of these fires, which has been reported as 5 per day. Very heavy loss of life, however, has been reported in 2 church fires in foreign countries. Of 154 recorded fires in churches only 11 occurred while the buildings were occupied, and in no case was there any difficulty in getting the occupants out. ${ }^{12}$

$\checkmark$ School Fires, Nat. Fire Protect. Assn.

10 Peabody School fire, School Fires, Nat. Fire Protect. Assn.

11 School Fires, Nat. Fire Protect. Assn.

12 Church fires, Quart. Nat. Fire Protect. Assn. (Jan. 1928). 
Class 2, institutional, as established in the report, Recommended Minimum Requirements for Fire Resistance in Buildings, consists of hospitals, sanitariums, homes for the aged, prisons, and buildings of similar occupancy. It has helped materially to swell the total of loss of life by fire in buildings. Poor construction, bad housekeeping, inadequate and poorly maintained exit facilities, isolation, frequently poor fire-fighting equipment, and the character of the occupancy, including as it does persons kept under restraint, and a lack of enforcement of existing laws in some cases, all share in the responsibility for loss of life.

Class 3 , residential, as established by the report, Recommended Minimum Requirements for Fire Resistance in Buildings, consists of apartment houses, hotels, tenement houses, lodging houses, dormitories, and dwellings. It would probably show the heaviest loss of life of any occupancy if available records were complete. But fatal fires in residence buildings so frequently cause only one or two deaths that attention is not focused on them as in the more spectacular theater or school fire involving heavy loss of life. C. Heller, consulting engineer, stated in a paper published a few years ago: ${ }^{13}$ "By far the greatest part of the annual life loss occurs in the many small fires in which one or two die and which attract only passing comment." This is shown in table 3, reporting 426 fires recorded by Heller.

TABLE 3.-Deaths per fire

\begin{tabular}{|c|c|c|c|c|c|c|c|c|}
\hline \multirow[b]{2}{*}{ Class of occupancy } & \multirow{2}{*}{$\begin{array}{l}\text { Number } \\
\text { of fires }\end{array}$} & \multirow{2}{*}{$\begin{array}{l}\text { Lives } \\
\text { lost }\end{array}$} & \multicolumn{6}{|c|}{ Number of deaths- } \\
\hline & & & 1 & 2 & 3 & 4 & 5 to 9 & $\begin{array}{l}10 \text { or } \\
\text { more }\end{array}$ \\
\hline $\begin{array}{l}\text { Dwellings } \\
\text { Nondwellings.-.-..-..-. }\end{array}$ & $\begin{array}{l}195 \\
231 \\
\end{array}$ & $\begin{array}{r}398 \\
2,141 \\
\end{array}$ & $\begin{array}{r}122 \\
73 \\
\end{array}$ & $\begin{array}{l}25 \\
34 \\
\end{array}$ & $\begin{array}{l}15 \\
26 \\
\end{array}$ & $\begin{array}{l}12 \\
13 \\
\end{array}$ & $\begin{array}{l}21 \\
52 \\
\end{array}$ & $\begin{array}{r}0 \\
33 \\
\end{array}$ \\
\hline Total_... & 426 & 2,539 & 195 & 59 & 41 & 25 & 73 & 33 \\
\hline
\end{tabular}

\section{Mr. Heller comments also:}

At first glance these figures give the impression that the life losses occurring in dwellings are smaller in number than those in other buildings. This is true only insofar as the loss per individual fire is concerned, but not the aggregate loss; for the fatal dwelling fires over a fixed time outnumber those of all other occupancies combined. In the United States dwelling-house fires, together with flats and apartments, constitute 65 percent of the total number of fires. The fires from which the table was compiled are those of which the writer has a record and which extend over a period of many years and include such catastrophes as those occurring in the Iroquois Theater, the Collingwood School, and the Asch Building, which greatly add to the total losses in buildings other than dwellings. It must be remembered also that prominence is generally given only to the more noteworthy fires, particularly those in which there is heavy life or property loss, so that thousands of lesser ones escape unnoticed or are not reported in the fire records. Were complete statistics available they would show that tne majority of lives are lost not, as is commonly supposed, in industrial buildings, theaters, and places of public assembly, but in the home; that the next greatest losses occur in institutional buildings (hospitals, orphanages, reformatories, and similar occupancies); and that the victims in both groups are mostly women and children. In the home, they generally lose their lives as the result of carelessness or ignorance. In institutional buildings, most of the disasters are due to poor construction and the gross negligence of those in charge, a sad commentary on our system of social organization.

\footnotetext{
${ }^{13}$ Some fundamentals of safeguarding life from fire, Quart. Nat. Fire Protect. Assn. (Oct. 1922).
} 
Table 4 lists the causes of deaths in 96 year-round and 14 seasonal hotel fires, as compiled by the National Fire Protection Association. ${ }^{14}$

TABLE 4.-Causes of loss of life in hotel fires

(NFPA Chart, Jan. 1930)

\begin{tabular}{|c|c|c|c|}
\hline \multirow[b]{2}{*}{ Cause } & \multicolumn{3}{|c|}{ Number of deaths } \\
\hline & $\begin{array}{l}\text { Year- } \\
\text { round } \\
\text { hotels }\end{array}$ & $\begin{array}{c}\text { Seasonal } \\
\text { hotels }\end{array}$ & Total \\
\hline $\begin{array}{l}\text { Inadequate exits } \\
\text { Attempt to descend, using stairway } \\
\text { Rapid spread of fire cut off exits. } \\
\text { Jumped to death } \\
\text { Burned to death }- \text { no data } \\
\text { Burned to death while asleep. } \\
\text { Suffocated while asleep }\end{array}$ & $\begin{array}{l}24 \\
22 \\
69 \\
33 \\
43 \\
41 \\
11\end{array}$ & $\begin{array}{r}15 \\
0 \\
22 \\
0 \\
3 \\
0 \\
0\end{array}$ & $\begin{array}{l}39 \\
22 \\
91 \\
33 \\
46 \\
41 \\
11\end{array}$ \\
\hline $\begin{array}{l}\text { Subtotal } \\
\text { Burns and ignition of clothing } \\
\text { Fire fighting, salvage } \\
\text { Miscellaneous }\end{array}$ & $\begin{array}{r}243 \\
10 \\
14 \\
51\end{array}$ & $\begin{array}{r}40 \\
1 \\
2 \\
14\end{array}$ & $\begin{array}{r}283 \\
11 \\
16 \\
65\end{array}$ \\
\hline Grand total & 318 & 57 & 375 \\
\hline
\end{tabular}

The exits apparently do not share in the responsibility for loss of fire in the residential classification, when dwellings are included, to the same extent as in the public and institutional occupancies. While fatal fires in hotels and apartment houses occasionally occur, it is mainly from the dwellings that the death list is built up and here carelessness and ignorance, coupled with poor construction, are the principal factors. There seems to be small possibility of improvement in the mortality statistics for the home until as a result of education and improvements in equipment some of these factors are brought more under control. Certainly no improvement in exit facilities can affect the number of deaths caused .by explosions of various sorts and burns from the many causes reported in dwelling statistics. In the case of the multiple dwelling, exits are more of a factor and the necessity for and benefits from their regulation are more easily appreciated.

Class 4, business, as established in the report, Recommended Minimum Requirements for Fire Resistance in Buildings, includes factories, warehouses, stores, office buildings, and buildings of like character devoted to business. The loss-of-life record for this classification is even less complete than for the other occupancies, except for dwellings. While there has been some loss of life in office-building fires it has been relatively small, although the records disclose several fires resulting in heavy property damage. The slight loss of life is possibly explained by the fact that the majority of office-building fires apparently start at night when the buildings are unoccupied, and also, because of the alert population of these buildings, daytime fires are usually discovered at an early stage and sufficient warning is given to enable the occupants to escape. Panic conditions have not often developed during office-building fires. The National Fire Protection Association has compiled a record of 119 fires in office buildings, 46 of which caused property losses of over $\$ 5,000 .{ }^{15}$ The

14 Hotel fires, Quart. Nat. Fire Protect. Assn. (Jan. 1930).

15 Quart. Nat. Fire Protect. Assn. (Oct. 1923). 
record of these fires discloses that less than half originated in office rooms.

Factory fires reveal rather heavy loss of life in the incomplete records available. This probably results from the density of population and poor maintenance of exits combined with inferior construction and, in some cases, the fire hazard of the contents. Locked or obstructed exits are mentioned frequently in the reports as causes of loss of life, and apparently altogether too much dependence has been placed on fire escapes in the past. The loss of life in factory fires demonstrates most clearly that, regardless of how perfect building-code regulations may be, unless such regulations are properly enforced, particularly the maintenance provisions, they are almost valueless. A locked exit door may render useless all of the carefully considered provisions of the building code tending toward safe and sure egress in a time of emergency.

Records of department-store fires are too incomplete for the compilation of statistics and the fires involving heavy loss of life have been too few to make this occupancy stand out prominently in the records. A casual survey of department stores would at once raise the question why more fatal fires have not occurred. Certainly the piles of highly flammable materials, open stairways, and crowded condition of many of our older department stores offer excellent opportunities for fires, panics, and consequent loss of life. The relatively slight loss of life is probably explained by the fact that as in office buildings the occupants are alert and fire is discovered before it has gained any great headway; also, because more attention is usually given to fire protection of the property than in some other occupancies, thereby adding to the protection of the occupants.

Class 5, garages, hangars, barns, as established in the report, Recommended Minimum Requirements for Fire Resistance in Buildings, consists of garages, hangars, stables, barns, and other buildings of similar occupancy. The class was at one time considered especially hazardous because of the nature of the contents, particularly the garages, but as a result of generally thorough regulation is not now so regarded. In support of this conclusion evidence submitted by Rudolph P. Miller to the Commission for the Revision of the Tenement House Act of New York, July 6, 1927, is presented consisting of figures from the annual reports of the fire department for 8 years (1918 to 1925, inclusive). The figures for the entire city are given in table 5.

TABLE 5.-Relation of garage and tenement fires to total in New York City

\begin{tabular}{|c|c|c|c|c|c|}
\hline Year & Total & $\begin{array}{l}\text { In public } \\
\text { garages }\end{array}$ & $\begin{array}{c}\text { In private } \\
\text { garages }\end{array}$ & $\begin{array}{l}\text { In tene- } \\
\text { ments }\end{array}$ & $\begin{array}{l}\text { In tene- } \\
\text { ments, orig- } \\
\text { inating in } \\
\text { stores }\end{array}$ \\
\hline 19231920 & $\begin{array}{l}14,483 \\
14,318 \\
13,475 \\
13,281 \\
11,700 \\
10,807 \\
10,158 \\
10,552\end{array}$ & $\begin{array}{l}368 \\
364 \\
331 \\
307 \\
311 \\
269 \\
205 \\
157\end{array}$ & $\begin{array}{r}140 \\
139 \\
122 \\
118 \\
109 \\
93 \\
80 \\
80\end{array}$ & $\begin{array}{l}7,054 \\
6,650 \\
6,458 \\
6,073 \\
5,248 \\
4,883 \\
5,052 \\
5,319\end{array}$ & $\begin{array}{r}953 \\
924 \\
991 \\
1,059 \\
664 \\
583 \\
599 \\
639\end{array}$ \\
\hline $\begin{array}{l}\text { Total } \\
\text { A verage } \\
\text { Percentage of total }\end{array}$ & $\begin{array}{r}98,774 \\
12,347 \\
100\end{array}$ & $\begin{array}{r}2,312 \\
289 \\
2.4\end{array}$ & $\begin{array}{l}881 \\
110 \\
0.9\end{array}$ & $\begin{array}{r}46,737 \\
5,842 \\
47.5\end{array}$ & $\begin{array}{r}6,412 \\
802 \\
6.5\end{array}$ \\
\hline
\end{tabular}


The tables in the reports from which the above figures are taken classify buildings in which fires have occurred into 31 groups. Those in which the number of fires for 8 years (1918 to 1925 , inclusive) has averaged more than 200, in the order of greatest frequency, are as follows:

Type of building

Fires

Tenements.

Dwellings

Tenant factories

Factories

Store buildings,

Furnished rooms. 321

Public garages....... 289

Office buildings.... 203

The only yearly variations from this order are occasional transpositions of factories and store buildings in fourth and fifth places, and of furnished rooms and garages in sixth and seventh places.

It is conceded that the number of fires is not the only element entering into the consideration of the fire hazard. The frequency in relation to total number of structures of a given occupancy class is important. The information necessary for a definite conclusion on this point is not available. However, in 1925, fires occurred in 11.4 percent of public garages and 0.6 percent of private garages; for all garages the percentage was 2.5. In the same year the percentage for tenement houses was 6.5 , or more than twice as great as for garages.

Fortunately, the density of population of garages is low, and property damage rather than loss of life usually results from fires in such buildings. The National Fire Protection Association ${ }^{16}$ reports 13 fires in garages involving a loss of 32 lives for the period 1921 to 1928 . The exits do not figure prominently among the causes of loss of life, these being principally burns and explosions. It seems unlikely that the capacity of the exits in this class of occupancy would ever be severely taxed; the distance to the exits and the proper distribution, however, are of primary importance in these buildings. With the increasing use of public garages the necessity for wise regulation of exit facilities becomes more apparent.

\section{BUILDING EXITS SURVEY}

\section{PROCEDURE}

At an early meeting of a joint conference consisting of representatives from the Department of Commerce Building Code Committee and from the Building Exits Code Committee of the American Standards Association, it was agreed that a study could profitably be made of exit design practice and performance, especially as it concerned buildings erected within the last 10 years. The staff of the Department of Commerce committee was therefore asked to conduct such a survey to the extent that time and funds permitted.

The primary object of this survey was to build up a reservoir of facts about actual exit conditions that could be tapped at the time when minimum requirements for building exits were being considered. The value of such data is readily appreciated.

${ }^{16}$ Garage fires, reprinted from Quart. Nat. Fire Protect. Assn. (A pril-July 1929).

$1158-35-3$ 
Nearly all construction design today makes use of mathematical formulas applicable to the problem involved. Numerous series of controlled tests can often be made, and, from the data obtained, formulas can be evolved which will apply generally. Criteria for the design of means of egress from buildings present a different problem. It is impractical to conduct tests of exit discharge that would simulate actual conditions during a fire. However, experience has dictated certain necessary requirements, and current practice in exit design can be reviewed as to performance, desirability, and economic effect.

The number, location, size, and type of exits seemed to be major items to investigate. The population or area served by the exits and the maximum distance traveled to reach an exit were also important. Additional features, such as building height, number of fire towers, fire escapes, spiral chutes, and horizontal exits, permanent obstructions in the stairway enclosures, conditions of final discharge of stairways, size and type of doors in stairway enclosures, continuity of stairways, dimensions of treads and risers, and other construction elements related to exits, had to be noted to complete the picture.

\section{SOURCES OF INFORMATION}

The desired data were collected in two ways: (1) by an office study; and (2) by an inspection of buildings in several cities.

As a first approach in the office study, floor plans from architectural and technical magazines were inspected for exit facilities. Plans obtained from architectural and engineering offices likewise furnished excellent material exemplifying current design practice. Suggestions solicited from architects, engineers, school superintendents, officials of hotel chains, theater executives, and others having specialized knowledge of exit requirements made a valuable contribution as the collection of material progressed. The restrictions on design of exits imposed by some of the laws in effect received their share of attention in the form of a digest of exit regulations in building codes, labor laws, and tenement-house acts. These were listed and the fundamental requirements of each compared.

Additional information was obtained by means of a questionnaire sent out to some of the leading architectural offices in all parts of the country and containing, among others, this question: Are the present code requirements for means of egress too severe or too lax?

The answers to this question indicated that this group believed almost unanimously that many of the present building regulations as regards exits were too severe. Some of the general arguments cited to substantiate this opinion were as follows: That many ordinances have been rushed through after some catastrophe and are illadvised and extreme; that heretofore these requirements have been worked out in an unscientific manner; that improvements in building construction such as increased fire resistance and the inclosure of stairways now obviate many of the requirements formerly necessary, and that more reasonable consideration should be given to the location of buildings and to their occupancy.

But one observer thought that the code requirements were too lax, referring to exits in summer hotels. These buildings usually fall outside the jurisdiction of municipal building regulation.

This information reflected an important point of view and helped to make the exit problem clearer. 


\section{FIELD INVESTIGATIONS}

The experience gained in the office study indicated that certain questions which had arisen could be answered only by observation of conditions in actual buildings. Accordingly, exit measurements were taken and general exit conditions tabulated for buildings in Atlanta, Ga., Greenville, S. C., Greensboro, N. C., Roanoke, Va., Washington, D. C., Frederick and Baltimore, Md., and Pittsburgh, $\mathrm{Pa}$. These cities were chosen with a view to covering places varying in size and sufficiently distributed to give a fair general cross section of building construction.

The smallest city had no building code. The codes of the others ranged from rather sketchy requirements to those as elaborate as in any city.

Building officials in the cities visited rendered valuable assistance by furnishing plans of buildings erected since 1920. After a study of the plans, detailed measurements were taken at the buildings selected for inspection. Special attention was given to buildings where people slept or were housed for medical or other care. Building managers supplemented the field notes in some instances by generously donating floor plans. During the building inspection, notes were also kept on the marking of the exits and on their maintenance. Wherever possible, figures on the population served by the exits were secured. Questions were also asked concerning any difficulties experienced with the exits under normal or emergency conditions. Interviews with building officials, State labor officials, architects, and school superintendents further enriched the field notes.

\section{TABULATION OF DATA COLLECTED}

Much of the information secured is too detailed to warrant publication here. However, conclusions reached are based on a study of these plans and the mass of other data that was collected. Summaries and tables of the more outstanding findings are included for those particularly interested in exit design. Tables 6 to 14, beginning on page 14, list some of the points recorded in the field survey. Table 15 gives some general averages obtained from both the field and the office surveys.

\section{POPULATION STUDIES}

The figures under the heading "Population on typical floors" given in the tables were obtained in a number of ways. In apartment buildings the resident manager usually had accurate knowledge of the number of people occupying any floor; in hotels an estimate of the population on a typical floor was made by counting the number of beds and then assuming all rooms to be occupied; in office buildings, factories, and schools actual counts were taken where possible; in theaters the number of seats was noted; and in other occupancies accurate estimates from those in charge of the building were accepted. 


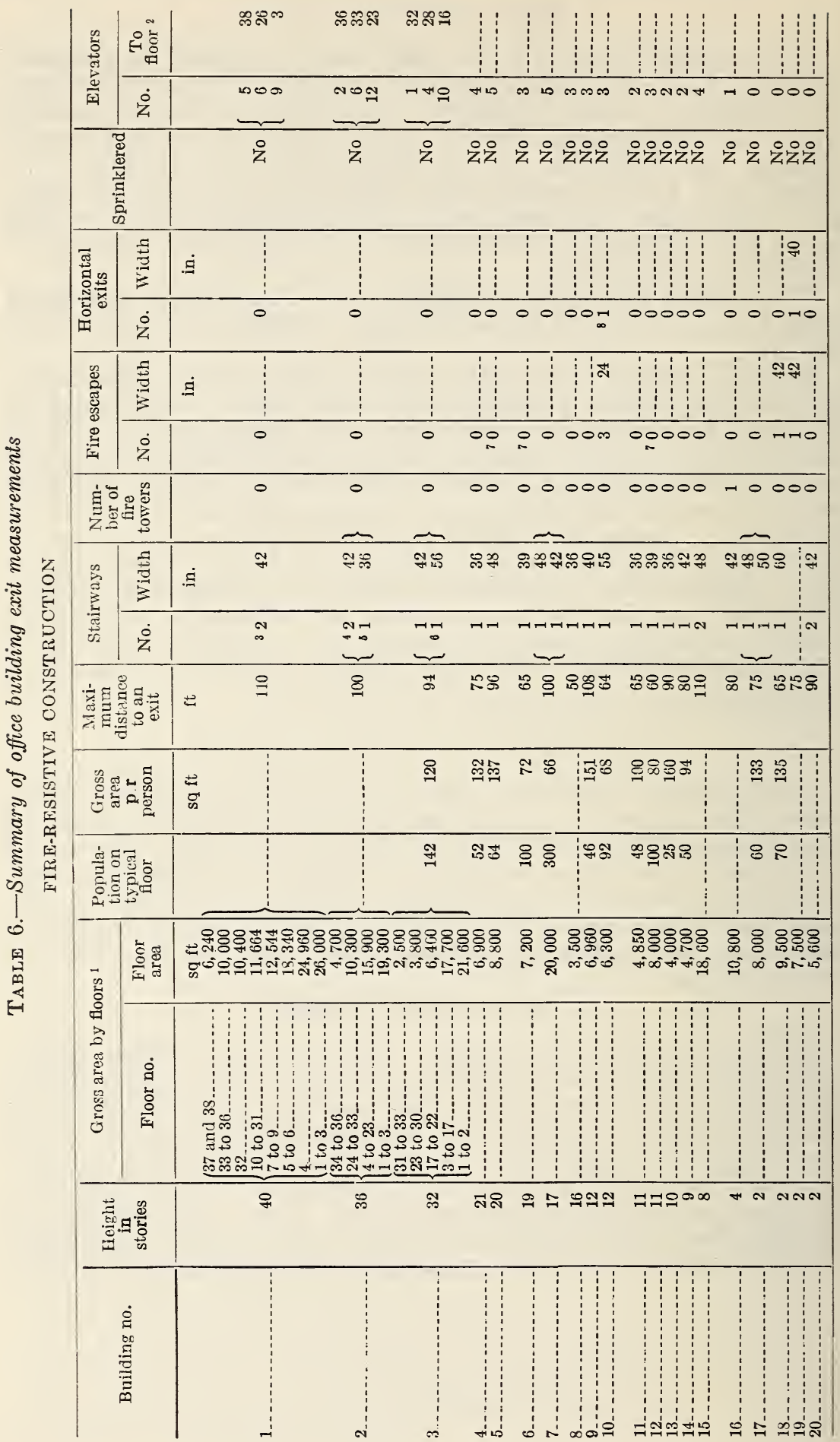




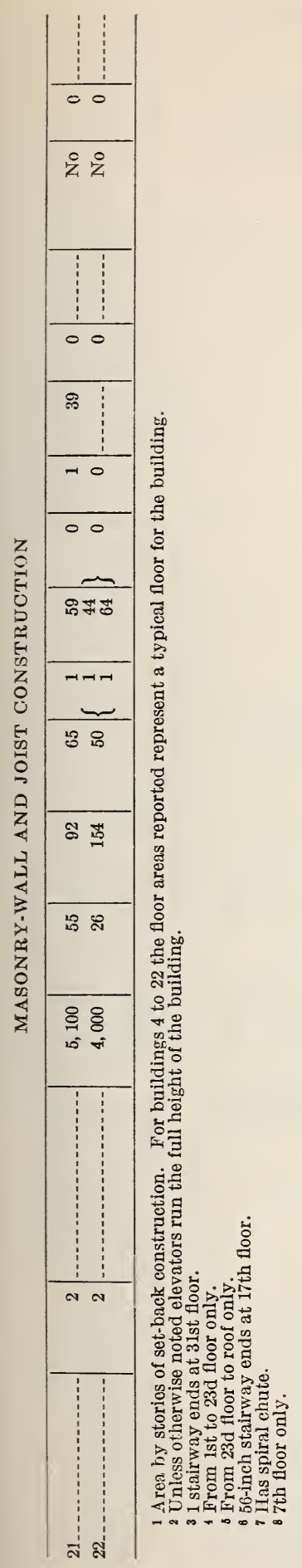




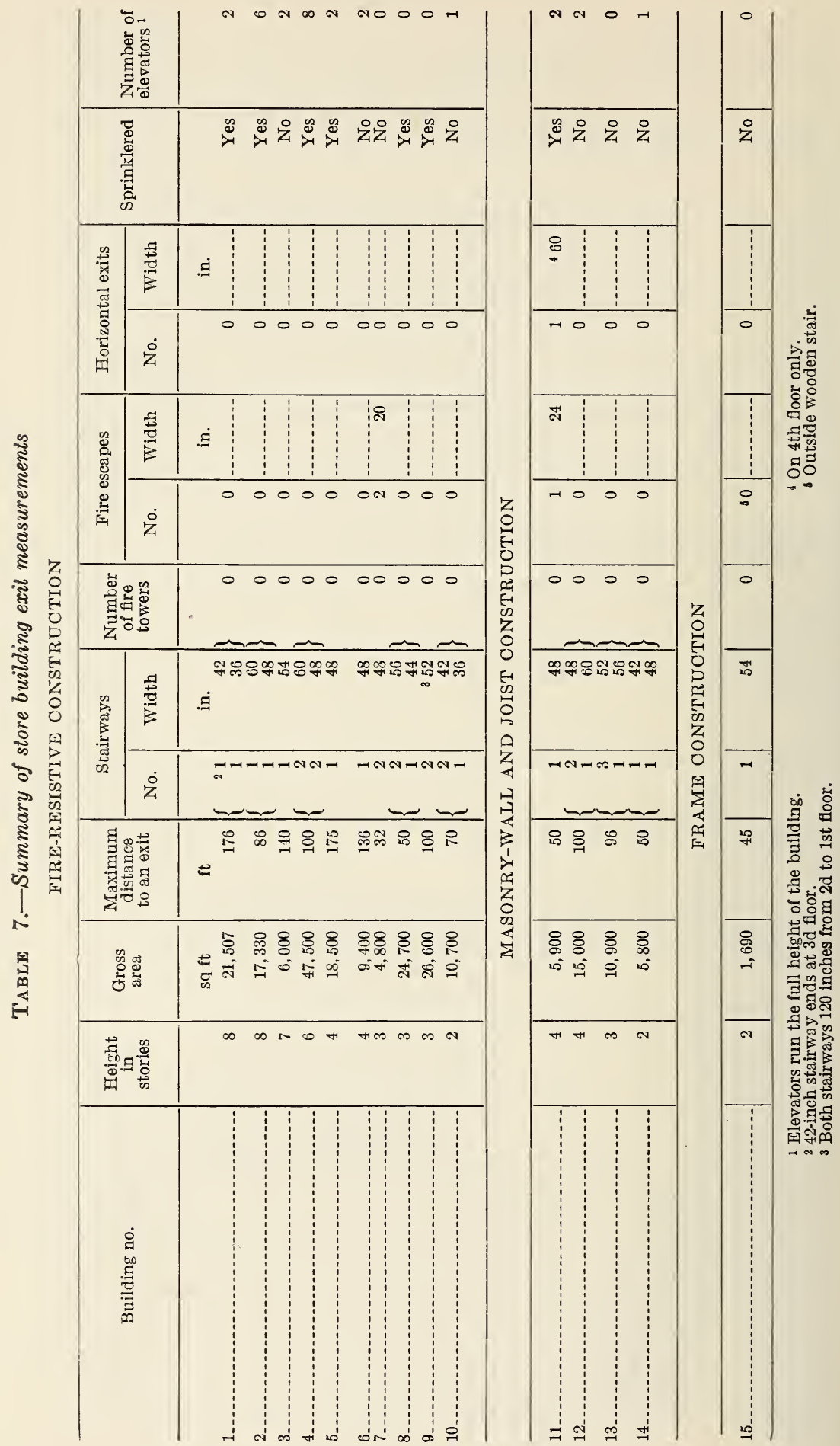




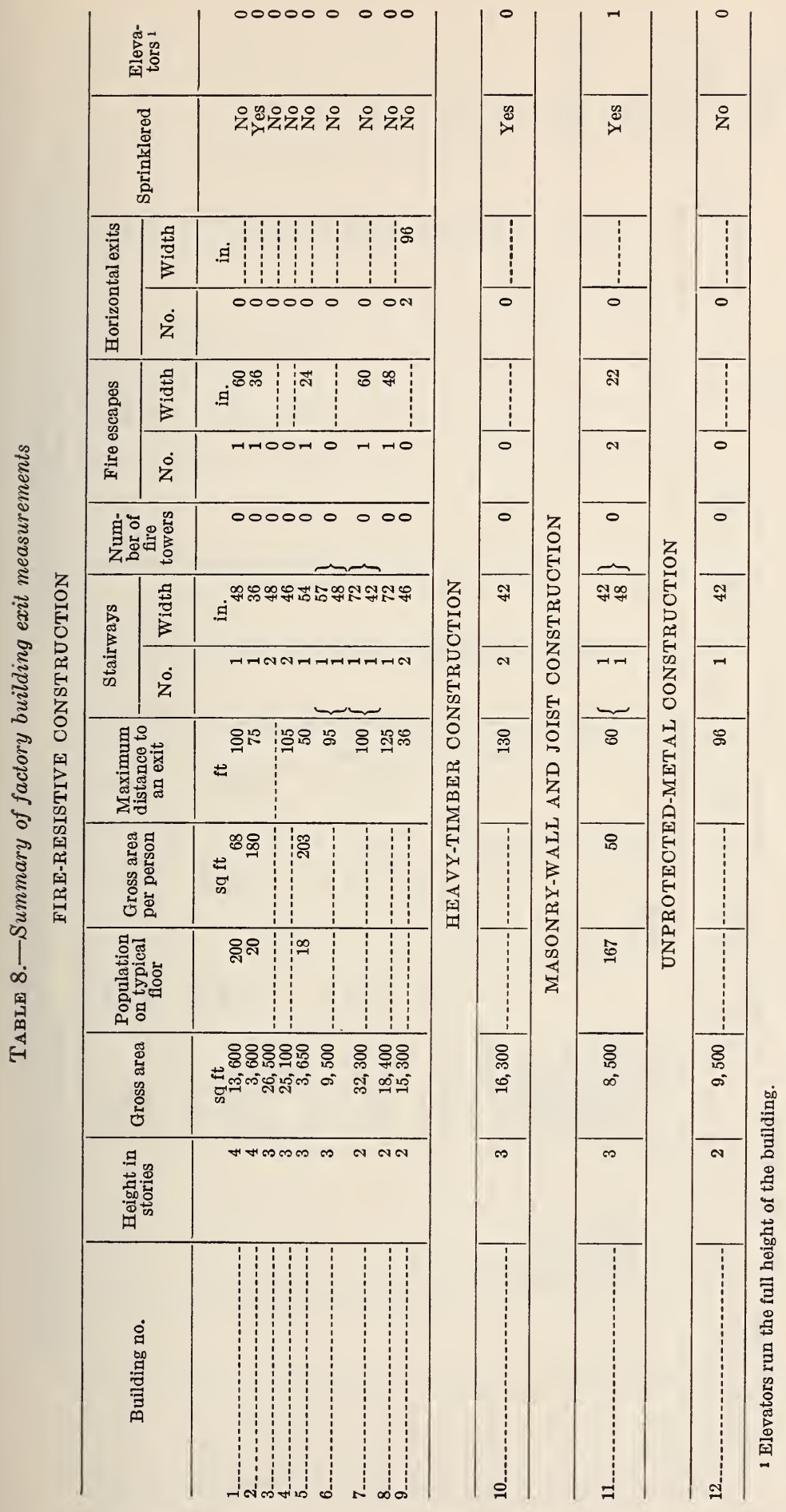




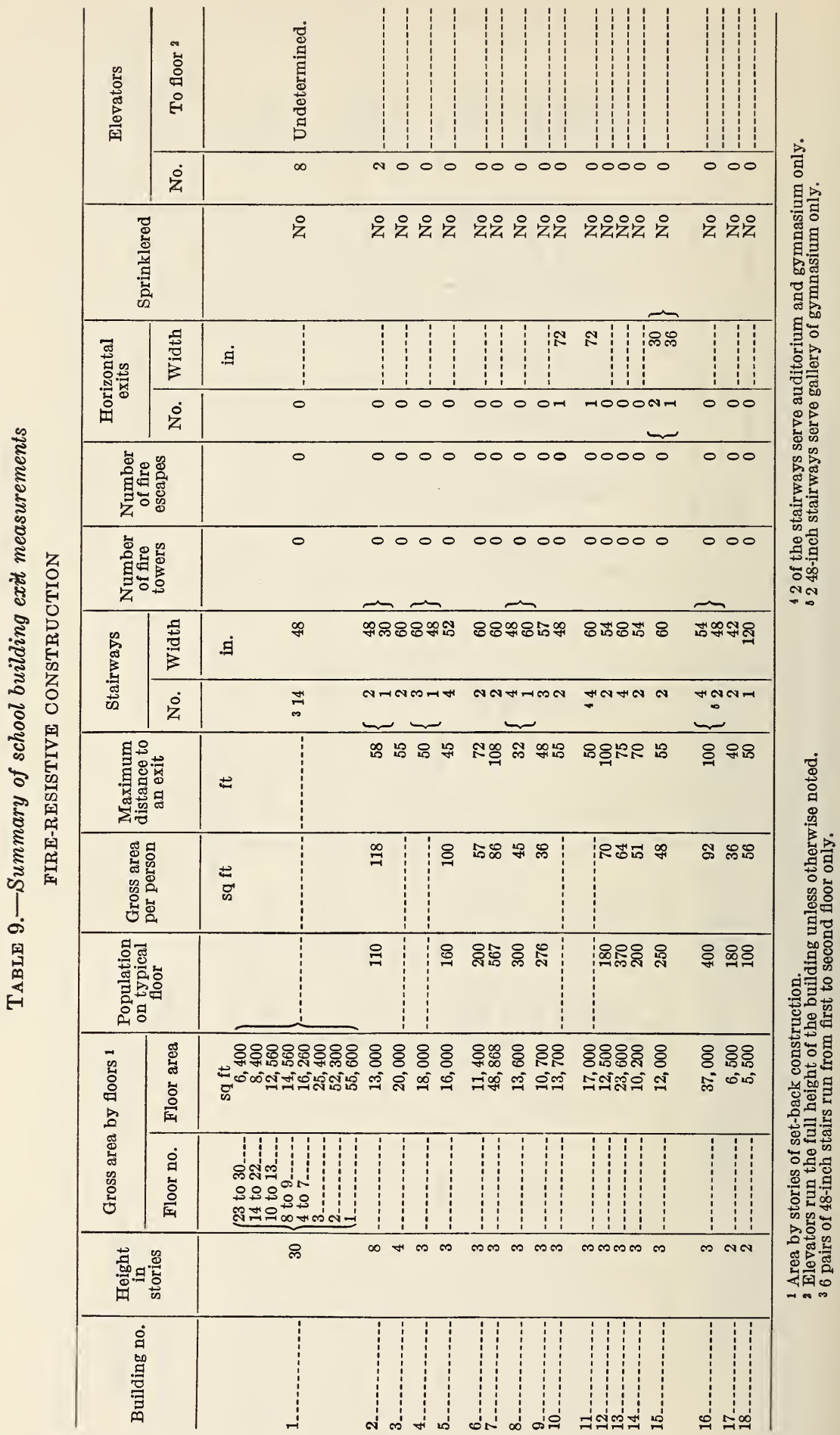


Design and Construction of Building Exits

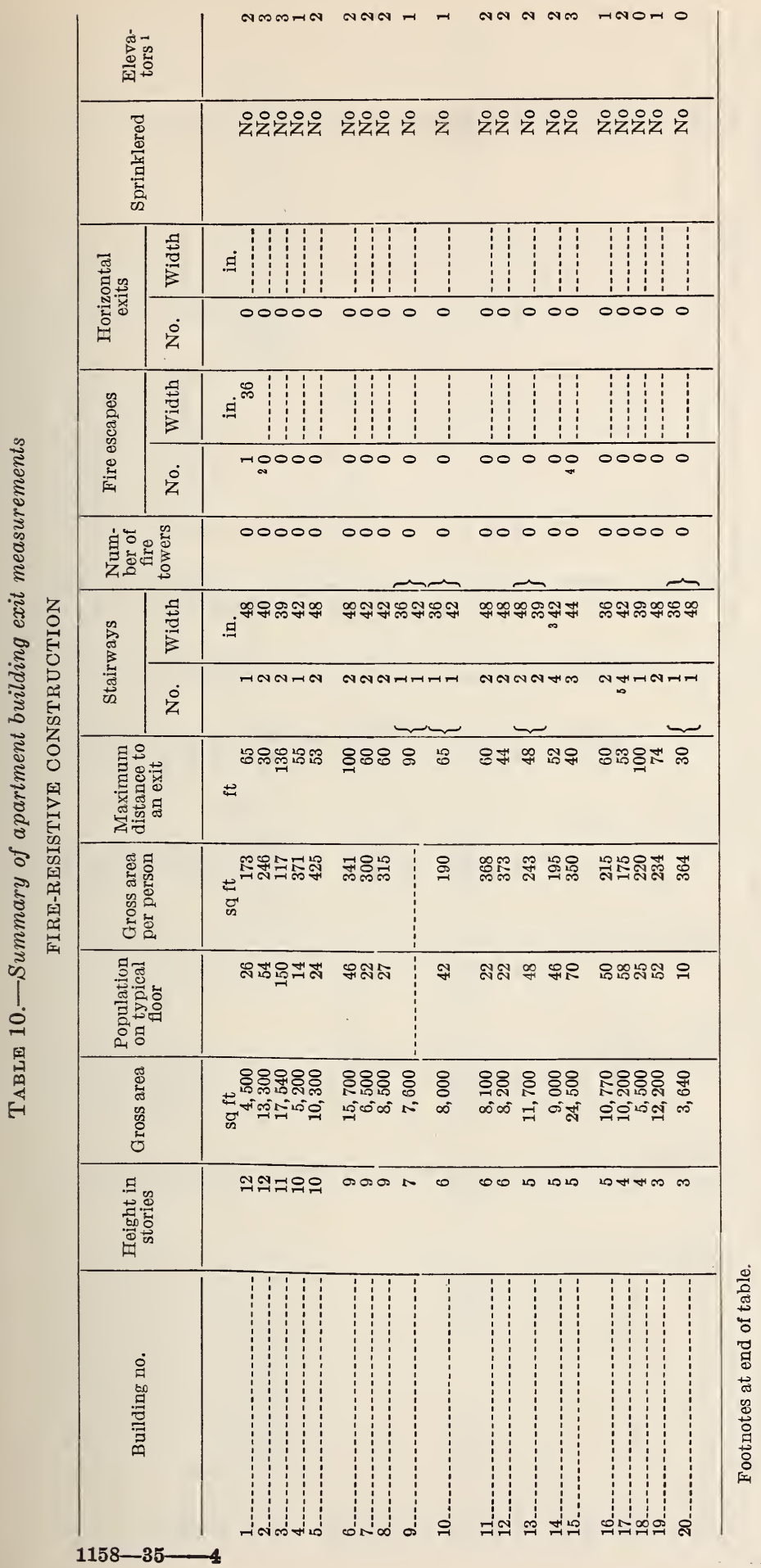




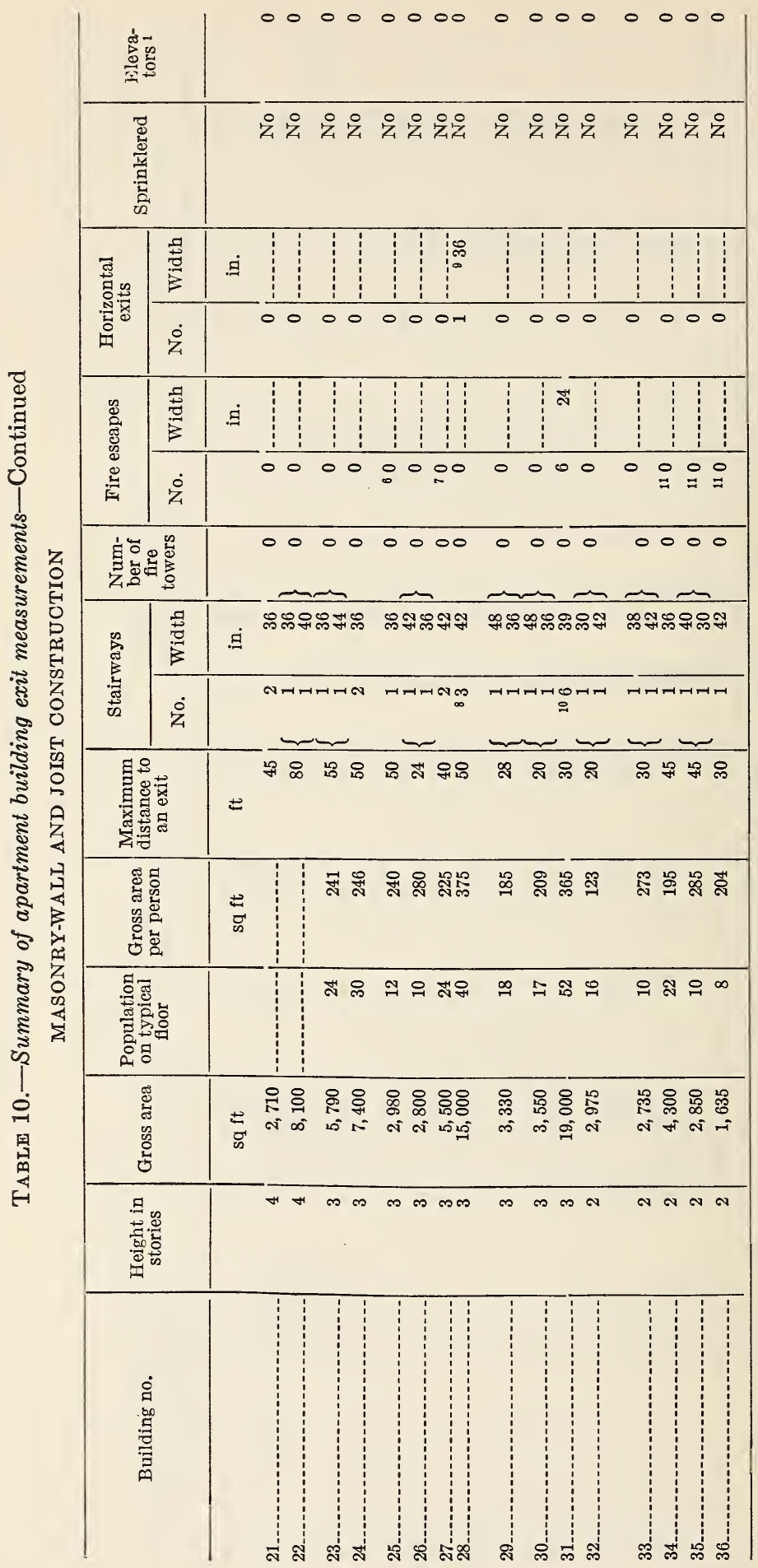




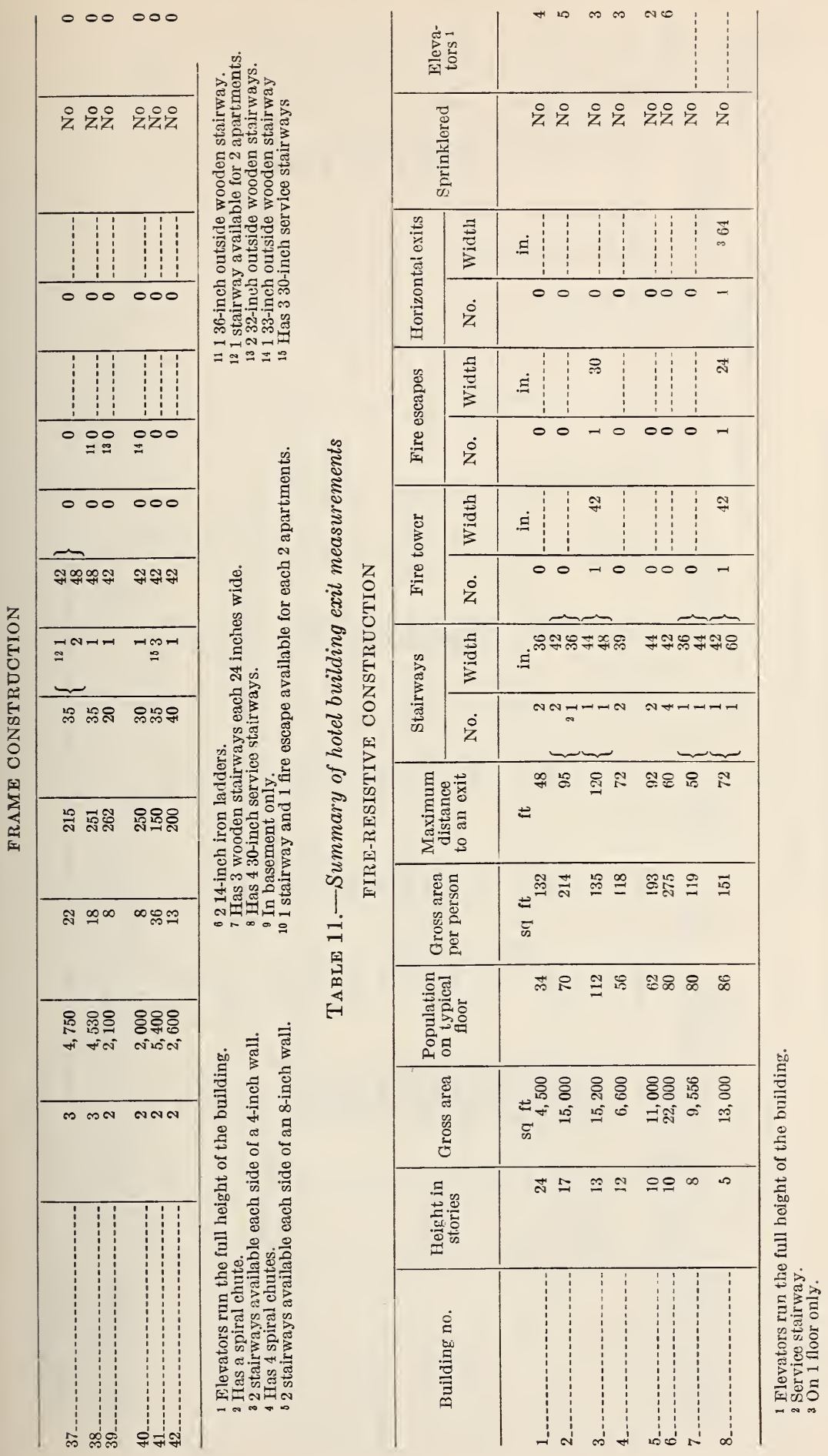




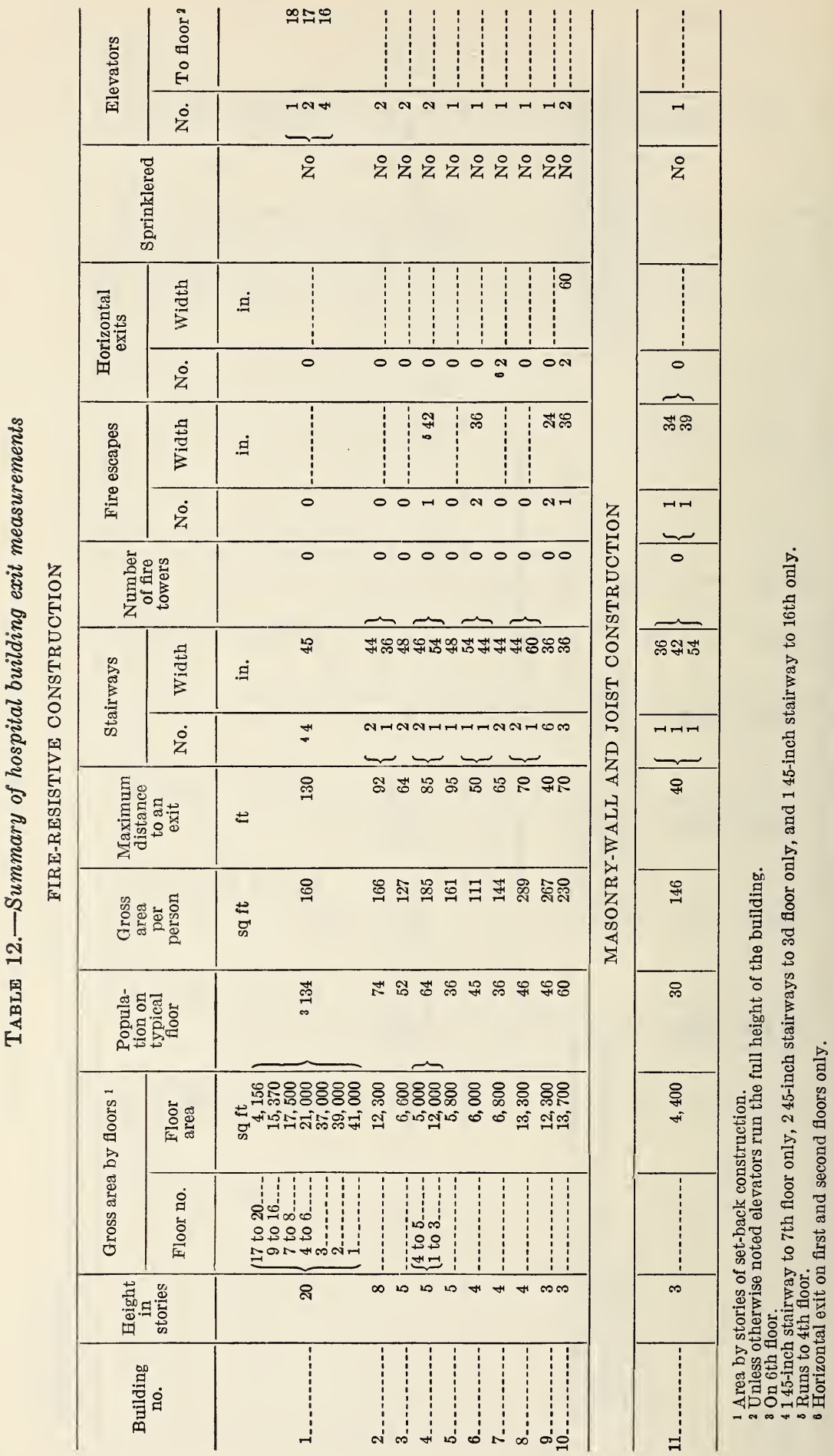




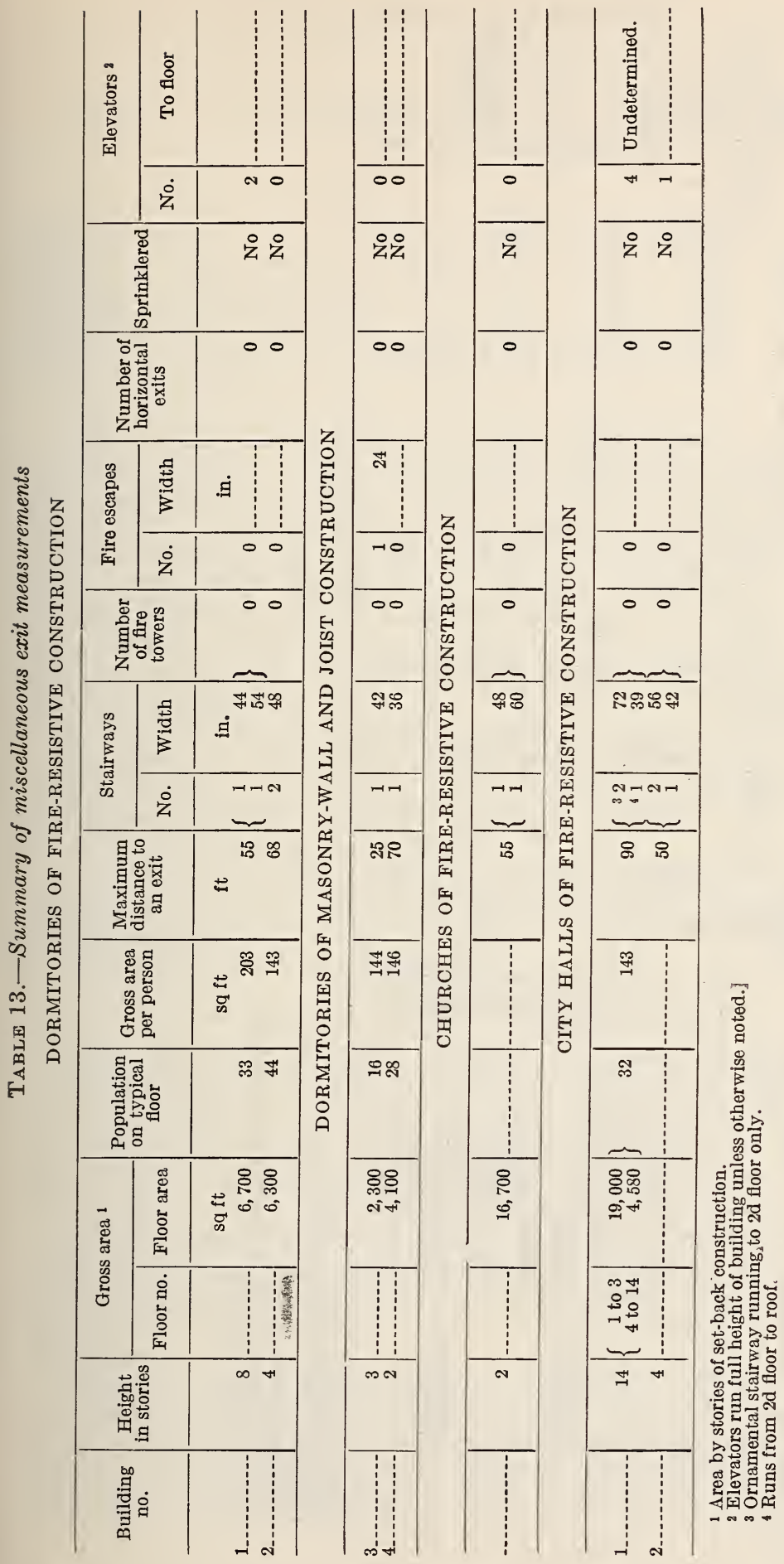


24 Miscellaneous Publications, National Bureau of Standards

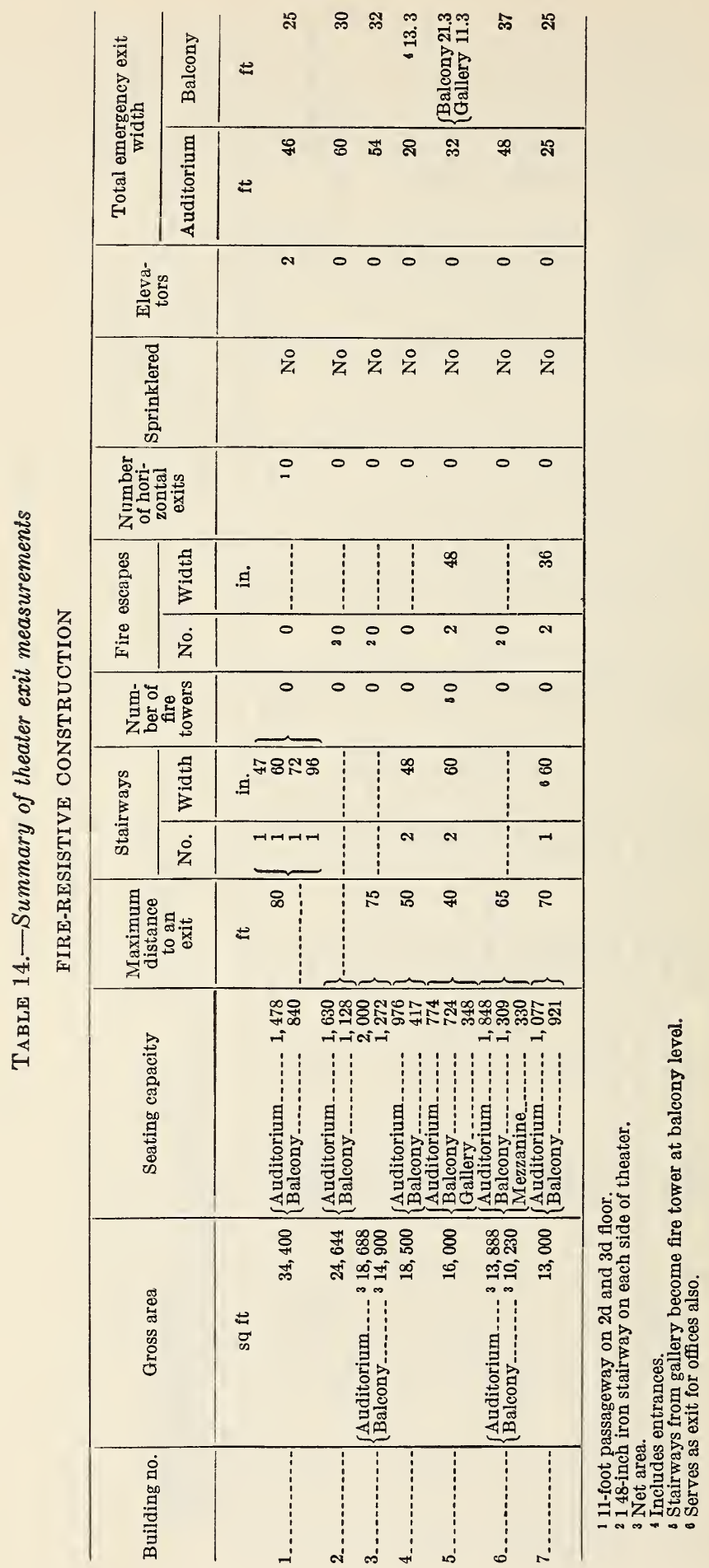


TABLE 15.-Average of exit measurements

\begin{tabular}{|c|c|c|c|c|c|c|}
\hline \multirow{2}{*}{ Occupancy } & \multirow{2}{*}{ Type of construction } & \multicolumn{2}{|c|}{$\begin{array}{l}\text { Percentage of build- } \\
\text { ings having- }\end{array}$} & \multirow{2}{*}{$\begin{array}{l}\text { Average } \\
\text { floor area } \\
\text { served by } \\
\text { stairway }\end{array}$} & \multirow{2}{*}{$\begin{array}{l}\text { A verage } \\
\text { width of } \\
\text { stairway }\end{array}$} & \multirow{2}{*}{$\begin{array}{c}\text { Average } \\
\text { maximum } \\
\text { distance } \\
\text { to exit }\end{array}$} \\
\hline & & $\begin{array}{l}1 \text { stair- } \\
\text { way }\end{array}$ & $\begin{array}{l}2 \text { or more } \\
\text { stairways }\end{array}$ & & & \\
\hline $\begin{array}{l}\text { Office buildings. } \\
\text { Hospitals. } \\
\text { Hotels } \\
\text { Dormitories.- } \\
\text { A partments.- } \\
\text { A partments.- } \\
\text { Schools. } \\
\text { Stores.-. } \\
\text { Factories. }\end{array}$ & $\left\{\begin{array}{l}\text { Fire resistive } \\
\text { Nonfire resistive. } \\
\text { Fire resistive }\end{array}\right.$ & $\left\{\begin{array}{r}\text { Percent } \\
55 \\
10 \\
7 \\
\hdashline 15 \\
32 \\
6 \\
30 \\
44\end{array}\right.$ & $\begin{array}{r}\text { Percent } \\
45 \\
90 \\
93 \\
100 \\
85 \\
68 \\
94 \\
70 \\
56\end{array}$ & $\begin{array}{r}\text { sq ft } \\
8,000 \\
2,700 \\
6,500 \\
2,540 \\
4,200 \\
2,550 \\
8,700 \\
8,900 \\
10,500\end{array}$ & $\begin{array}{r}\text { in. } \\
45 \\
43 \\
42 \\
48 \\
42 \\
40 \\
55 \\
59 \\
50\end{array}$ & ft $\begin{array}{r}86 \\
77 \\
88 \\
53 \\
63 \\
38 \\
63 \\
106 \\
86\end{array}$ \\
\hline
\end{tabular}

Lack of time prevented counts of the population on the floors in department stores. Only one manager interviewed had ever made any study of the number of people on any given floor during a rush period. Many had figures on the total number visiting the store during a business day, but these figures could not be broken down in order to estimate the population on any given floor. Numerous checks on the population in office buildings and department stores were available through investigations made by the Committee on Safety to Life of the National Fire Protection Association. Studies made by engineers in connection with live-load considerations also furnished some data on population density.

The check on apartment population was made in the better residential sections. If counts had been made in the tenement districts, it is believed that the gross area per person would have been materially lower than that shown in the tables.

A number of factories visited had notices required by the State departments of labor which specified the maximum population permitted on any floor. The actual basis for these allowances could not be obtained from those interviewed.

\section{LOCATION AND NUMBER OF EXITS}

With but few exceptions, field measurements revealed that the maximum distance traveled to reach an exit was less than that permitted in the local building code. These measurements were taken along the line of travel. In office buildings, for instance, the distance from the door of the office to the stairway was recorded, rather than the distance to any remote point within the office itself.

As most stairways were found to be placed in dead corners or other areas least rentable, design considerations played an important part in fixing the distance to exits. It is also possible that the maximum distance to exits specified in the code sometimes fixed the design of buildings.

When compared with the other occupancies, department stores completely equipped with sprinkler systems showed the greatest distance of travel to exits. Comparisons between buildings of fireresistive construction and other types did not indicate that construction type had been definitely related to maximum distance to exits. 
E The majority of the buildings studied were provided with two stairways. A notable exception to this occurred in office buildings where one stairway might be said to be the rule rather than the exception. Table 6, pages 14-15, shows that office buildings of uniform horizontal cross section and tower sections of set-back construction frequently were provided with a single stairway.

\section{STAIRWAY WIDTHS}

All the tables indicate a great variation in stairway width, even for nearly identical conditions. Repeated questioning failed to establish specific reasons for making stairways $40,41,42$ or 43 inches, or any dimension approximately 4 inches either way from 44 inches, in preference to a 44-inch width. Although codes specified certain minimum dimensions for stairway width, variations up to several inches either side of the minimum were common. Construction details might account for some of this discrepancy.

Stairways 36 inches wide were found rather frequently while the great majority were between 40 and 50 inches. Just what increment of width added to, say a 36-inch stairway, increases the capacity of the stairway was a question which very few of the architects had given any detailed study. As might be expected, stairways in schools and department stores were appreciably wider than those in offices, apartments, or hotels. A number of those interviewed were of the opinion that for the same aggregate width it was more beneficial to increase the number of stairways than to increase the width of a few-that is, three 44-inch stairways resulted in better traffic conditions than two 66 -inch stairways.

\section{PROPORTION OF TREADS AND RISERS}

Dimensions of treads and risers measured indicated that the 2 or 3 rules customarily used for proportioning risers and treads are adhered to very closely. Risers of 7 or $7 \frac{1}{2}$ inches and treads of 10 and $10 \frac{1}{2}$ inches far outnumbered any other dimensions. These proportions will be seen to check the rules that the sum of riser height and tread width, in inches, shall not be less than $17 \frac{1}{2}$, nor more than 18; that the sum of 2 risers and 1 tread, in inches, shall be not less than 24 , nor more than 25 ; or that the product of the riser and tread, in inches, shall fall between 70 and 75 .

The risers in school buildings occupied by small children averaged around 6 or $6 \frac{1}{2}$ inches. Opinions of architects and school superintendents on the advisability of this practice fell into 2 groups. One group claimed that the fatigue was much less where the lower riser was used; the other group maintained that children were not accustomed to the lower riser in their homes and other buildings, and, therefore, that it was more logical and less dangerous to use a 7- or $7 \frac{1}{2}$-inch riser in this occupancy.

Because of the different uses of stairways, including those in industrial, private, public, and semipublic occupancies, and because of their position in the plan, the variations of color and materials used, and the differences in railings and type of nosings, a suggestion was advanced calling attention to the inadvisability of attempting to design all stairways under any one rule for proportioning treads and risers. 
It was pointed out that certain classes of people would consider a stairway very tiresome while others would take no notice of fatigue. On the basis of a limited study, it was therefore suggested that the treads and risers should be proportioned for the different uses to which the stairways were subjected. Further study of this question may reveal more rational methods of accomplishing this end than are now in common use.

\section{STAIRWAY ENCLOSURES}

Enclosed stairways could be said to be current practice, judging from the large majority found in the buildings visited. An openexit stairway in office buildings, hotels, and apartments was extremely rare, those not exceeding 2 or 3 stories in height excepted. In school buildings about equal percentages of open and enclosed stairways raised a question as to most favorable design. Many superintendents and teachers preferred the open stairway because of its efficiency in handling the changes of classes. Although the larger department stores visited had enclosed stairways, many of them were used only as emergency exits. Stores of 2 or 3 stories and having a small area had enclosed stairways in but few instances. Despite the questions raised concerning the efficiency of enclosed stairs for certain occupancies and their increased cost for small buildings, an analysis of those buildings erected only within the past 5 years bore witness to the obsolescence of the unenclosed stairway.

If the definition of an enclosed stairway means that it must be enclosed from the topmost story to the final discharge to the street, many of the stairways examined would be puzzling to classify. Stairway enclosures found in hotels and office buildings frequently terminated at the second floor or a mezzanine from which ornamental open stairways continued to the street-floor level.

\section{EXIT OUTLETS}

Where stairway enclosures terminated within the building at the ground floor, the discharge was either into large corridors, in some cases having small shops on either side, or directly into a lobby. It was unusual to find a stairway discharging into a corridor so constructed as to constitute a protected passageway leading to a street, except in public-occupancy buildings such as theaters and auditoriums. Stairways discharging directly to the outside at ground-floor levels are greatly in the minority when compared with those discharging into ground-floor areas, corridors, or lobbies. Value of street frontage apparently controlled this factor, as the stairways of most factories discharged directly to the outside at the ground floor. Where stairways continued enclosed to the basements in apartments, hotels, and office buildings, many of them discharged directly to the outside. Some builders claimed that if many building codes were enforced to the letter buildings would be too severely penalized when erected under requirements calling for direct discharge to streets or to protected passageways leading to the street. 


\section{SPECIAL FORMS OF EXITS}

The number of iron fire escapes still in use occasioned some surprise in this investigation. A further review of buildings having this type of exit disclosed, however, that many of them had been added as a supplement to the existing means of egress to take care of occupancy changes. Old wings of buildings now enlarged accounted for a number of others. However, some recently erected buildings still made use of fire escapes as one of two means of exit. Testimony of building officials was against the use of fire escapes on new buildings. A few officials thought that firemen could use outside escapes advantageously when fighting fires.

The tables of the field survey reveal the limited use of fire towers, spiral slide chutes, and horizontal exits. If tall buildings in New York and Philadelphia had been included, the total number of fire towers found would undoubtedly be much increased. Opinions solicited on the use of fire towers as one means of exit as compared with the use of enclosed stairways for all means of exit in any given building favored the enclosed stairway. Opponents of the fire tower pointed to the increased space necessarily deducted from the rentable area where these towers are required; defendants of the fire tower claimed additional safety over the enclosed stairway. Further study of the relative value of these two types of exits may be necessary before this question can be conclusively settled.

Table 6, pages 14-15, lists a spiral chute in one office building of 11 stories and in another of 19 stories. These chutes were unlighted within the slide. No check could be made of their performance and neither had been used under emergency conditions at the date of the survey. Opinions differed on the advisability of permitting chutes as one of the two required exits. One school of thought would allow them as an additional safeguard after sufficient stairways or horizontal exits had been provided.

The number of horizontal exits listed was small. Approximately 8 percent of the buildings checked were thus equipped. Of the 8 percent, the majority could be accounted for in those cases involving exits between new wings or additions connected to older construction. Few were found in new buildings, and those that were might be said to be for convenience such as bridges connecting office or factory buildings, rather than as a distinct means of egress.

Confusion often existed as to the amount of credit that should be given to a horizontal exit when installed on only 1 floor of a multistoried building - for instance, when a bridge connects 2 buildings on the fourth story. It has been argued that a horizontal exit on the fourth floor was of no value to the occupants of the ninth floor should a serious fire occur on the sixth. In line with this reasoning, a number of those who had studied the question believed that horizontal exits, if to receive credit as a means of egress, should be provided on all floors.

\section{EXIT DESIGNATION}

During the survey special attention to exit marking resulted in a number of interesting disclosures. There was a woeful lack of plainly indicated street-floor levels within enclosed stairways running to the basement. Many stairway doors had exit signs placed flat on the wall - a position rendering the sign invisible at a short distance down a 
hallway. Practically no signs existed telling whether any given stairway ran to the roof. Numerous office buildings and hotels with enclosed stairways ending on the second floor possessed no type of directional sign pointing out the line of travel from that point to the ground floor, and, thence to eventual discharge outside of the building. Theater exits stood alone as the only example of efficient exit designation. Churches displayed an almost complete omission of any exit signs. Many of them now have apparatus for lantern slides or motion pictures, involving need for exit designation within the darkened room.

\section{EXIT MAINTENANCE}

Exit maintenance, or rather lack of proper exit maintenance, proved to be a serious handicap to many buildings well provided with exits. In one large department store visited the ground-floor door of an enclosed stairway was found padlocked. Doors opening to the roof were frequently found locked. Building managers claimed it was essentia! to keep certain doors locked to prevent robberies. The total number of locked exit doors found would give anyone cause for alarm.

A very common practice in many buildings, and apartments topped the list, was to prop open the fre doors of enclosed stairways in an attempt to increase the ventilation. For the sake of easier communication during congested periods, fire doors in schools and stores were also found propped open. In one or two instances fire doors originally installed had been removed to make communication easier between floors.

Packing boxes, receptacles, advertising, and articles of all kinds were found in stairway enclosures, on landings, in hallways and corridors, and in front of exit doors, or horizontal exits. Exposed radiators, piping, incinerator chutes, chimneys, columns, and beams frequently cut down the normal width of stairway enclosures. While building officials recognized the hazard of blocking exits, or interfering with the intended purpose of fire doors, they were unanimous in declaring that successful enforcement of provisions dealing with exit maintenance was one of their most difficult problems.

Building officials also made frequent observations on the exit problem involved in the remodeling of old buildings. One pointed out that in his own city many old private residences had been converted into rooming houses, often without his knowledge and resulting in totally inadequate exit facilities for the new use. Increase in the population of a building over that contemplated in the original design of the exits caused many inspectors unpleasant moments. From the number of plans examined where additional exits were ordered to comply with the code, some latitude evidently exists on the part of those designing exits. One inspector was said to have lost his job because he insisted on the number of exits specified by the code. On the other hand both architects and engineers claimed that the exit provisions of some codes were almost impossible to interpret without frequent explanation from the building official, that they hamper design, and that they were all too often unreasonable and economically unsound.

This summary has touched but briefly on the exit conditions found. However, taken in connection with other conditions peculiar to individual buildings, it furnishes a background of current practice that is useful in developing rational provisions for exits. 


\section{SURVEY OF TRAFFIC MOVEMENT IN EXITS}

\section{PROCEDURE}

The rate at which people normally ascend or descend stairways, or pass through hallways and doorways, is of primary interest to those responsible for exit design. Knowledge of this rate enables the designer to adjust his exit widths more rationally to the building population, and as they should relate to each other if efficiency and economy are to be secured.

The joint conference already mentioned believed that as a complement to the survey of current design practice found in buildings erected within the past 10 years, a survey of traffic movement in exits would help in pointing the way to more logical conclusions for exit requirements.

The staff of the Department of Commerce Committee, after completing the inspection of exits in existing buildings, then proceeded to secure data on the movement of people through exits. The second survey was carried out in much the same manner as the firstby office and field studies-for it was found that preliminary office investigation not only contributed largely to the total information but also revealed those points on which a field investigation might well be concentrated.

The inquiry was to include: (1) The relation of discharge rate to exit width; (2) the difference between rate of flow up and down stairways and the relation of rates of flow on stairways to rates on ramps, on the level, and through doors; and (3) the number of square feet occupied per person in exits when discharging crowds of people. It was hoped that sufficient evidence could be secured to answer controversial questions, to check existing data on the subject, and to determine what basic facts, if any, had not been developed.

\section{SOURCES OF INFORMATION}

Many observations have undoubtedly been made on the rate at which crowds of people normally move through different types of exits. The complete data readily available on observed conditions of this movement are, however, rather meager.

A number of traffic observations have been made in the past by engineers of railroad companies as an aid in the design of terminal stations. The Illinois Central Railroad courteously supplied the detailed traffic studies made in connection with the Chicago Terminal Improvement, summaries of which appear in volumes 25 and 26 of the Proceedings of the American Railway Engineering Association. ${ }^{17}$ The firm of Jacobs and Davies, Inc., furnished a reprint of a paper by J. Vipond Davies and J. Hollis Wells, presented before the American Institute of Architects at Washington, D. C., December 16, 1909. This paper contained summaries on traffic counts made at congested points in New York City as a preliminary step in the Hudson Terminal design.

The conference also had the benefit of studies conducted by the Committee on Safety to Life of the National Fire Protection Association. The findings of this committee are discussed in the Proceedings

17 Vol. 25, pages 512 to 524 (1924); vol. 26, pages 728 to 734 (1925). 
of the National Fire Protection Association, particularly those for the years 1917 and 1918, and in the Quarterly of this association. Other studies on the capacity of revolving doors, efficiency of exits in schools, and a test on discharge rate in a large theater completed the information which was collected and studied before attempting a field survey.

\section{CONCLUSIONS OF PREVIOUS TRAFFIC COUNTS}

Summaries of some of the conclusions reached as a result of the studies made by the Illinois Central Railroad and those for the Hudson Terminal are given in table 16, as follows:

TABLE 16.-Summary of some previous traffic movement observations

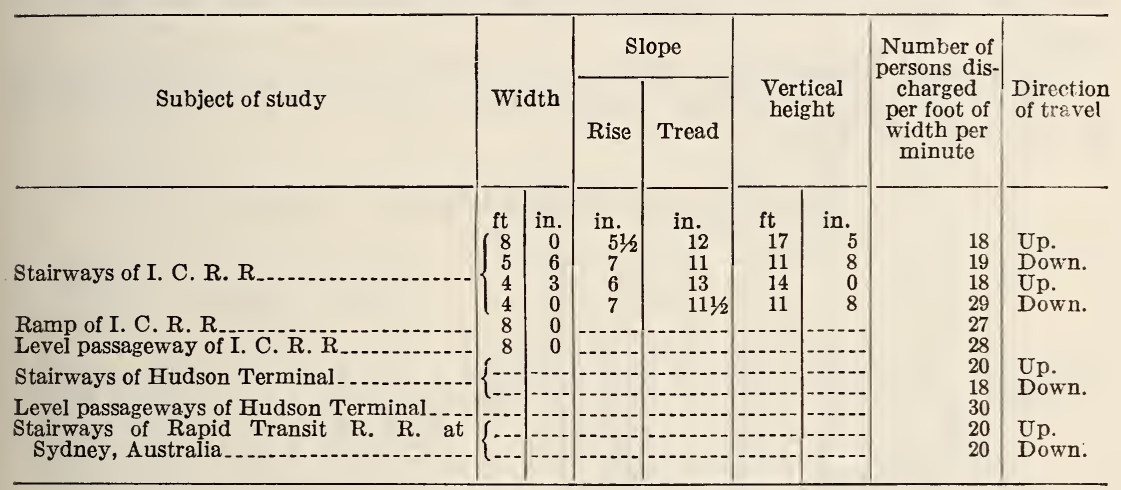

The rate at which passengers can pass through doors was also checked in the Illinois Central study. A double swinging door, each leaf 3 feet wide and both leaves open, accommodated 117 persons in 1 minute, the movement being in 1 direction only. The same door, 1 leaf locked, accommodated 77 persons in 1 minute. These figures, when reduced to discharge rate, show that the 6 -foot opening had a discharge rate of 19 persons per foot of width per minute, while the 3 -foot opening had a discharge rate of 26 persons per foot of width per minute.

Computations made on the number of square feet occupied per person on stairways, on ramps, and on passageways checked in the Illinois Central studies gave a figure of 5.7 square feet per person on the stairways, 10.5 square feet on the ramps, and 11.1 square feet on level passageways. The Hudson Terminal study noted 10.0 square feet per person on a level passageway under crowded conditions, the passageway discharging approximately 30 persons per foot of width per minute at that time.

A check of the discharge rate from a theater, made under the direction of the late Philip A. Mason, when building commissioner of Hartford, Conn., showed a stairway discharge of 13 persons per foot of width per minute and a doorway discharge of 32 persons per foot of width per minute. These figures are the average of a number of observations and represent a normal rate of discharge at the end of the performance. The theater in question had a capacity of 3,200 , and was filled the night the count was taken. 
A very interesting and extensive study of exits in schools was conducted by J. M. Tracy, superintendent of schools, Rochester, N. Y., as part of the program prompted by the Committee on Safety to Life of the National Fire Protection Association to determine the efficiency of exits in such buildings. The individual discharge rate for separate exits was not recorded and it is not known how these exits were distributed on the floor areas. However, the actual time necessary to empty a building of its occupants during a fire drill was checked for over 50 schools. An average rate of discharge, assuming all the exits in the building to be used, was computed for a 22-inch unit of exit width-that is, a building having a total of eight 22-inch units of exit width, and discharging 600 pupils in 2 minutes, was computed to have an average discharge rate of 37.5 pupils per 22 -inch unit per minute. The results of these studies are given in table 17 below.

The results of capacity tests on revolving doors furnished by one of the large companies that manufacture such doors, are reproduced in table 18, page 33.

TABLE 17.-Survey of exits in school buildings, Rochester, N. Y.

\begin{tabular}{|c|c|c|c|c|c|c|c|c|c|c|c|c|c|}
\hline \multirow[b]{2}{*}{$\begin{array}{l}\text { School } \\
\text { number }\end{array}$} & \multicolumn{2}{|c|}{$\begin{array}{l}\text { Existing } \\
\text { exits }\end{array}$} & \multirow{2}{*}{ 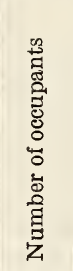 } & \multirow{2}{*}{\multicolumn{2}{|c|}{ 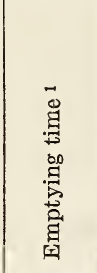 }} & \multirow{2}{*}{ 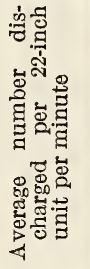 } & \multirow[b]{2}{*}{$\begin{array}{c}\text { School } \\
\text { number }\end{array}$} & \multicolumn{2}{|c|}{$\begin{array}{l}\text { Existing } \\
\text { exits }\end{array}$} & \multirow{2}{*}{ 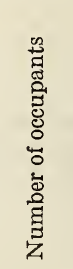 } & \multirow{2}{*}{\multicolumn{2}{|c|}{ 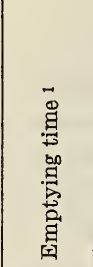 }} & \multirow{2}{*}{ 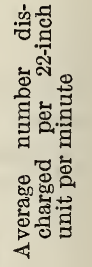 } \\
\hline & 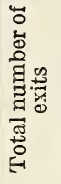 & 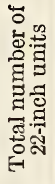 & & & & & & 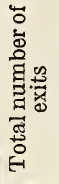 & 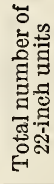 & & & & \\
\hline & $\begin{array}{l}5 \\
5 \\
9 \\
9 \\
3\end{array}$ & $\begin{array}{r}10 \\
8 \\
14 \\
18 \\
8\end{array}$ & $\begin{array}{l}400 \\
600 \\
485 \\
662 \\
691\end{array}$ & \begin{tabular}{c}
$\min$ \\
1 \\
2 \\
\hdashline 2 \\
1
\end{tabular} & $\begin{array}{c}\text { sec } \\
20 \\
00 \\
48 \\
00 \\
58\end{array}$ & $\begin{array}{l}30 \\
37.5 \\
43.1 \\
18.3 \\
43.6\end{array}$ & $\begin{array}{l}26 \\
27= \\
28 \\
29 \\
30 \\
-\end{array}$ & $\begin{array}{r}8 \\
20 \\
5 \\
4 \\
3\end{array}$ & $\begin{array}{r}18 \\
40 \\
11 \\
38 \\
6\end{array}$ & $\begin{array}{r}1,550 \\
920 \\
580 \\
609 \\
525\end{array}$ & \begin{tabular}{c}
$\min$ \\
2 \\
\hdashline 1 \\
\hdashline 1 \\
1
\end{tabular} & $\begin{array}{c}\text { sec } \\
00 \\
40 \\
48 \\
45 \\
40\end{array}$ & $\begin{array}{l}43.0 \\
34.5 \\
65.9 \\
43.5 \\
52.5\end{array}$ \\
\hline - & $\begin{array}{l}3 \\
6 \\
7 \\
6 \\
5\end{array}$ & $\begin{array}{r}8 \\
13 \\
12 \\
12 \\
12\end{array}$ & $\begin{array}{r}416 \\
930 \\
1,400 \\
780 \\
834\end{array}$ & $\begin{array}{l}1 \\
2 \\
1 \\
1 \\
1\end{array}$ & $\begin{array}{l}15 \\
00 \\
30 \\
30 \\
40\end{array}$ & $\begin{array}{l}41.5 \\
35.7 \\
77.7 \\
43.3 \\
41.7\end{array}$ & $\begin{array}{l}31 \\
32 \\
33 \\
34 \\
35\end{array}$ & $\begin{array}{r}2 \\
5 \\
7 \\
5 \\
25\end{array}$ & $\begin{array}{r}4 \\
12 \\
14 \\
11 \\
50\end{array}$ & $\begin{array}{r}275 \\
779 \\
500 \\
1,230 \\
865\end{array}$ & $\begin{array}{l}1 \\
1 \\
1 \\
1\end{array}$ & $\begin{array}{l}00 \\
10 \\
10 \\
30 \\
30\end{array}$ & $\begin{array}{l}68.7 \\
55.5 \\
30.6 \\
74.5 \\
34.6\end{array}$ \\
\hline 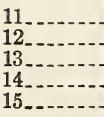 & $\begin{array}{l}6 \\
3 \\
7 \\
2 \\
8\end{array}$ & $\begin{array}{r}12 \\
8 \\
16 \\
4 \\
13\end{array}$ & $\begin{array}{r}450 \\
522 \\
1,145 \\
260 \\
800\end{array}$ & $\begin{array}{l}1 \\
1 \\
2 \\
1 \\
1\end{array}$ & $\begin{array}{l}30 \\
25 \\
00 \\
05 \\
30\end{array}$ & $\begin{array}{l}25.0 \\
46.0 \\
35.8 \\
60.0 \\
41.0\end{array}$ & & $\begin{array}{l}8 \\
8 \\
8 \\
4 \\
6\end{array}$ & $\begin{array}{r}19 \\
19 \\
19 \\
8 \\
13\end{array}$ & $\begin{array}{r}404 \\
875 \\
291 \\
903 \\
1,000\end{array}$ & $\begin{array}{l}1 \\
2 \\
1 \\
1 \\
1\end{array}$ & $\begin{array}{l}30 \\
15 \\
09 \\
40 \\
15\end{array}$ & $\begin{array}{l}14.1 \\
20.4 \\
13.3 \\
67.7 \\
61.6\end{array}$ \\
\hline- & $\begin{array}{l}6 \\
8 \\
5 \\
5 \\
6\end{array}$ & $\begin{array}{r}15 \\
15 \\
10 \\
9 \\
10\end{array}$ & $\begin{array}{r}1,536 \\
1,700 \\
531 \\
1,060 \\
580\end{array}$ & $\begin{array}{l}2 \\
1 \\
1 \\
2 \\
1\end{array}$ & $\begin{array}{l}00 \\
35 \\
05 \\
35 \\
40\end{array}$ & $\begin{array}{l}51.2 \\
71.5 \\
49.1 \\
45.6 \\
34.8\end{array}$ & $\begin{array}{l}41- \\
42= \\
43 \\
44- \\
45\end{array}$ & $\begin{array}{r}6 \\
2 \\
10 \\
4 \\
6\end{array}$ & $\begin{array}{r}12 \\
5 \\
11 \\
10 \\
24\end{array}$ & $\begin{array}{r}530 \\
240 \\
67 \\
372 \\
1,639\end{array}$ & $\begin{array}{c}1 \\
-1 \\
2 \\
2\end{array}$ & $\begin{array}{l}30 \\
50 \\
05 \\
45 \\
54\end{array}$ & $\begin{array}{r}29.4 \\
57.6 \\
5.6 \\
13.5 \\
23.5\end{array}$ \\
\hline 24 & $\begin{array}{r}9 \\
3 \\
24 \\
28 \\
10\end{array}$ & $\begin{array}{r}23 \\
8 \\
48 \\
56 \\
22\end{array}$ & $\begin{array}{r}1,221 \\
600 \\
600 \\
1,115 \\
1,298\end{array}$ & \begin{tabular}{c}
1 \\
1 \\
\hdashline 2 \\
2
\end{tabular} & $\begin{array}{l}35 \\
45 \\
45 \\
30 \\
00\end{array}$ & $\begin{array}{l}33.5 \\
42.7 \\
16.6 \\
39.8 \\
29.5\end{array}$ & $\begin{array}{l}46 \ldots- \\
47-- \\
48 \\
49 \\
50 .\end{array}$ & $\begin{array}{r}6 \\
10 \\
5 \\
7 \\
5\end{array}$ & $\begin{array}{r}24 \\
16 \\
9 \\
28 \\
20\end{array}$ & $\begin{array}{r}1,528 \\
516 \\
548 \\
1,668 \\
1,532\end{array}$ & \begin{tabular}{c|}
2 \\
1 \\
1 \\
2
\end{tabular} & $\begin{array}{l}15 \\
10 \\
47 \\
45 \\
10\end{array}$ & $\begin{array}{r}28.3 \\
-77.6 \\
34.0 \\
35.3\end{array}$ \\
\hline
\end{tabular}

1 Actual time required under normal conditions in September 1927 to empty the buildings during fire drill. 
$\mathrm{T}_{\mathrm{ABLE}}$ 18.-Capacity tests on revolving doors of certain buildings in New York City ${ }^{1}$

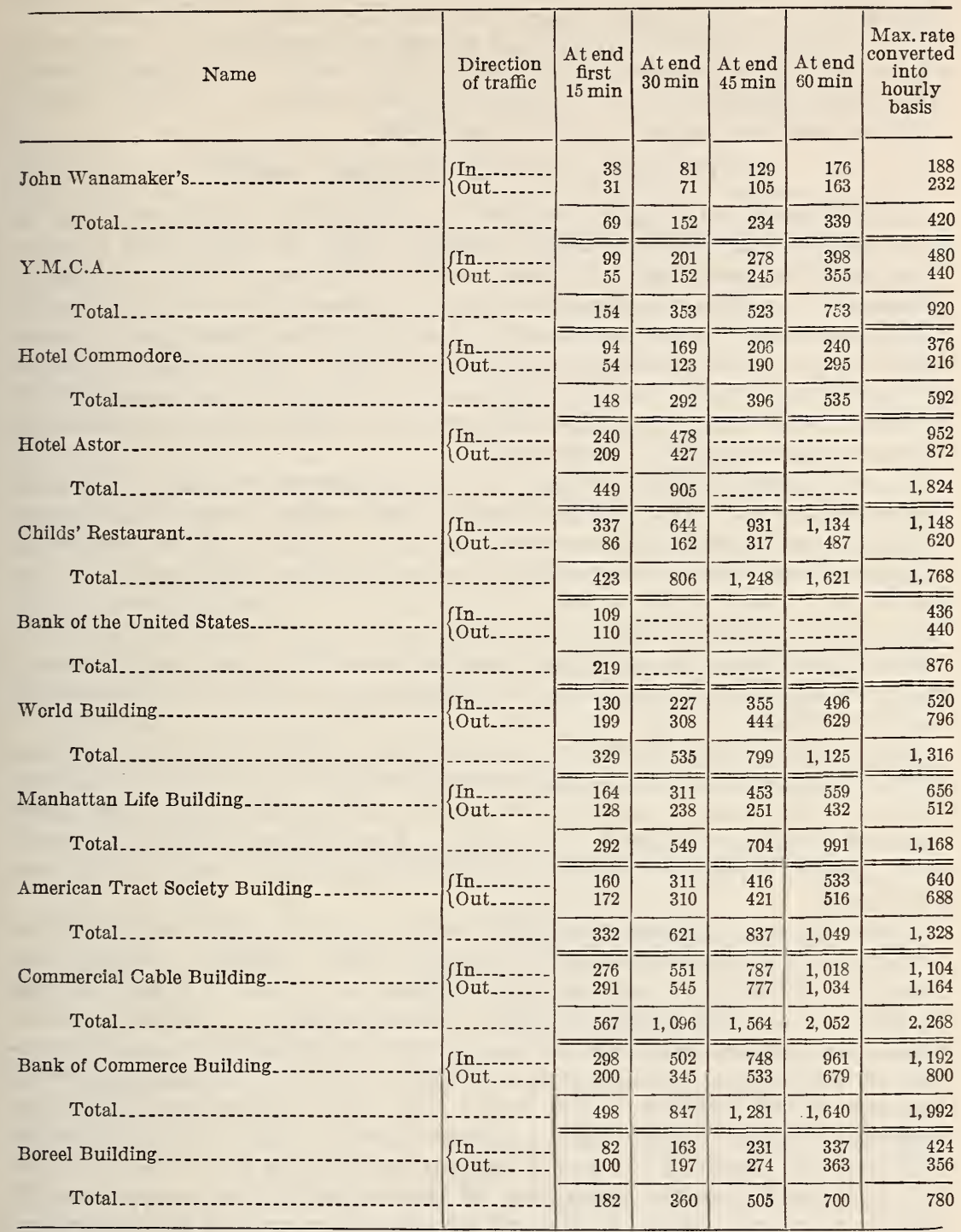

1 Count made through 1 door only. Courtesy Van Kannel Revolving Door Co.

\section{FIELD WORK}

A review of the tests on traffic movement, summaries of which have been enumerated in preceding paragraphs, indicated that certain gaps in these data could well be closed up by making further counts. It also appeared desirable to check some of the previous findings, especially those where but few observations were available. A field survey was then instituted in Washington, D. C. Traffic counts were taken at some of the larger Government office buildings, at department stores, and at theaters. Congested conditions which would produce 
maximum use of exits were extremely difficult to obtain, so to broaden the field work additional observations were made in New York City at the Grand Central Terminal, at certain of the subway and elevated exits, at theaters, and at a number of other points where there was a likelihood that the exits would be used to capacity. All these observations were on random conditions of flow.

\section{METHODS USED IN MAKING COUNTS}

The mechanical details involved in timing the movement and in counting the number of people walking through exits were simple. The time was recorded by a stop watch. The counts were taken by means of a mechanical hand counter. The probable error involved in making a count was determined by having 2 observers make concurrent checks of the discharge of people through a few typical exits at a congested period. Several trials showed that the counts differed by approximately 2 or 3 people for every 300 , a difference so small as to warrant the use of but 1 counter.

It was found preferable also for the observer recording the time with the stop watch to read the counter, rather than to ask the observer making the count for the reading thereby momentarily interrupting a continuous check and probably introducing a slight error in the count as a few people would pass by while the reading was made. When the exits were filled for periods of several minutes the count was taken at intervals of 30 seconds; at other times any interval that gave an apparent maximum flow whether it was 10 or 60 seconds, was recorded.

Stairway or ramp discharge was studied in different ways. Where rates were only checked, both observers stationed themselves at a convenient point and counted the number of people passing as they reached the top or bottom of the exit. The readings were not started until the stairways or ramps were filled from top to bottom between handrails.

Observations to determine the number of square feet occupied per person at the time when people are moving normally up or down stairways as well as the rate were taken in 2 ways. Where it was possible to see the people as they entered a flight of stairs, an individual was picked out as he entered the stairway, the count was immediately started at the other end and continued until the person selected completed the passage. The count was then stopped and the time recorded, thus giving the total number of people in the stairway during the interval required for any 1 person to traverse it. Where it was not possible to see the beginning of the discharge, the observer with the stop watch stationed himself at the other end of the stairway, whistled as he entered with the crowd as a signal to start the count, and then walked through the stairway recording the time required to reach the observer making the count. Naturally, fewer counts are possible by this second method during any peak period. These counts were made only when the stairways discharged at what appeared to be capacity.

A large number of counts were taken of the traffic movement on stairways ranging in width from 3 to 8 feet. Unfortunately, it was not found possible in this survey to obtain discharge rates on stairways whose widths varied by increments of about 6 inches. The relative 
efficiency of stairways, say one 44 and the other 50 inches in width, is open to question.

All essential measurements of stairways, ramps, passageways, and doorways were taken in order to make the necessary computations for discharge rates. The width of stairways was that measured from wall to wall rather than the clear width between handrails, the width for treads included any nosings, and for doorways the actual door width was recorded. Any peculiarities of movement or conditions that might make interpretation of test results easier were also noted.

\section{CONDITIONS AFFECTING TRAFFIC COUNTS MADE}

The counts of traffic movement at the Grand Central Terminal, where more than 165 separate observations were taken on stairways, 40 on ramps, and more than 50 on gateways, were made during the morning and evening rush hours. The points selected for traffic checks were chosen after a brief study to determine where traffic appeared to be the greatest. The exits commonly used by commuters-those people who are always in a hurry to get in and out of a station-proved to have a faster discharge rate than those used by through passengers, who were, of course, encumbered with baggage and unfamiliar with the exits. No counts were recorded when any contrary movement took place in an exit because of the apparent retarding effect on discharge.

A number of theaters were studied, but many of the counts made in them were rejected. Theater patrons, when leaving at the close of a performance, usually walked slowly. This leisurely exit is reflected in the rates of discharge for theater stairways, approximately 13 persons per foot of width per minute as listed in table 19, below, which coincides with the rate obtained in the study previously mentioned for a theater in Hartford, Conn.

TABLE 19.-Summary of observations of traffic movement on stairways

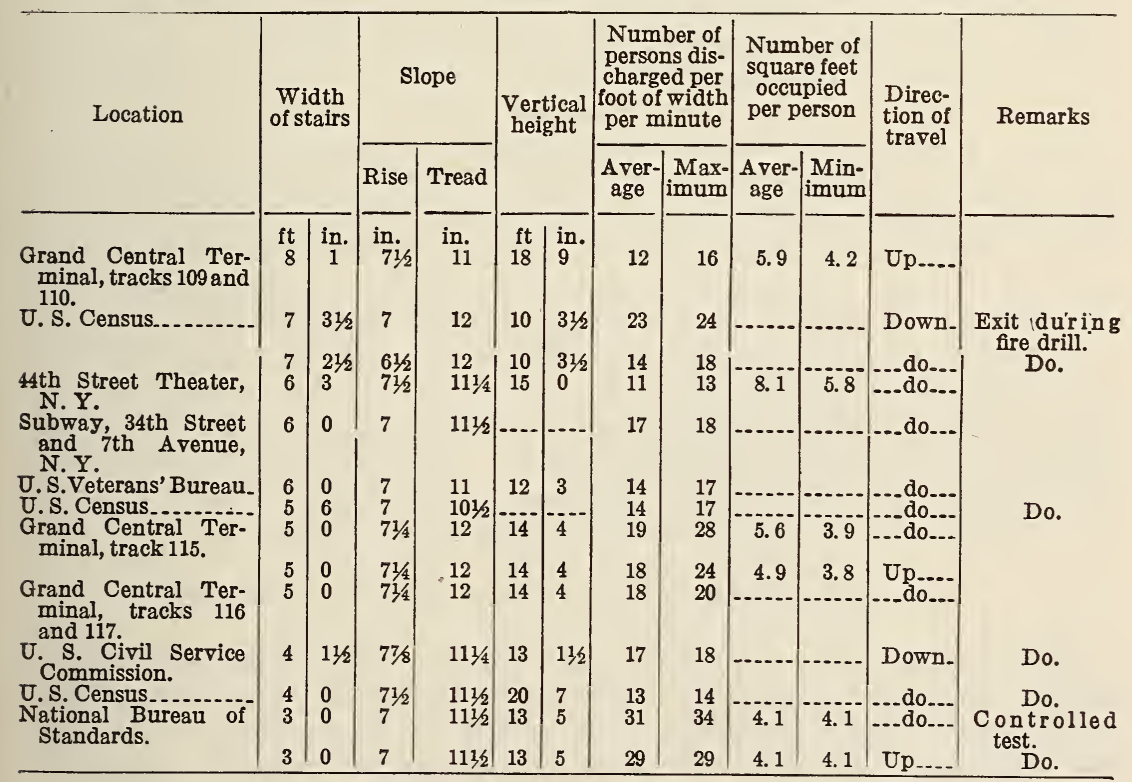

$1158-35-6$ 
Government office buildings in Washington, D. C., were studied at the closing hour. Some interesting counts were also made of the traffic movement during fire drills at the so-called "temporary office buildings." These drills were compulsory, and were conducted by the fire marshal in charge of the buildings. The occupants were not warned when a drill was to take place. At the sound of the fire gong everyone left the building at a normal rate by exits which had been assigned to specified floor areas. No attempt was made to form ranks. A high rate of discharge for a stairway checked during one of these drills will be noted in table 19, page 35. A maximum flow condition was created by closing a stairway ordinarily used, thus adding its entire load to the particular stairway under observation. This stairway was unusual in that two 5-foot stairways were connected at an intermediate landing with a single stairway 7 feet $31 / 2$ inches wide, producing a bottle neck in the direction of flow.

A controlled test of traffic movement on a 36-inch stairway was made at the National Bureau of Standards. This stairway was unenclosed, had a railing on one side, treads of $11 \frac{1}{2}$ inches and risers of 7 inches, a story height of 13 feet 5 inches, and was constructed with two landings, each 3 feet square and each one making a 90degree turn. A crowd of people was assembled in the hallway at the top of the stairway and asked to descend as they naturally would without attempting to run. As will be noted in table 19, page 35, a maximum rate of discharge of 34 persons per foot of width per minute was obtained. During this test the number of square feet occupied per person averaged 4.1. However, by placing all the people in the stairway that could be accommodated when there was no motion, but 1.4 square feet was occupied per person.

\section{TABULATION OF COUNTS ON STAIRWAY DISCHARGE}

The results of the observations on stairways are given in table 19, page 35. The average figures in the tables represent a large number of observations taken not only at different hours of the day, but also on different days. The column giving the number of persons discharged per foot of width per minute was calculated by determining the number of persons passing in 1 minute and dividing this number by the stairway width in feet. Thus, on a 3 -foot stairway, where 93 people were discharged in 1 minute, the rate per foot per minute was computed to be 31 . If a 22 -inch unit were used to compute discharge as is sometimes done, a rate of 93 per 22 -inch unit per minute would be obtained where credit for only a single unit was allowed the 36 -inch stairway; if the same 22-inch unit were used and the computation based on the proportion of 36 inches to 22 inches, the rate would be 57 persons per 22 -inch unit per minute. The results obtained in the Illinois Central and Hudson Terminal studies, table 16, page 31, were also referred to the rate per foot of width per minute.

\section{CHARACTERISTICS OF STAIRWAY DISCHARGE}

The varying rates of stairway discharge found, while they bear a certain relation to stairway width, also indicated that normal discharge rates may vary widely with different occupancies. For any one stairway with the same class of occupancy using it, the total 
number of persons discharged per unit of time remained nearly constant - that is, with rapid movement necessitating considerable space between the individuals, the number of people discharged per unit of time remained the same as when the movement was slower but therefore denser. This condition has been noted in other tests.

Discharge rates as related to stairway width indicated a number of possibilities. For average conditions of stairways varying in width from 3 or 4 feet up to 6 or 7 feet, the number of persons discharged might be taken as roughly proportional to the width of the stairway. On the other hand, stairways 3 or 4 feet wide appeared to give much higher rates of discharge per foot of width than those 7 or 8 feet wide, especially where the wider stairs had no intermediate handrails. Even where an overflow was waiting to enter a stairway, a condition existing on the stairway ( 8 feet 1 inch wide) in the Grand Central Terminal, as soon as the crowd entered the stair it became scattered and the discharge rate was therefore reduced.

Observations of the characteristics of the movement on stairways showed that the movement was slower and denser on the first half of any flight than it was on the second half. Increased space between individuals resulting in faster movement took place after the intermediate landing was passed. In both flights, the appearance of the movement under random flow appeared similar. Whenever a rank of people formed to take up the complete width of the stairway, it was invariably followed by a lesser number, so the final effect might be said to resemble a series of successive wedge-shaped units distributed rather evenly over the length of the flight. Conditions of maximum flow did not occur unless a number of people were waiting: to enter an exit.

The space occupied per person while moving up or down a stairway necessarily varies widely with the speed of the movement. Table 19, page 35 , shows the fluctuation in these figures. Although under fast discharge a little over 4 square feet is occupied per person, when the discharge is leisurely nearly double this space will be occupied.

\section{RAMPS}

Studies on ramps were difficult to make as very few could be located that were used to anything near capacity. Table 20, below, lists the results of some 30 observations made on 2 ramps in the

TABLE 20.-Summary of observations of traffic movement on ramps

\begin{tabular}{|c|c|c|c|c|c|c|c|c|c|c|c|}
\hline \multirow[t]{2}{*}{$\begin{array}{c}\text { Grand Central } \\
\text { Terminal track } \\
\text { nos. }\end{array}$} & \multirow{2}{*}{\multicolumn{2}{|c|}{$\begin{array}{l}\text { Width of } \\
\text { ramp }\end{array}$}} & \multirow{2}{*}{\multicolumn{2}{|c|}{ Length }} & \multirow[t]{2}{*}{ Slope } & \multirow[t]{2}{*}{ Area } & \multicolumn{2}{|c|}{$\begin{array}{l}\text { Number of per- } \\
\text { sons discharged } \\
\text { per foot of width } \\
\text { per minute }\end{array}$} & \multicolumn{2}{|c|}{$\begin{array}{l}\text { Number of } \\
\text { square feet } \\
\text { occupied per } \\
\text { person }\end{array}$} & \multirow[t]{2}{*}{$\begin{array}{l}\text { Direc- } \\
\text { tion of } \\
\text { travel }\end{array}$} \\
\hline & & & & & & & $\begin{array}{l}\text { Aver- } \\
\text { age }\end{array}$ & $\begin{array}{l}\text { Maxi- } \\
\text { mum }\end{array}$ & $\begin{array}{l}\text { Aver- } \\
\text { age }\end{array}$ & $\begin{array}{l}\text { Mini- } \\
\text { mum }\end{array}$ & \\
\hline $\begin{array}{l}111 \text { and } 112 . . . .- \\
109 \text { and } 110 . . . .\end{array}$ & $\begin{array}{l}\mathrm{ft} \\
6 \\
6\end{array}$ & \begin{tabular}{r|} 
in. \\
$41 / 2$ \\
$41 / 2$
\end{tabular} & $\begin{array}{l}\text { ft } \\
137 \\
137\end{array}$ & $\begin{array}{r}\text { in. } \\
2 \\
2\end{array}$ & $\begin{array}{l}1 \text { in } 9.7 \\
1 \text { in } 9.7\end{array}$ & $\begin{array}{r}\text { sq ft } \\
875 \\
875\end{array}$ & $\begin{array}{l}15 \\
21 \\
19\end{array}$ & $\begin{array}{l}21 \\
23 \\
22\end{array}$ & $\begin{array}{l}8.1 \\
7.9\end{array}$ & $\begin{array}{l}6.2 \\
6.3\end{array}$ & $\begin{array}{l}\text { Down. } \\
\text { Up. } \\
\text { Do. }\end{array}$ \\
\hline
\end{tabular}

Grand Central Terminal used by commuters. Wider ramps were also observed in the terminal, but, inasmuch as they never seemed to 
be used to capacity, no counts were taken. An attempt to make a count on a ramp at the Griffith Stadium in Washington, D. C., which was 17 feet 6 inches wide, proved unsuccessful because the observers were unable to get anything approaching accurate readings on a ramp of this width.

Given similar conditions, the discharge rate on ramps was faster than on stairways. Naturally, the width of stairway treads reduces the normal 30 -inch stride more than a ramp with a slope of 1 in 10 or less, and would therefore result in effecting a slower discharge rate for the stairway.

\section{DOORWAYS}

Table 21, below, lists the average discharge rates for counts made at gateways, swinging doors, and revolving doors. It should be borne in mind that these studies were not made to determine the efficiency of the various types of doors. Most of the counts of traffic through doorways were taken when the doors were fastened open. Just how much slower the discharge rate is when doors are swinging, would require further special study.

At the Grand Central Terminal, the readings were taken at the gateways as they were opened to let the crowds through that had been waiting in the concourse; they therefore show a higher rate of discharge than the doorways in the office buildings or department stores.

TABLE 21.-Summary of observations of traffic movement through gates and doorways

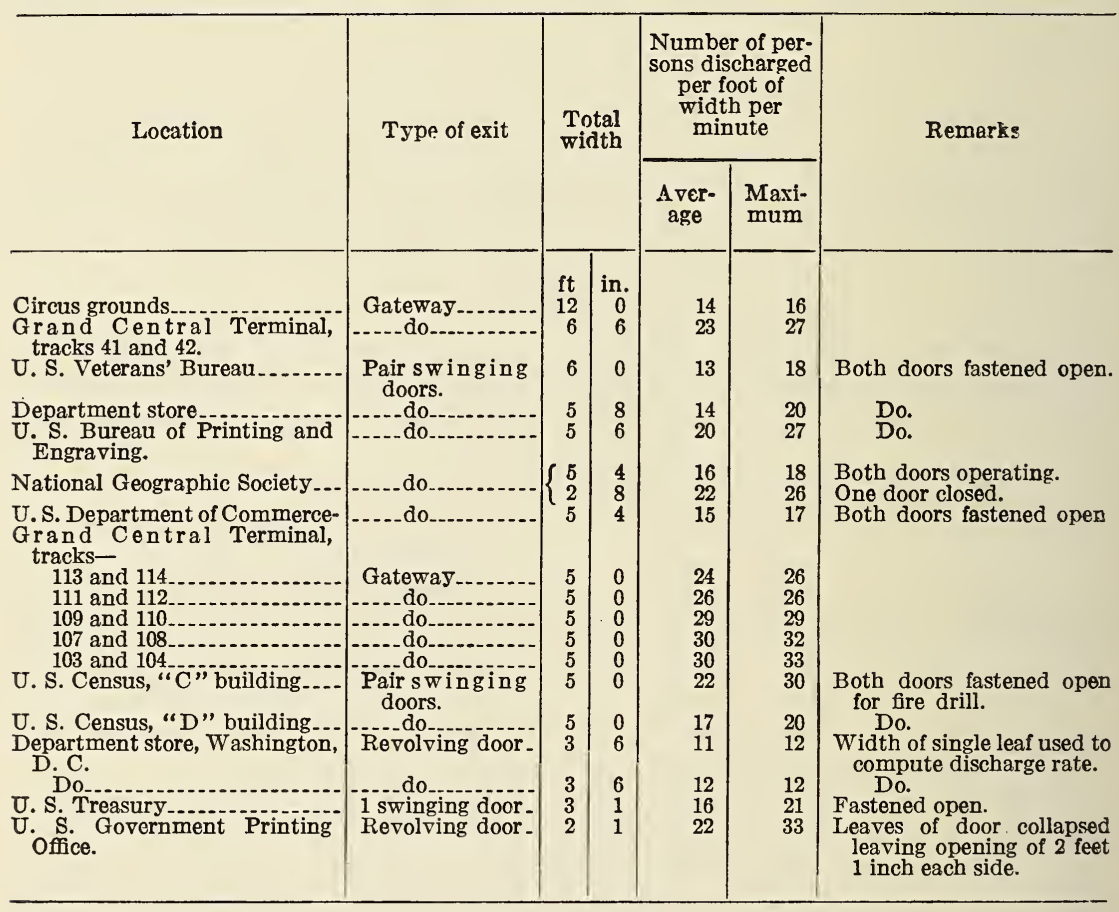


The figures for revolving doors do not necessarily represent absolute capacity. The readings were clocked for those moments when the doors appeared to be accommodating people as fast as convenient. Egress only was checked. Observations of the action of people in revolving doors led to the belief that the width of the leaf has very little relation to the number of persons discharged. As might be expected, it was exceptional for 2 people to pass through a single pocket of these doors at the same time.

Movement through doorways displayed one characteristic in common with stairways - the tendency for those having a width of about 5 feet or less to have a higher rate of discharge than those over about 8 feet in width. A comparison of the rates of discharge through doorways with those up or down stairways shows a faster rate for doorways under similar traffic conditions.

The figures in tables 19,20 , and 21 , giving the summary of observations of traffic movement in various types of exits, were carefully considered by the joint conference. Although there were marked variations in results, probably attributable to the fact that in some cases the exits were not used to their maximum capacity, the judgment of the conference was that rates of 45 persons per 22-inch unit per minute for travel down stairways, and 60 persons per 22-inch unit per minute through doorways, which had been in use on the basis of earlier observations, were sufficiently confirmed to warrant their retention in connection with the requirements under development. This is equivalent to a ratio of 4 to 3 as between the flow to be expected through doorways and down stairways.

Varying width, story height, and proportions of treads and risers, coupled with the mental and physical traits of people, render it nearly impossible to obtain other than general averages of discharge rates from exits.

\section{METHODS OF CALCULATING EXIT WIDTH}

Several broad controlling principles are utilized to compute the necessary exit width. These are discussed below:

\section{CAPACITY METHOD}

This method is based on the theory that sufficient stairways should be provided at each floor to accommodate all the occupants on that floor without the necessity of any movement within the stairway. There are two principal ways of arriving at the necessary stairway size. In one the total area of landings and stair treads is obtained and is divided by a figure representing an assumed area per person. In the other, 1 person is assumed to stand on every other tread in a 22-inch width, and the area of landings is divided as in the previous case to give the additional persons that may be included.

Theoretically this provides a safe area of refuge for everyone within the protective barrier formed by the stairway enclosure. It allows for the subsequent safe and orderly evacuation of the building without the necessity of forcing aged or infirm people to travel at a rate beyond their physical capacity. It recognizes that travel down a long series of stairs in high buildings is exhausting even to normal persons. The knowledge that there is a safe place for everyone is held to minimize the possibility of panic. 
Such a method takes a large amount of space away from the rentable area of the building and reductions are resorted to to overcome this objection by making allowances when the building is sprinkled or when horizontal exits are provided. These devices are not always conveniently installed and the arbitrary allowances made for them may or may not accurately represent their value in replacement of stairway facilities. While it is true that safety should be the first consideration, there is a very real question whether the degree of safety offered by this method is necessary, particularly in low buildings where a certain amount of flow out of the building appears to be inevitable. Authorities also maintain that people will not stand still in stairways even in high structures.

\section{FLOW METHOD}

This method is based on an assumed rate of flow of people, commonly at the rate of 45 persons per 22-inch width per minute down stairways and of 60 persons through doorways. It is usually coupled with an assumed length of time within which it is expedient to evacuate the building. The object is to get the people out and away from the threatened area in as short a time as possible.

With certain occupancies such as theaters where simultaneous exit by all is needed and in certain cases where drills are a regular feature as in schools, the method has many desirable features. It provides a definite objective to be accomplished. The result calls for considerably less stairway width than the preceding method. For comparatively low structures the method has an obvious application since it recognizes that flow out of such structures is a natural procedure. However, its use is confined to a few occupancies and to buildings of moderate height. Continuous movement down stairways, especially in high buildings, cannot be expected without serious effects upon some of the occupants. Any calculations assuming continuous orderly movement in such structures runs contrary to observation and experience.

\section{COMBINED METHOD}

This method attempts to correct the defects of the capacity and flow methods through a formula intended to apply the flow method to low buildings and an increasing emphasis upon capacity until this controls in high buildings. The formula contains various factors involving such features as type of construction, enclosure of openings, hazard of occupancy, presence of horizontal exits, etc., all of which affect the final result.

The method offers a means by which definite relationships may be preserved between height, character of construction, and other features. It recognizes that people can file out rapidly in low buildings and cannot be expected to do so in high ones. And it effects a transition from one method to the other in a gradual and systematic manner.

The results reached through application of this formula have never been entirely satisfactory even to its advocates. The relative weights assumed for the various factors are empirical. There is a constant increase in the aggregate stairway width throughout the building, as the building becomes higher which is a principle whose 
necessity is doubted by many authorities. The results obtained in terms of stairway width, especially where fire towers, horizontal exits, and other features are not present, are very large in tall structures, causing disproportionate amount of space to be devoted to stairways as compared with usable floor area.

\section{PROBABILITY METHOD}

This method secures an answer directly in terms of number of standard 2-unit-width stairways by dividing an arbitrary figure varying with the occupancy, such as 1,000, into the total population of all floors above the first, with a proviso that a maximum of only the 6 most densely populated of such floors need be considered. Provision is made for taking care of fractions in the result.

The method is direct and simple. It introduces an element that is absent in the preceding ones, namely, a limit as to the probable need for simultaneous use of the stairways. Other methods have assumed that all persons on each floor will need egress facilities at once, while this method infers that such an arrangement is neither practical nor necessary.

In the case of set-back buildings the method is further complicated by supplementary provisions in order to make it work. In the case of high buildings there is a doubt as to whether 6 stories out of 40 are all that need to be considered. The method also makes use of assumptions as to the influence of type of construction that are not agreed to by all authorities. In the case of low buildings of large floor area the results are so small as to be of questionable value.

\section{FLOOR-AREA METHOD}

This method presents in tabular form a series of floor areas with the number of standard 2-unit-width stairways required for each. The areas vary with the type of construction and class of occupancy. They are further modified by the position of a given floor in the building. The table represents some typical floor such as the third, with an increase in allowable area per stairway for floors below and a scale of percentage reductions for higher floors. Like the probability method this concedes that it is impracticable to provide a place for everyone in the stairway enclosure. However, it retains a slight variation according to height instead of fixing a maximum number of floors to be considered.

Computations are fairly easy to make. Results do not reach such large numbers of stairways as to cut down useful area excessively. However, there appears to be no consistent relationship between stairways and number of persons accommodated by them. The allowance for increase in height is so slight that there is a question whether it is significant enough to warrant the additional calculations required. The method, being based on area rather than occupants, takes no account of varying population within a given occupancy. Abrupt jumps also occur in the tables at points where floor areas change. 


\section{DEVELOPMENT OF A SATISFACTORY METHOD}

Each of the methods already described selects certain conditions which must be fulfilled in order to insure a reasonable degree of safety. Refuge for all, escape at a predetermined rate, a combination of the two, and probable need for simultaneous use, all start with certain assumptions and then endeavor to apply mathematics that will accomplish the desired result. No method attempts to apply any factor for panic. Only one makes assumptions that some exits will be blocked because of smoke or fire. This, as worked out by means of a formula, applies not to the number of stairways but to increase in the aggregate width and there is thus no assurance that the extra allowance will be transformed into additional stairways.

In view of all the uncertainties involved in the problem, complicated methods and refinements of detail seem scarcely justified. At the outset it may be pointed out that the needs of probably over 95 percent of all buildings will be covered by the minimum requirement for 2 stairways. Perhaps on a basis of population contained the percentage would run somewhat higher, but the necessity for going beyond 2 standard 2-unit-width stairways does not arise in the average building. It may well be kept in mind that most of what follows applies to the relatively infrequent building of large size, usually of fireresistive construction and designed by experienced talent.

In weighing the advantages and disadvantages of each method the primary consideration, of course, is safety; but it is apparent that what constitutes safety cannot be definitely established. It therefore is fruitless to reject considerations of loss of usable space on the ground that such considerations have no standing. No one would dispute that profit should yield to safety where it can be shown that certain requirements will provide safety. But where it cannot be so shown it is legitimate to balance economic considerations against theoretical assumptions.

Experience is obviously one method of approach. If it could be shown that certain cities had utilized a particular method of dealing with egress requirements over a period of years, that buildings had been erected in strict conformity to it, and that maintenance had been perfect, and if the loss of life in fires where exits were a factor were known over the same period, some evidence would exist for or against a given method. Unfortunately, such evidence is not available in sufficient detail and over a long enough period to be of much use.

Another means of approach is to compare exits found in representative buildings in a number of cities with those demanded by the various methods already cited. It may be argued that simply because certain provisions for exits exist this is not necessarily proof that they are adequate, yet there is a certain weight in an accumulation of instances where certain measures have been followed coupled with no conspicuous trouble. Traditional principles developed by responsible architects and engineers in the design of buildings are not to be ignored. Such principles may not be susceptible of definite analysis as to the extent of provisions for safety, but competent designers come to have a certain "feel" for the right thing arising out of long study of needs and observations of buildings in actual use. There is a further consideration in that such buildings have been designed with thought to their economic use and that practical considerations have not been entirely subordinated to theoretical provisions for safety. 
There is one distinction which helps in building up a method in dealing with the subject. People who are awake, alert, and in good physical condition are better able to take care of themselves in such an emergency as fire than those who have been just aroused from sleep or are sick or infirm. The distinction is so obvious that it has been applied in the case of several of the methods described. There is a further classification, that of people assembled in such locations as theaters, assembly halls, and the like. Experience teaches that, although such people are alert, panic communicates itself much more readily under such circumstances. There is no interval before the exits come into full use. The demand is immediate and simultaneous on the part of all. Such a condition justifies separate treatment.

It now becomes necessary to search for those features of existing methods that will best fit the needs of each group of persons or to develop new methods. Manifestly, in the case of those asleep, the sick, aged, and the infirm, the most liberal provisions should be made. They cannot be expected to use the same degree of discretion nor to move with as great celerity as the others. Accordingly, it seems wise to apply the principle of a place for everyone within the stairway enclosure for this group. However, it was found by actual experiment in the course of the investigations already described that the space allotted per person in some existing methods that utilize this principle can be reduced.

Coming to those awake and alert, a different problem presents itself. Here the greatest need and quickest alarm will develop naturally on the floor where the fire occurs. Other floors may not be involved at all, or if so, not until a later time because of the fire resistance of the building, particularly in its required enclosed shafts and stairways. On the floor where the fire starts it is possible that panic will develop, but this would hardly extend to all floors of the building at once. Here appears to be a reasonable field for the use of the method of probable need. As a matter of fact, on reexamining the principal methods for providing exits, we find that this principle is rather generally recognized. Some do this directly by a rather drastic reduction while others do so indirectly and partially by extremely liberal reductions in stairway sizes where sprinklers are present. The net result in all cases is to provide less stairway space than would be necessary for simultaneous use by all floors.

If this premise is accepted, and it seems necessary to do so unless so large an area is allotted to stairways as to make the building of doubtful utility, the question arises how much reduction should be made, or stating it another way, what is a reasonable probability of the number of floors that will need to be accommodated at one time. One of the methods described sets a maximum for the 6 most densely populated floors above the first. While this has a very evident merit it takes no account of the problem created by high buildings. For instance, a 7 -story building and a 20 -story building would each have facilities for only 6 floors at a time. After reviewing this problem at length it appears that the probability would be better expressed by some other method. In the case of the lower buildings, flow takes place; but in the case of high buildings a definite proportion of the floors should be provided for at all times. As a reasonable assumption, one-half of the floors above the first was selected and checked back against values plotted to show the results of the survey of existing 
buildings segregated as to occupancy. The results showed that current practice was substantially in accord with the percentage chosen. The results were applied also to a number of plans of buildings and were submitted to representative architects for their opinions as to their adequacy. Their reaction was favorable.

In the case of occupancy involving assembly there is virtually unanimous agreement in existing methods on the flow principle, that is, in providing for the escape of the occupants through exits proportioned to bring about a complete evacuation within a given maximum time. There appears to be no reason why this principle should be altered and it has constituted the basis for dealing with this particular group.

It will thus be evident that a selection may be made of those features in existing methods that appear to have the most practical usefulness when considered in relation to the principal groups constituting building occupants. No new principle is introduced but a more logical application is effected. The method of arriving at actual results in terms of units of exit width depends upon the use of several simple divisional factors, as will be shown under the particular paragraphs to follow dealing with details.

\section{CREDIT FOR ELEVATORS}

In some methods examined, attempts were made to give a credit to elevators in computing aggregate exit width. This allowance was so small, however, as to offer very slight reduction in required stairway space. Recognizing the growth in speed and other improvements in elevator construction, special attention was given to the part that might be played by elevators in providing exit from buildings. Certainly these devices have the merit of being familiar means of egress to which people would naturally turn in time of need.

It was assumed that automatic push-button elevators would not be suitable. Although these have a considerable vogue in apartment houses and small business buildings, their capacity and rate of speed is not great. Furthermore, they are not subject to a single will as in the case of an elevator operator, but to demands from many tenants. Their successful functioning in a time of emergency would be problematical.

The potential usefulness of other passenger elevators appears to depend on the reliability of the operators and the ability to discharge people at a reasonable rate. Testimony differs on the first point, some citing dereliction of elevator operators at critical times, while others point to examples of heroism. The probability of the operators staying on the job is at best uncertain. The possibilities of power being cut off, of cars stopping between floors, and of smoke filling shafts, also have to be considered.

As to the capacity and speed of elevators, one of the methods examined made use of a formula indicating that 5 elevators were about equal to one unit of stairway width, the exact relationship varying with the number of persons that could be carried, the speed, and the height of the building. A stairway of course, traverses the entire height of the structure and furnishes some accommodations at each story, while the elevator can serve only 1 floor at a time. With the modern high-speed elevator, however, running in an enclosed shaft, 
the conditions are favorable for taking out a considerable number of people. If an emergency is well sized up by some one in authority, it can often be met by taking people from above the floor involved to a lower floor, from which they can find their way to safety by means of the stairways. Thus, the elevators do not necessarily have to descend to the street floor each time. Such a utilization of them calls for intelligence and good discipline, qualities that cannot always be safely assumed.

In general, a safer policy appears to be not to give direct credit to elevators, but to recognize their availability in high buildings in the stairway requirements. The presence of these devices makes it possible to apply the assumption of probability with greater confidence. With some possibility of flow out of the building down stairways in the case of low buildings and with modern elevators acting as a valuable auxiliary in high buildings, proposed stairway requirements are considerably strengthened, while in the case of certain occupancies for which floor space is required in the stairways for the occupants of all floors, the elevators in use are likely to be of the pushbutton variety or else not able to carry a significant number of people in case of fire.

Thanks are due a large number of architects, engineers, building officials, and others who supplied information and cooperated in various ways. The procedure employed in the surveys was possible only because of the courtesy of building managers who permitted measurements and traffic counts to be taken in buildings under their jurisdiction. Suggestions and criticism from numerous individuals helped materially as the work progressed. Data on earlier traffic counts was supplied by J. Vipond Davies; the Illinois Central Railroad; and J. M. Tracy, superintendent of schools, Rochester, N. Y. Others to whom particular acknowledgment should be made are Frank Burton, consulting engineer, Detroit, Mich.; C. Heller, consulting engineer, San Francisco, Calif.; Nolan D. Mitchell, structural engineer, National Bureau of Standards; and Robert S. Moulton, technical secretary, National Fire Protection Association, Boston, Mass. 


\section{APPENDIX}

\section{MEANS OF EGRESS}

\section{RECOMMENDATIONS}

Throughout this study the ultimate object was to determine what were suitable exit requirements for building codes. It was not intended to produce a complete manual of practice covering all conditions but to find the minimum that appeared to be necessary for the usual occupancies. As the work proceeded, various tentative requirements were drawn up and compared with the results obtained in the field studies. Eventually, a set of suggested requirements was formulated representing the consensus of the committee.

It was the intention to publish these findings as part of the series of recommendations issued by the Department of Commerce Building Code Committee. Before time came for publication, however, the committee was discontinued. The suggested requirements, therefore, could not be put out as one of its series, but there were requests for issuance of a document giving the results of the studies and the interpretation placed upon them by the committee. Rather full footnotes have been given in connection with the various recommendations to explain the reasoning leading to specific recommendations and to illustrate their effect.

\section{DEFINITIONS}

The following terms shall, for the purpose of this chapter, have the meanings indicated.

Approved.-As applied to a material, device, mode of construction, or testing agency, means approved by the building official under the provisions of this code, or by other authority designated by law to give approval in the matter in question.

Automatic.-As applied to a fire door or other protection for an opening, means normally held in an open position and automatically closed by a releasing device that is actuated by abnormal high temperature or by a rate of rise of temperature exceeding some fixed value.

Dwelling.-A building occupied exclusively as a residence for 1 or 2 families or as a boarding or rooming house serving not more than 15 persons with meals or sleeping accommodations, or both.

Exit.-As applied to a stairway or doorway, means constructed and arranged as specified in this chapter.

Exit passageway.-An enclosed hallway or corridor connecting a required exit to a street or an open space leading to a street.

Fire wall.-A wall which subdivides a building or separates buildings to restrict the spread of fire, starting at the foundation and extending through all stories to or above the roof, and having an ultimate fire resistance of at least 4 hours. 
Fire door.-A door construction consisting of door, frame, and sill, which under approved fire-test conditions meets the requirements for the location in which it is to be used.

Fire window. - A window consisting of frame, sash, and glazing which under approved fire-test conditions meets the requirements for the location in which it is to be used.

Floor area.-An area enclosed by exterior walls or by walls or partitions having at least 2 hours' ultimate fire resistance.

Grade.-(a) For buildings adjoining 1 street only, the elevation of the sidewalk at the center of that wall which adjoins street; (b) for buildings adjoining more than 1 street, the average of the elevations of the sidewalk at centers of all walls adjoining streets; and (c) for buildings having no wall adjoining the street, the average level of the ground (finished surface) adjacent to the exterior walls of the building. All walls approximately parallel to and not more than 5 feet from a street line are to be considered as adjoining a street.

Hereafter.-The time after this code is adopted.

Heretofore.-The time before this code is adopted.

Horizontal exit.-The opening or passage between any 2 floor areas, whether in the same structure or not, by means of a vestibule, by an open-air balcony or bridge, or through a fire wall or a partition having an ultimate fire resistance of at least 2 hours.

Occupied.-As applied to a building, shall be construed as though followed by the words, "or intended, arranged, or designed to be occupied."

Place of assembly.-A room, floor area, or building seating or accommodating 100 persons or more and used as a place for meetings, performances, and other gatherings.

Required.-Complying with a mandatory clause of this chapter.

Self-closing.-As applied to a fire door or other opening protective, means normally closed and equipped with an approved device which will insure prompt closing after having been opened.

Sprinklered.-Equipped with an approved automatic sprinkler system.

Stairway.-One or more flights of stairs and the necessary landings and platforms connecting them, which provide a continuous and uninterrupted passage from 1 story to another in a building or structure.

Story.-That portion of a building included between a floor and the floor or roof next above.

Street.-A highway or thoroughfare dedicated or devoted to public use by legal mapping, user, or other lawful manner; and includes avenue, road, alley, lane, boulevard, terrace, concourse, driveway, sidewalk.

Theater.-A place of assembly in which movable scenery is used or moving pictures are shown.

Ultimate fire resistance.-Resistance shown when tested under the conditions prescribed in the standard fire test approved by the American Standards Association as "American Standard."

\section{CLASSIEICATIONS}

Classifications of buildings by occupancy and by type of construction are to be found in the report of the Department of Commerce 
Building Code Committee entitled "Recommended Minimum Requirements for Fire Resistance in Buildings." ${ }_{18}$ They are inserted here prior to the exit requirements themselves in order to define terms appearing in these requirements and to emphasize the close relationship existing between fire protection and exits. Sections $3-1$ and 3-2 of that report are as follows:

\title{
Section 3-1. Classification of Buildings by Occupancy.
}

Buildings or parts of buildings shall be classified by occupancy or use into the following groups:

\author{
Class 1.-Public. \\ Class 2.--Institutional. \\ Class 3.-Residential. \\ Class 4.--Business. \\ Class 5.-Garages, hangars, barns.
}

Each class is intended to embrace buildings or parts of buildings as hereinafter defined and those of similar character or use. Where there is any uncertainty as to the classification of a building, the administrative building official shall fix the classification within which it falls.

Class 1. Public.-This classification includes buildings or parts thereof in which people come together for transaction of public business; for civic, political, social, or religious purposes; for educational purposes; or for entertainment or recreation; such as city halls, churches, schools, theaters, and grandstands.

Class 2. Institutional.-This classification includes buildings or parts thereof in which people are harbored for medical, charitable, or other care or treatment or in which people are detained for penal or correctional purposes; such as hospitals, sanitariums, homes for the aged, prisons, and reformatories.

Class 3. Residential.-This classification includes buildings or parts thereof in which families or households live or in which sleeping accommodations are provided, such as apartment houses, hotels, dormitories, and dwellings.

Class 4. Business. - This classification includes buildings or parts thereof in which goods are manufactured, stored, converted, or sold, or in which business or professional services are rendered; such as factories, warehouses, stores, and office buildings.

Class 5. Garages, hangars, barns.-This classification includes buildings or parts thereof used for the storage or repair of automotive vehicles and airplanes, such as public and private garages and hangars; also for the keeping of horses and cattle, such as stables and riding academies.

\section{Section 3-2. Classification of Buildings by Type of Construction.}

Construction shall be classified into 6 general types according to the character of materials employed and their method of assembly as follows:

Type 1. Fully protected.

Type 2. Protected.

Type 3. Heavy timber.

Type 4. Masonry wall and joist.

Type 5. Wood frame.

Type 6. Unprotected metal.

18 BS BH14 (1931). 
Type 1. Fully protected.-Fully protected construction is that in which walls are of masonry or of reinforced concrete and the structural members are of incombustible materials having an ultimate fire resistance sufficient to withstand the hazard involved in the occupancy, but not less than 4 hours for bearing walls, fire walls, party walls, piers, columns, trusses, and for girders which support walls; $21 / 2$ hours for walls and girders not otherwise specified, floors including beams and girders, and for roofs; and in which the degree of fire resistance for other construction features and the materials acceptable for the purpose are as given in chapter $11 .^{19}$

Type 2. Protected.--Protected construction is that in which walls are of masonry or reinforced concrete and the structural members have an ultimate fire resistance of not less than 4 hours for fire walls and party walls; 3 hours for bearing walls, piers, trusses other than roof trusses, and columns and girders supporting walls; 2 hours for walls, columns, and girders not otherwise specified; $1 \frac{1}{2}$ hours for floors, including beams and girders, roof trusses except as provided for in section 11-2-3, and for roofs except as provided for in section 11-8-1; and in which the degree of fire resistance required for other construction features and the materials acceptable for the purpose are as given in chapter 11 (of $\mathrm{BH} 14$ ).

Type 3. Heavy timber.- Heavy-timber construction is that in which walls are of masonry or reinforced concrete and the interior framing is of timbers, or, in part, of protected steel or reinforced concrete having an ultimate fire resistance of at least 1 hour, except for roof trusses as specified in section 11-2-4, the plank floors and roof being arranged in heavy solid masses and smooth flat surfaces, avoiding thin sections, sharp projections, and concealed or inaccessible spaces; and in which the degree of fire resistance required for other construction features and the materials acceptable for the purpose are as given in chapter 11 (of $\mathrm{BH} 14$ ).

Type 4. Masonry wall and joist.-Masonry-wall and joist construction is that not included in type 3 in which the exterior walls are of masonry or reinforced concrete and the interior framing is partly or wholly of wood or unprotected iron or steel.

Type 5. Wood frame.-Wood-frame construction is that in which structural parts and materials are of wood or are dependent upon a wood frame for support, including construction having an incombustible exterior veneer.

Type 6. Unprotected metal.-Unprotected-metal construction is that in which the imposed loads are carried by an unprotected metal frame and in which the exterior walls and roof are of sheet metal or other incombustible material.

\footnotetext{
${ }_{19}$ The reference to chapter 11 is to the same chapter number in BS BH14 (1931).
} 


\section{Section 7-1. Application of Chapter. ${ }^{20}$}

7-1-1. New Buildings.

Buildings hereafter erected, except dwellings, ${ }^{21}$ shall be provided with exit facilities in accordance with the requirements of this chapter. These regulations shall be taken as the minimum necessary for the conditions stated. For unusually hazardous conditions the building official may order additional exit facilities to assure the safety of the occupants.

\section{7-1-2. Existing Buildings.}

Buildings heretofore erected, except dwellings, which are not provided with exit facilities as prescribed in this chapter for buildings hereafter erected and in which the existing exit facilities are inadequate in the judgment of the building official for the safety of the occupants, shall be provided with such good and sufficient stairways, fire escapes, ${ }^{22}$ or other means of egress as shall be specified in a written order by him. ${ }^{23}$

\section{7-1-3. Alterations. ${ }^{24}$}

No buildings shall hereafter be altered so as to reduce the number or width of exits to less than required for buildings hereafter erected.

No change of occupancy whether necessitating physical alterations or not shall be made in any building unless such building conforms with the requirements of this chapter applying to new buildings of the proposed new use.

\footnotetext{
20 The chapter numbering as set forth in the report of the Department of Commerce Building Ccde Com mittee entitled "Recommended Practice for Arrangement of Building Codę" (BS BH8 (1925)) is given on the assumption that the chapter would be the seventh in a complete series of building-code requirements. ${ }_{21}$ No practical way has been found to require exits in dwellings beyond those customarily supplied as a matter of convenience. It is true that there is considerable loss of life in such structures. This could be considerably reduced by attention to proper construction, adequate fire-stopping, proper spacing of heating appliances from combustible construction, and other details of fire protection where a large degree of improvement is possible over many present buildings. Such details may be consulted in the report Recommended Minimum Requirements for Small Dwelling Construction (BS BH18 (1932)). A further suggestion made by the committee on fundamental equipment of the President's conference on home building and home ownership in the conference report entitled "House Design, Construction, and Equipment" was that sprinkler heads placed in especially hazardous locations, such as over the heater in the basement and in the kitchen, offered additional security where such measures were practicable.

${ }_{22}$ Fire escapes are recognized only as supplementary means of egress for the purpose of this chapter. Where used, they should conform in design and construction to the Building Exits Code as approved by the American Standards Association.

${ }_{23}$ Testimony of building officials indicates that the securing of adequate exit facilities in existing buildings is much more difficult than in the case of new buildings. The installation of fire escapes has been the usual solution to this problem in the past and will probably continue to be chosen as the easiest one. Modern practice condemns the use of fire escapes on new buildings, but their use on existing buildings is often the only means of providing sufficient egress facilities without prohibitive cost. Because they are an emergency device and but infrequently used, their maintenance is often neglected. These devices are exposed to snow and ice, and are often inadequately lighted. Fire from wall openings along the path of travel may render a fire escape usoless. For these and other reasons fire escapes are regarded as particularly unsatisfactory as a means of egress.

${ }_{24} \mathrm{~A}$ wide range of remoleling and alteration projects are continually going on. Changes in occupancy must be provided for specifically. In both instances it is preferable that exit facilities should equal those required for a now building of the same occupancy. While the owner of a building may be put to considerable inconvenience and expense to meet re quirements e qual to those for new buildings, there appears to be no reason why the occupants should not be assuced the same degres of safety as occupants of buildings erected for the specific purpose. In other words, if the owner wishes to profit from the alteration he should not expect to do so at the expense of hazard to the tenant. It will frequently happen that the existing exit facilities are ample for the use of the new occupancy and therefore no changes will be required.

Many occupancy changes do not require physical alterations of the buildings, as, for example, changing a dwelling inta a rooming house. The increase in population may be sufficient to put the building into another occupancy class requiring more exits but when there are no alterations the matter seldom comes to the building official's attention. Such changes are so frequent and the possible hazard so great that it should be sposifically providad, as here, that no change of occupancy of any kind shall be made unless the exits are adequate. All such cases should be referred to the building official for authority to make the change.
} 


\section{Section 7-2. Kinds of Exits.}

Exits ${ }^{25}$ shall consist of stairways, horizontal exits, passageways, doorways providing direct exit to a street or to an exterior open space leading to a street; or ramps, designed, constructed, and arranged as specified in this chapter.

\section{Section 7-3. Minimum Number of Exits.}

\section{7-3-1. Room Doorways. ${ }^{26}$}

Where floor areas are divided into rooms every room occupied by 100 or more persons shall have at least 2 doorways as remote from

25 The term "exits" refers to the means of egress mandatory under recommended minimum requirements. Means of egress provided in addition to the exits contained in the recommended minimum requirements are not subject to regulations of width, construction, etc. However, in order to distinguish between such means of egress and the exits required, the latter must be so marked that their function is plainly evident to any occupants. (See sec. 7-13.) Hallways, lobbies, and ordinary room door ways, except in special cases, are not considered as exits since they serve only as a means of reaching an exit. Requirements covering the width of hallways and lobbies have been included in order to maintain necessary relationships between their width and those of exits to which they are connected. No decrease in width of the means of egress can be permitted in the direction of exit travel or "bottle necks" would be created, thus materially reducing the egress efficiency. This principle is elementary.

Fire towers or smokeproof towers have long been regarded as very desirable means of egress and believed by some to possess certain advantages not found in the ordinary enclosed stairway. Their principal characteristic is that they are reached by means of vestibules or balconies opening to the outer air, so that smoke and fire cannot directly enter the stairway from the building itself. Some codes make their installation mandatory in buildings over a certain height. However, to give special credit to fire towers seems illogical because a certain amount of exit width must be provided in any event in order to provide egress for a given population.

In recent years many questions have been raised as to the supposed advantages of fire towers. Opinions have been advanced by competent persons to the effect that these towers, while desirable, do not possess sufficient extra advantage over the enclosed stairway to justify making their use mandatory. They might well be provided because of their immunity from smoke in cases where the extra expense involred in its construction is not a deciding factor. Where used, the details of construction for fire towers should be at least equal to those recommended in the Building Exits Code, as approred by the American Standards Association.

The term "exit passageway" has a special meaning as indicated by the definition. (See p. 46.) Ordinarily it denotes a fire-resistive corridor leading from the base of a stairway to the outside of the building. It also includes corridors such as are frequentiy found in theaters and other places of assembly, which furnish a means of getting from emergency courts, so-called, to the street.

${ }_{26}$ Room doorways, while not in themselves exits, except in special cases, provide means of reaching an exit. However, there is a point at which it becomes necessary in the interests of safety to make certain requirements for such doorways. As a matter of convenience requirements concerning them are presented here.

One of the fundamental principles of exit design is that every building, regardless of its size or the number of occupants, should have a certain minimum number of exits, the number varying with the class of occupancy. This section deals not only with the minimum number of exits in buildings of different occupancy, but also with exits from different portions of the building.

In formulating the requirements the room may bo taken as the starting point of travel to the street. A minimum of 100 persons has been chosen as the limit at which 2 room doorways are required. At the rate of travel estimated through doorways, 60 persons per minute per 22-inch unit of width, a room occupied by 100 persons could be emptied through 2 doorways in approximately 1 minute. This is a safe interval of time to be assumed in arriving at emergency requirements. Calculations for the required aggregate width of doorways are provided in section 7-8-1 of this chapter, but section 7-3-1 is concerned only with the minimum number of such doorways.

The expression "as remote from each other as practicable" is used several times in this report and has been inserted to give both the designer and building official some latitude in regard to the arrangement of exits. In some codes, exits are required to be "as remote from each other as possible".

The most remote arrangement of doors in a room would be in the diagonally opposite corners. In figure 1 , two situations are presented in which it may not be feasible for various reasons to provide such an arrange-

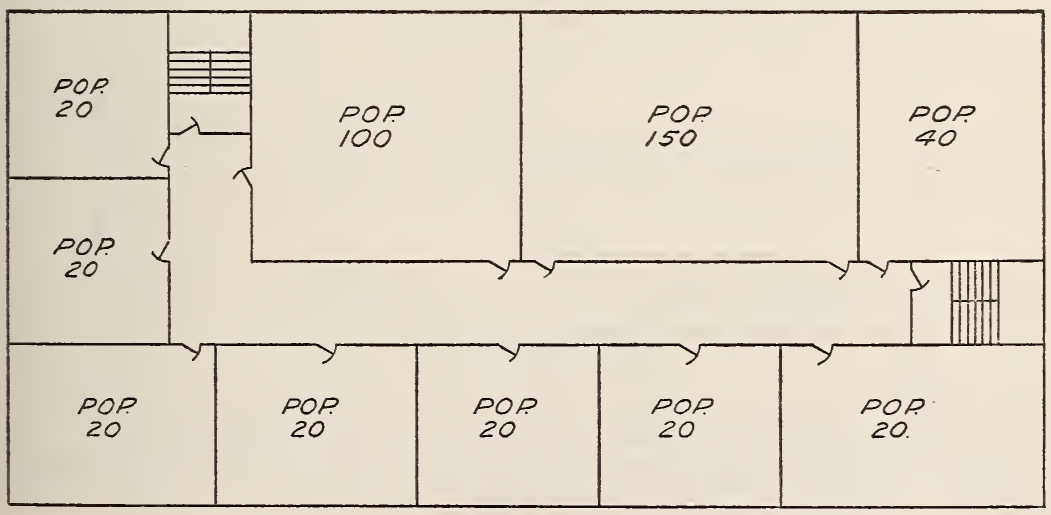

FIGURE 1.-Doorways placed "as remote as practicable." 
each other as practicable, at least 1 of which shall lead directly, or through a corridor or other open space, to an exit and any other doorway may lead into an adjoining room from which there is access to an exit or exits.

\section{7-3-2. Ground-Floor Exits. ${ }^{27}$}

When a floor area has direct exit to a street or to an exterior open space leading to a street and is occupied by 100 or more persons or is

ment. Both the room with a population of 100 and that with 150 are, however, considered sufficiently safe as to exit facilities.

Permitting 1 of the required room doorways to lead into another room having access to an exit allows for flexibility in design. Since the adjoining room must have access to an exit safety is not sacrificed. This provision prohibits the designing of a succession of rooms, 1 leading into the next, with the end room only having access to an exit. A correct design for room doorways from 2 or more rooms is shown in figure 2.

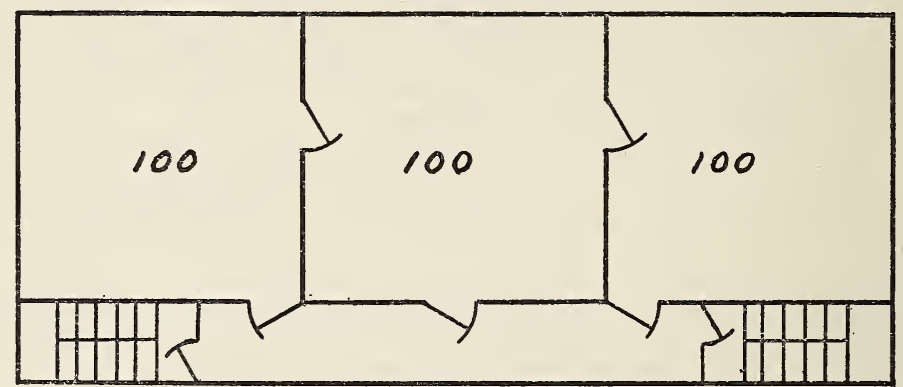

FIGURE 2.-Doorway location for connecting rooms occupied by 100 or more persons.

27 A ground-floor exit is one that is so situated that it leads from a floor or story directly to a street. In fixing 100 persons as the limit beyond which 2 or more exits are required from these floors the same reasoning is used as in fixing the limit for rooms. If the limit were fixed at any lower figure, many small shops with narrow frontages would be required to have 2 front entrances, as a rear entrance is often impracticable for the small shop. In view of the small population found in these shops even with an area of 3,000 square feet, the limit fixed should be safe under ordinary conditions.

The expression "direct exit to a street" used in this section means that the floor area communicates directly with the street either by a doorway, or by a short flight of steps.

Throughout the chapter certain exits are required to lead directly to a street, or to an exterior open space leading to a street. This expression is used to permit the designer to discharge the occupants into a yard or court which in turn communicates with the street, either directly or through properly protected passageways, as illustrated in the sketch below. This method is considered to be satisfactory for egress purposes and permits flexibility in the design of the building. It assumes that the same principle applies here as to all exit facilities, namely, that they shall never diminish in the direction of exit travel.

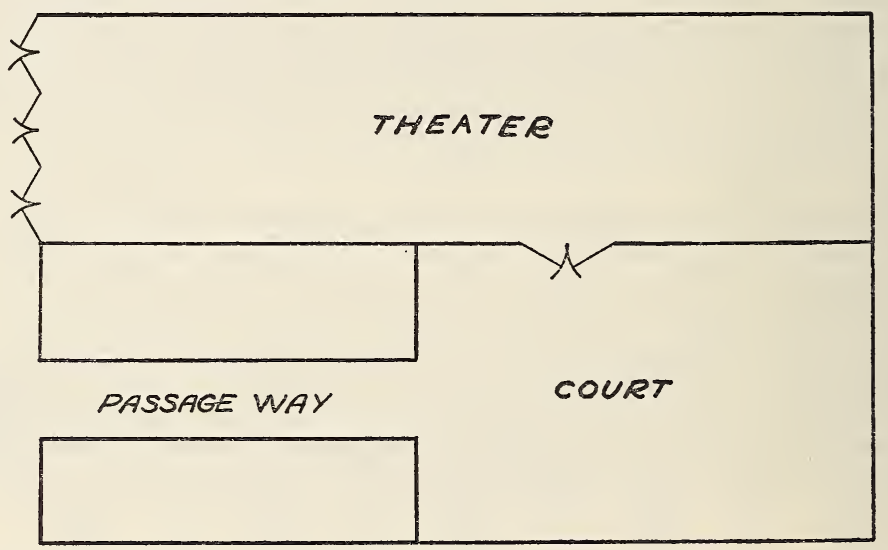

FIGURE 3.-Discharge from a theater into a court, thence through a passageway to the street. 
3,000 square feet or more in area, it shall be provided with at least 2 exits.

\section{7-3-3. Floor-Area Exits. ${ }^{28}$}

A floor area not having direct exit to a street or to an exterior open space leading to a street shall have access to at least 2 exits; provided, that in the following cases there shall be access to at least 1 exit:

Floor areas 3,000 square feet or less in buildings of type 1, fully protected, or type 2 , protected construction, whose occupancies come under class 3 , residential, class 4 , business, or class 5 , garages, hangars, barns;

Floor areas 3,000 square feet or less in buildings of other types of construction not over 2 stories in height, whose occupancies come under class 4 , business, or class 5 , garages, hangars, barns;

Floor areas 6,000 square feet or less devoted to office occupancy in buildings of type 1 , fully protected, or type 2 , protected construction, when the maximum distance to an exit does not exceed 50 feet;

Floor areas 6,000 square feet or less used for manufacturing purposes in buildings of type 1, fully protected, or type 2 , protected construction, when the maximum distance to an exit does not exceed. 50 feet and the buildings are sprinklered throughout.

\section{7-3-4. Exits for Institutional Occupancies. ${ }^{29}$}

For occupancies coming under class 2 , institutional, those portions of a floor area which exceed 3,000 square feet occupied by bedridden patients shall have a horizontal exit, ramp, or doorway leading directly

28 It has been an accepted principle of exit design that in general every floor area should be provided with not less than 2 exits. While the principle is undoubtedly sound, slight modifications result in economy in construction without necessarily affecting the safety of the occupants. Buildings in which people sleep or are harbored for care, or in which public assemblies are held, require better exit facilities than buildings housing only able-bodied and alert persons and containing no sleeping quarters. This does not imply a lowering of standards for the latter group of buildings but does recognize a distinction between the two classes. This distinction is based on the relative ability of the occupants to evacuate the buildings promptly in an emergency.

The provisions of this chapter adhere to the requirement of 2 exits, except in certain cases in which it is considered safe to permit a relaxation. Low-hazard occupancies in buildings of fire-resistive construction, buildings having a slight density of population, and sprinklered factories constitute the only exceptions that should be permitted within the occupancy groups cited. In addition, certain specified conditions must not be exceeded. As a check against these requirements, a survey of modern buildings was conducted in several cities to determine current practice in the design of exits. The findings of this survey indicated that modern architcctural practice favored the permitted exceptions.

Floor areas of public and institutional buildings should always be provided with not less than 2 exits, regardless of the area or type of construction. Within the limitations just given, however, and where the contents of the building are not such as to constitute a hazardous occupancy, an area of 3,000 square feet may be taken as the general limit of safety for 1 stairway, except when the building is of fire-resistive construction and additional factors of safety in the form of sprinkler protection or short distances to exits are provided. In such cases, a limit of 6,000 square feet has been considered safe. This recognizes the tendency in modern office-building design to provide a tower section of comparatively small area. In permitting 1 stairway in these towers under certain conditions the fire resistance of the buildings was considered, as was also the probability of the use of elevators. It has long been recognized that in very high buildings it is a physical impossibility for most persons to descend to the street by means of stairways, and that some dependence must be placed on the elevators.

A further consideration is the possibility of re-entering at a floor beneath the fire in the case of a fireresistive building. With the fire-resistive floors and protected openings characteristic of this type of construction such a procedure is practical. Normally, when there is but 1 stairway in a tower, this will. be used as the service stairway from floor to floor. The practice of locking doors of stairways so that a person cannot re-enter at a lower floor impairs the usefulness of the stairway, both for service and escape purposes, and is to be condemned.

The maximum of 3,000 square feet area for residential construction having 1 stairway was set some time before intensive studies of low-rental housing had been initiated. Some of these studies point to the need of an area approximately 10 percent greater in the case of the so-called "cross-plan" type having 4 apartments to a floor using a common stairway. This is required in order to meet standards of light, ventilation, minimum room area, privacy, and other factors held to be essential.

${ }_{29}$ Buildings of institutional occupancy require special provisions for means of egress. A study of records over a period of years shows that a large loss of life has occurred in buildings of this class as a result of fires. The fire records do not state directly that the exits were a contributing cause of loss of life, but the facts point to the need for special exit facilities in these buildings. There are many records of institutional fires in which the occupants have been carried to safety by attendants and firemen, in some cases through windows, indicating that the conventional exits had been rendered impassable. The mental and physical condition of the occupants is such that the ordinary protected exit adequate for buildings of other occupancy will not suffice for the institutional building. Helpless children, bedridden and incarcerated 
outside the building not less than 48 inches wide so located that no point in such portions is more than 100 feet from such horizontal exit, ramp, or doorway leading directly outside the building; provided that in buildings sprinklered throughout this distance may be increased to 150 feet.

\section{7-3-5. Exits for Places of Assembly. ${ }^{30}$}

7-3-5-1. Rooms.

Every room, tier, balcony, or other space used as a place of assembly shall have at least two means of exit.

\section{7-3-5-2. Buildings.}

Exits for buildings used as places of assembly shall be supplied as follows:

Not less than 2 exits when 600 persons or less are accommodated in each room, balcony, tier, or other space; not less than 3 exits when more than 600 but not more than 1,000 persons are accommodated; and not less than 4 exits when more than 1,000 persons are accommodated.

7-3-5-3. Separation of Theater Stairways. ${ }^{31}$

Exit stairways serving theaters located in buildings containing other occupancies shall be separate and independent from the stairways serving other occupancies in the building.

Exit stairways serving theater balconies above the first shall be separate from other stairways.

\section{7-3-6. Boiler Room Exits. ${ }^{32}$}

Every building, in which steam boilers, or apparatus using or producing gas or vapor, are placed below curb level, in addition to

patients, the feeble-minded, and hopelessly insane may require special exit facilities and assistance in an emergency.

The horizontal exit, while it does not always provide a direct means of exit to the exterior of the building, does permit egress to a protected portion of the building from which there is access to an exit leading to the exterior. Both the horizontal exit and enclosed ramp are particularly applicable to the institutional building housing bedridden persons because of the facility with which beds may be transferred from one section to another. Their use in buildings housing occupants of other than normal mentality and occupants physically unfit is especially to be recommended because of the difficulty of getting such persons into stair enclosures in the first place, and the slow movement down the stairs after egress has been assured. With the spread of fire restricted by the walls of the horizontal exit, a much longer period of time can be utilized to evacuate the area on the safe side of the horizontal exit.

There is a further necessary limitation of the requirements for institutional occupancies in the case of such institutions as prisons and reformatories where escape of occupants must be prevented. In view of the gravity of the problem, it seems advisable to leave the provisions for exit facilities to the designers of prisons and to the officials upon whom rests the responsibility for guarding of their charges. Some formal certification that the exits provided on the plans are sufficient in the judgment of the designer and the responsible prison official might well be made in order to make it clear upon whom the responsibility rests for this feature of the building.

30 Places of assembly may be considered in two groups, one consisting of rooms used as places of assembly, the other of buildings entirely devoted to places of assembly. As a general proposition, places of assembly are those buildings or rooms in which people congregate for civic, political, social, or religious purposes, or for entertainment; such as court rooms, churches and theaters. Classified by occupancy, they are a part of class 1, public, but, due to the fact that they include a large density of population, they are generally considered to require special treatment in the matter of minimum number of exits. The internal arrangements of theaters, such as width of aisles, spacing between seats, and other details have not been taken up as they fall naturally into a chapter on special occupancy provisions not covered at the time this chapter was prepared. Details concerning them will be found in the Building Exits Code, 1934 edition, approved as American Tentative Standard by the American Standards Association.

31 A theater, by definition, is a special form of place of assembly in which there is provision for movable scenery, or in which moving pictures are displayed. It presents hazards beyond those customarily met in other places of assembly. The presence of scenery, and of projection booths and screens, is a special fire and smoke hazard. Performances are presented while the space is darkened, thus presenting greater possibility of panic than in ordinary places of assembly.

In order to avoid any interference with the flow of people from a theater, the theater stairways need to be independent of any other stairways in the building. It is obvious that with any arrangement of stairways in which the use is common to all, the uninterrupted flow of traffic is impossible, and jams are likely to occur at the intersection of the two streams of traffic. Any stoppage of the orderly discharge of a crowd, as from a theater, is likely to develop panic conditions, regardless of how serious the fire which necessitated evacuation may be. To eliminate any such possibility, free and uninterrupted exit must be assured.

${ }_{32}$ In the case of isolated occupancies, such as small tailor shops or hat-cleaning shops, it is assumed that a reasonable interpretation will be placed upon the requirement by the building official if in his judgment, adequate safety of the occupants is secured. 
the exit stairways shall have stairs or a stationary iron ladder leading directly to the street from the story in which such boiler or such apparatus is located, or some other additional exit by means of an enclosed stairway or a horizontal exit.

\section{Section 7-4. Location of Exits.}

\section{7-4-1. Distance to Exits.33}

Exits shall be so located that no point in a floor area, room or space, served by them is more than 100 feet distant from an exit, measured along the line of travel; provided, that in office buildings, and in buildings sprinklered throughout, this distance shall be not more than 150 feet. $^{34}$ In the case of floor areas subdivided into apartments or small rooms, as in office buildings and hotels, the distance shall be taken from the corridor entrance to such rooms to the nearest exit.

\section{7-4-2. Distribution of Exits..$^{35}$}

Where a floor is required to have 2 exits, they shall be placed as remote from each other as practicable.

${ }_{33}$ The requirement fixing the maximum distance which must be traveled to reach an exit is the chief factor controlling the location of exits. It is not sufficient to require a certain minimum number of exits; the building regulations must go further and limit the distance traveled to reach an exit in order to locate them within the immediate reach of the occupants, and thus prevent any serious delay in reaching the exit.

In some codes this distance depends upon the occupancy; in others, the type of construction controls. The distance of 100 feet has been selected as a practical compromise between the two methods and as representing a reasonal maximum which might be imposed. Special occupancies possessing unusual hazards will, of course, require shorter distances but these distances may well be left to the judgment of the building official. A hazard classification useful for reference is contained in the Building Exits Code approved by the American Standards Association.

Office buildings, because of the character of the occupancy, the low-hazard contents of the building, and the customary subdivision of the floor areas, are permitted an increase in this distance up to 150 feet. Sprinklered buildings also have been permitted an increase on the assumption that fires in such buildings will be checked promptly before assuming sufficient proportions to cut off the line of retreat.

In the case of undivided floor areas, the distance to the exit is measured in a straight line. In other cases, the distance is measured along the normal pathof travel, such as corridors or hallways, from the room entrance to the nearest exit.

${ }_{34}$ For exceptions to this requirement, see section 7-3-3.

35 Proper distribution of exits is very important. Elsewhere maximum distances from a given point on the floor are given, but this does not prevent concentrating all stairways near a given point with the result that all might be cut off by a single fire. So vital is this requirement that some experienced officials ad vocate

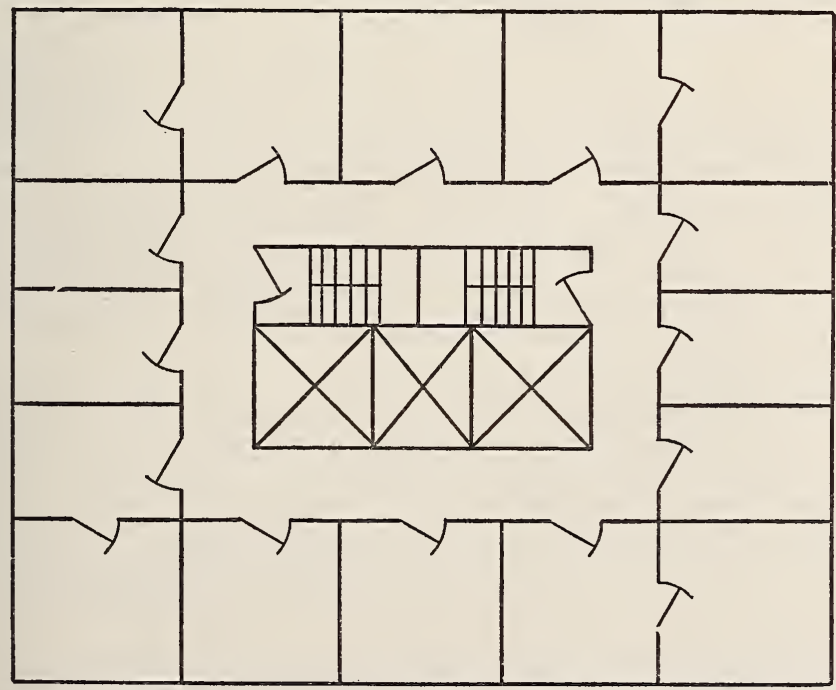

FIGURE 4.-Distribution of stairways in a building where services are in a central core. 
Where more than 2 exits are required, they shall be distributed as uniformly as practicable within or around the floor area, room or space they are to serve.

\section{7-4-3. Outlets from Exits. ${ }^{36}$}

An exit stairway shall lead either directly or through an exit passageway to a street or to an exterior open space leading to a street, except as follows:

In buildings of type 1 , fully protected, or type 2 , protected construction, devoted to office, or class 3 , residential occupancy, such stairway may terminate in a hallway or lobby; provided that when there are stores, restaurants, or other business occupancies within or opening

a definite method of separating exits by expressing a minimum distance as a percentage of the longest wall of the building. This method has certain disadvantages, since it prohibits installations as shown in figure 4 . Such layouts would seem to be reasonably safe, although the exits are not as remote from each other as
possible, nor in compliance with the percentage of wall-length rule. Having in mind that no 2 buildings are alike, it was deemed best in the interests of practical design to word the requirement as given. Where 2 exits only are required, it is assumed that they will be so placed as to make them accessible to all the occupants of the floor without subjecting both the exits to the possibility of being cut off by fire.

${ }_{36}$ The theory of exit design contemplates a safe, unobstructed path of travel of undiminished width from the starting point to the street. For the last portion of this travel, the path from the foot of the stairway to the street, an ideal arrangement would consist of all stairways discharging either directly into the street or through a protected passageway leading directly to the street, the latter device being considered the best substitute for direct discharge to the street. Practical considerations, however, suggest modifications of this arrangement in certain occupancies.

The economic requirements of use of modern buildings are such that lobbies with plate-glass windows opening into ground-floor spaces are a desirable feature for certain occupancies, and it has been deemed impractical to require such lobbies to be completely closed off. The survey of current practice in construction made in connection with the preparation of these requirements revealed that large numbers of buildings are being built with stairways terminating in lobbies having windows and doors opening upon the firstfloor area. Office buildings and hotels are representative of this type of arrangement. Apartment buildings having apartments, restaurants, and shops opening into ground-floor corridors and lobbies are also found so frequently as to constitute the rule rather than the exception. This current practice has been recogrized in permitting exceptions for office and residential buildings, but it has been safeguarded by requiring sprinkler protection for commercial occupancies opening on such corridors and lobbies. It was believed that this protection would compensate for the safety lost by the departure from the ideal requirement of a protected passageway. Inasmuch as plate glass soon shatters under heat, the expression "opening upon" a corridor should be construed to include occupancies having windows but not necessarily doors in the corridor walls.

A further desirable protection in some locations where plate-glass windows open upon public lobbies consists of metal or fire-resistive shutters to cover the glass area. These shutters operate automatically by some form of sensitive releasing device.

In the building of institutional occupancy at least one avenue of safety leading directly to the street should be provided. The remaining stairways may be permitted to discharge into hallways or lobbies leading to the street, and extra protection for these hallways may be omitted in order to permit their utilization as service corridors for those rooms which open thereon.

In the case of department stores permission to allow one-half the stairways from the upper floors to discharge directly into the first-floor area recognizes a special situation. In these buildings such a method appears to be customary procedure and comparatively unobjectionable in case the building is of fire-resistive construction and completely sprinklered. Here again, direct discharge to the street is regarded as preferable, but not always practicable. When one-half of the population of the upper floors find their way out from the first-lloor area the aggregate width of doorways must take into account the width of the stairways from the upper floors in order to prevent a jam at the doorways.

Places of assembly, due to the fact that the entire population is visible at one time, are particularly exposed to the possibility of panic conditions. It is, therefore, extremely desirable that a rapid discharge of the occupants be effected without any delays or interruptions. For this reason a limit is necessary for the distance of upward travel which will avoid any waiting in line to secure entrance to stairways or ramps. Appreciating that the nonfire-resistive building offers more opportunity for spread of fire than the fire-resistive building, the distance of upward travel permitted in the nonfire-resistive building has been restricted.

To insure egress to the street from areas below grade, at least 1 stairway is required to lead up directly to the street or to a passageway leading to a street. This provision has particular reference to densely occupied areas, such as department-store basements, or basement workshops, but the principle is applicable to all areas below grade.

As an emergency line of retreat in the event that stairways are cut off below, provision has been made for a single stairway leading to the roof. Provision for 2 stairways by means of which persons can cross over by way of the roof and descend by a stairway not cut off was considered but has not been required.

There are various theories exemplified in present code requirements on the role played by stairways leading to the roof. Some codes require all stairways serving the upper stories to continue on through; others require 2 to go through on the theory that a person can escape up by 1 , cross over the roof, and then descend through the other. Other provisions recognize the use of a passageway from 1 stairway to another in the topmost story as a substitute for crossing over by way of the roof. With present-day architecture involving numerous set-backs on high buildings, the value of stairways leading to the roof in these buildings is problematical. There seems to be a need for rationalizing the treatment of this subject. In the case of buildings of moderate height and with flat roofs there is a chance that a person who finds his downward path blocked may turn to the roof, and he may either escape by the roof of an adjoining building of similar height, or be taken down ladders by the fire department. Accordingly, the requirement has been made that at least 1 stairway shall continue through the roof in the case of structures whose height is limited because of the nature of their construction. The exits survey showed that stair doors leading to roofs are frequently kept locked, and served to emphasize that such means of escape are dependable only as a last resort and are not to be considered in any way as a substitute for properly constructed stairways leading to the street. 
upon the hallway or lobby, such occupancies shall be provided with an approved sprinkler system; ${ }^{37}$ in buildings whose occupancy comes under class 2 , institutional, at least 1 exit stairway shall discharge directly or through an exit passageway to the street or to an exterior open space leading to a street and the remaining stairways may discharge into a hallway or lobby; in buildings of type 1, fully protected, or type 2, protected construction, occupied as stores and sprinklered throughout not more than one-half of the exit stairways from upper floors may discharge into the ground-floor area; provided, that unobstructed aisles at least as wide as the stairways are maintained from such stairways to the exit doorways.

In places of assembly no required exit shall discharge by means of upward travel through a vertical distance of more than 15 feet in buildings of type 1, fully protected, or type 2, protected construction nor by more than 6 feet in buildings of other types of construction; provided, that in places of assembly occupied by not more than 150 persons such vertical distance shall not be limited.

Where there are 2 or more exit stairways serving floor areas below grade at least 1 shall lead up directly to the street, or to an exterior open space or exit passageway leading to a street.

In buildings of other than type 1, fully protected, or type 2, protected construction, more than two stories high above grade with roofs having a pitch of 1 foot in 4 feet or less, at least 1 exit stairway shall continue through the roof.

\section{Section 7-5. Relation of Population to Exits.}

\section{7-5-1. Determination of Population.}

The number of persons used in determining the necessary exit facilities on any given floor shall be the actual number ${ }^{38}$ to occupy the floor but in no case less than that determined by dividing the following areas per person into the gross area ${ }^{39}$ within the perimeter of the building serving each particular occupancy at the given floor level; for occupancies not specified the building official shall, by rule, establish the ratio to be used:

${ }^{37}$ Provision might well be made to allow the building official to make exemptions in the case of minor occupancies not of great fire hazard.

${ }_{38}$ In many instances floor areas are designed to accommodate a fixed number of persons and that number is customarily stated in the application for the permit. It is the intent of this section to make use of the actual number of persons contemplated by the design when it is known, or perhaps is fixed by other regulations such as labor laws. In case no actual number is stated, or known, the number of persons is, of course, determined on the basis of the areas given in this section. However, a minimum is also provided for regardless of what the design may contemplate in order to insure safety.

${ }_{39}$ It should be noted particularly that gross rather than net areas are to be used in determining the population in case it is not known.

The dimensions of exits as determined in subsequent sections of the report are proportioned to the number of occupants to be accommodated. The determination of the number of occupants on any floor becomes then of first importance in designing exits. There are numerous methods used in codes for making these calculations and very little agreement as to the assumptions. A method of determination involving least laborious calculation, but which gives results believed to be in reasonable accord with actual conditions is the most useful. Areas based on counts of occupants of buildings of different occupancy should be used by the building official to determine the population.

Some years ago Rudolph P. Miller, as superintendent of buildings of Manhattan, prepared a tabulation showing the density of population in workshops in the city of New York. The tabulation resulted from population counts in connection with "exit orders" in 500 workshops and factories. The occupants of each story of the buildings investigated were determined as accurately as possible and the area occupied per person computed from the gross area of the story. As might be expected the tabulation revealed a wide variation in areas per person ranging from 19 to 560 square feet. This variation is accounted for by the different kinds of industries represented in the tabulation.

The average for the entire group of buildings in the table was 107 square feet per person, which corresponds very closely with the average figure of 100 square feet per person adopted by the committee for this occupancy.

A census of the Equitable Building in New York City, taken in 1924, was made available to the committee through the courtesy of C. T. Coley, operating manager of that building. Here, again, there was a considerable variation, ranging from 43 square feet to 260 square feet per person, but the average was 107 .

The figures given are based on the net rentable area. When converted into terms of gross area they may range from 10 to 25 percent higher. On the other hand, they are based on the persons regularly employed 
Occupancy:

Areas per person (square feet)

Dance hall, lodge room, and places of assembly

Store:

Street floor and sales basement.

Other floors

School, courtroom, and other similar public; restaurant.... 40

Office, factory, and workroom . 100

Hotel and apartment_... 125

Institutional

Warehouse, storage, and garage... 300

In places of assembly, theaters, dance halls, lodge rooms, and similar occupancies when seating arrangements are used or contemplated, the seating capacity shall be established by allowing 6 square feet per person in that portion occupied by the audience.

The population of basements or portions of basements or of mezzanine floors shall be determined according to the occupancy.

The population of a mezzanine floor discharging through a floor below shall be added to the population of such floor.

\section{7-5-2. Population Limited. ${ }^{40}$}

It shall be unlawful to occupy any part of a building by a greater number of persons than that for which exits have been provided in accordance with this chapter.

in the building and do not take into account visitors, customers, or other transients. This increase in population is probably sufficient to bring the gross areas per person very closely in line with the committee's recommended figure of 100 square feet for office buildings.

The table of areas per person applies also to mixed occupancies provided the adjacent corridor areas, shafts, and service spaces are distributed to the several occupancies in proper proportions to obtain the gross area devoted to any one occupancy. For example, in figure 5 with 2 occupancies on a given floor of 12,000 square feet area, the area devoted exclusively to the 2 occupancies being 4,000 and 6,000 square feet, the proportion of the remaining 2,000 square feet of space utilized by ${ }^{\circ}$ corridors, elevator shafts, and service rooms, allocated to each occupancy will be $4,000 / 10,000$ and $6,000 / 10,000$, or 800 square feet and 1,200 square feet, respectively.

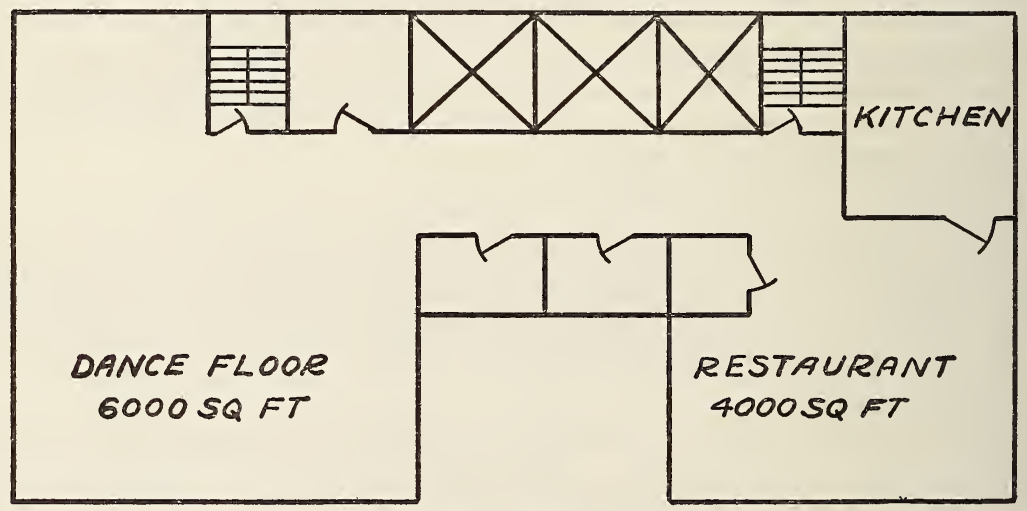

TOTAL AREA $=12,000 S Q F T$

FIGURE 5.-Example for computation of amount of service area allotted to mixed occupancies.

If the general occupancy contains a minor occupancy, as, for example, a kitchen in a restaurant, the area contained in the minor occupancy is to be added to the general occupancy and the population determined by dividing the total area by the area per person for the general occupancy.

40 When the exit facilities for a building have once been designed, the number of occupants of that building must be limited to the exit facilities provided. The requirements are thus definitely connected to administrative sections and insure that penalty provisions in the administrative chapter of the code will apply. 


\section{Section 7-6. Stairways.}

\section{7-6-1. Width.}

\section{7-6-1-1. Minimum Width.41}

The minimum unobstructed width of every exit stairway, except for handrails projecting inward not more than $3 \frac{1}{2}$ inches on each side, shall be not less than 2 units of 22 inches each; provided, that in institutional occupancies, exit stairways serving bedridden patients, shall be not less than 48 inches in width; and provided, further, that in buildings whose occupancy comes under class 4 , business, or class 5 , garages, hangars, barns, and which are occupied by a single tenant ${ }^{42}$ and limited in occupancy to 50 persons, and in case of exit stairways leading to roofs other than roof gardens and similar occupancies, such width shall be at least 36 inches.

\section{7-6-1-2. Aggregate Width.43}

Exit stairways shall be supplied in accordance with the following requirements, using the limitations and assumptions ${ }^{44}$ given in this chapter.

${ }^{41}$ In the opinion of many who have studied the matter, 22 inches can be taken as the width of a file of people in motion. Its origin is said to be in experience gained in the Army. A stairway width of 44 inches will permit 2 files of people to move freely down the stairs at the same time. In occupancies where fire drills are common, the 44-inch width permits the orderly movement of 2 files where individuals walk side by side. This width is measured between walls, or from wall to center line of hand rail or balustrade, in case 1 side of the stairway is open. It is the intention of this section to prohibit any building construction such as beams, columns, chimneys, etc., from encroaching on this space and reducing the reguired width. For wide stairways, the rounding or splaying of corners on landings is considered advantageous in elimiating points at which obstruction might occur to the forward movement of traffic.

42 This provision permits small stores, manufacturing and storage buildings, and office buildings occupied by 1 tenant as, for example, a real-estate company's building, to have 36 -inch stairs. This width is believed sufficient for the number of occupants allowed and permits some economy in construction. Where roofs are occupied as restaurants or used for recreation, etc., the stairways are required to be at least 44 inches, but where they are not used for such purposes 36 inches is permitted.

${ }_{43}$ The minimum number of stairways must be provided to meet previous requirements and these stairways must be so distributed that the distance traveled to reach a stairway does not exceed the limits otherwise fixed. The total aggregate width is then computed by the method described in section 7-6-1-2, and if additional width is required the designer is given the option of providing extra stairways or of increasing the width of those required to fulfill the other two conditions. Experienced designers have stated that the number of stairways in the majority of buildings is governed by the minimum number and maximum distance to an exit. This is probably true in buildings having a slight density of population, such as the average office building.

The requirements for aggregate width take into account the advantages and disadvantages of the various methods in use. The type of construction of the building does not affect the aggregate width of stairways. The class of occupancy does, however, control the aggregate width of stairways as indicated by the division factors as given on page 60. Buildings in which people sleep or are housed for care or medical treatment are provided with greater stairway width for a given population per floor than buildings housing ment are provided with

In arriving at the division factors, the traffic studies provided valuable information. These counts were made for various occupancies and were obtained under sufficiently varying conditions to give a general average. The studies took into account not only the rate of movement on stairs but also the capacity of stairs of different width. This enabled the committee to determine whether any advantage in either flow or capacity was gained by using wide stairs in preference to narrower ones.

In buildings in which people sleep or are housed for care of any sort, it is desirable that the stairs be made large enough to provide a place of refuge for the population if the need arises. On the other hand, the office building or store, containing a population necessarily alert and able-bodied, need not use its stairs as a place of refuge, since it is unusual for a fire to gain much headway before being discovered and the occupants given an opportunity to escape.

The typical 44-inch stair having return landings will accommo da te 64 persons in a 10 -foot story height assuming 2 persons for each tread and 1 person for each $1 \frac{1}{2}$ square feet of platforms and landings. This is absolute capacity and will permit little if any movement. As a practical matter, however, it is unlikely that the stairway will ever be called upon to accommodate its full capacity, since some of the occupants of the lower stories are certain to escape during the first few minutes of the alarm, and thus provide more room for the remaining population. At the rate of flow found in stairways in which people are moving without interference with one another, 45 persons can be discharged per minute for each 22 inches of stairway width.

A few typical examples of the computation for aggregate width of exits are given in the ensuing paragraprs.

Given an office building 21 stories in height and 36,000 square feet in area for the first 12 stories in its height and 24,000 square feet in area for the remaining 9 stories. The population per floor, unless known, will be assumed at $36,000 / 100=360$ persons on a typical floor within the first 12 stories. By this section $360 / 60$ will result in six 22-inch units of exit stairway for the floors up to and including the 12th where the set-back occurs for this particular case. At the 13th floor which is 24,000 square feet in area the population would be $24,000 / 100=240$. Then $240 / 60=$ four 22 -inch units of exit stairway required for that floor and those above. It should be noted, of course, that concentration of population on an intermediate floor may change the aggregate width of exit stairways for that floor and, inasmuch as exit width cannot diminish in the direction of exit travel, this would fix the width of the exit stair ways from that floor downward to eventual discharge.

Given a hotel building 16 stories in height and 15,000 square feet in area. An auditorium of 1,500 square feet $i$ located on the 5 th floor. The population on the typical floors will be $15,000 / 125$, or 120 per floor. 
The aggregate number of units of width necessary for exit stairways shall be determined for each floor of a building by dividing the population of each occupancy on that floor by 30 in the case of occupancies coming under class 2 , institutional, and class 3 , residential, and by 60 in the case of other occupancies, except as otherwise specifically provided for in this section.

Exit stairways in places of assembly having the main entrance at the street level and not communicating with any other occupancy in the same building shall be determined on the basis of 100 persons per unit of exit width.

In determining the aggregate width of exit stairways in any building, if the result contains a fraction, 12 inches of width shall be added for a fraction of one-half or less and 1 unit of width for a fraction greater than one-half.

If the required total number of units of exit width is greater than the total number of units of exit width for the minimum number of exit stairways of the minimum permissible width, the additional width ${ }^{45}$ shall be provided by additional stairways or by increasing the width of the minimum number of exit stairways.

\section{7-6-1-3. Changes in Stairway Width.}

The width of exit stairways shall not decrease in the direction of exit travel.

\section{7-6-1-4. Exit Stairways Serving Floor Areas Below Grade.46}

The aggregate width of exit stairways serving areas below grade shall be at least equal to that required for such stairways serving similar occupancies above grade in accordance with the provisions of this chapter. Under section $7-6-1-2,120 / 30=$ four 22 -inch units, or two 44 -inch stairways will be required. At the 5 th
floor, two 44 -inch stairways will be required for the normal population of this floor. The portion of the auditorium occupied by the audience is 1,300 square feet. This will accommodate $1,300 / 6$ or 217 persons. To accommodate this number of occupants $217 / 60$ or four 22 -inch additional units of exit width must be provided from the 5 th flcor down.

In a theater having a population of 1,000 persons in the balcony, the provisions of section 7-6-1-2 would include it as a place of assembly having the main entrance at the street level and the aggregate stairway width would then be computed at the rate of 100 persons per unit of exit width, that is, $1,000 / 100=10$ units of stairway width would be required. If conditions of maximum distance to an exit were satisfied, two 66 -inch stairways and two 44-inch stairways or any other grouping using the 10 aggregate units of width would fulinll the condition. The exit doorways for the orchestra population would be computed according to the provisions of section $7-8-1$

Given a school building 3 stories high and 14,400 square feet in area. The population per flcor will be $14,400 / 40$ or 360 persons. $350 / 60$, or six 22 -inch units of stairway width will be required. These may be supplied as three 44 -inch or two 66 -inch stairways, depending on the distance to the exits.

Given a 3-story factory, 60,000 square feet in area. $60,000 / 100=600$ persons per floor. $600 / 60=$ ten 22 -inch units of stairway required which could be satisfied by 4 stairways, 2 containing 2 units each and 2 containing 3 units each.

Given an 8-story department store 30,000 square feet in area. The upper floor population would be $30,000 / 60$ or 500 per floor. $500 / \% 0=9$ units of stairway width would then be required. The sales basement population would be $30,000 / 30=1,000$ persons. $1,000 / 60=17$ units of stairway width would then be required from the sales basement.

To illustrate the efiect of the requirements in the case of different occupancies and to compare these requirements with current practice as found in the field survey, figures 6 to 15 on pages $61-64$ have been prepared. The solid line representing requirements starts at the minimum set by section $7-3-3$. Points indicated on figures 8 to 15 represent actual conditions found in buildings during the survey.

44 Concerning minimum number of exits, ses section 7-3; locations of exits, see section 7-4; relation of population to exits, see section $7-5$.

45 After conditions of minimum number of stairways and minimum width of stairways are satisfied, the designer may distribute the computed width exceeding the minimum in any way he sees fit as long as the maximum distance to an exit is not exceeded. For example, if 2 stairways of 2 units each would satisfy the conditions of minimum number of stairways and maximum distance to an exit, but the computations required 6 units of width, an additional stairway could be provided, or 1 unit could be added to each of the stairways.

${ }_{46}$ Some codes require stairways from areas below grade to be increased in width over those required from areas above grade by amounts ranging from 50 to 100 percent. The particular application is to stores, but under this code the aggregate width of stairs from store basements is already twice that of stairs from upper stories due to the assumad areas par person. Considered in this light, no further increase is necessary but basement stairs should be required to be at least equal to the width of stairs from upper stories. Studies of movement show that for short distances the rate of flow up stairways approximates that downward. 


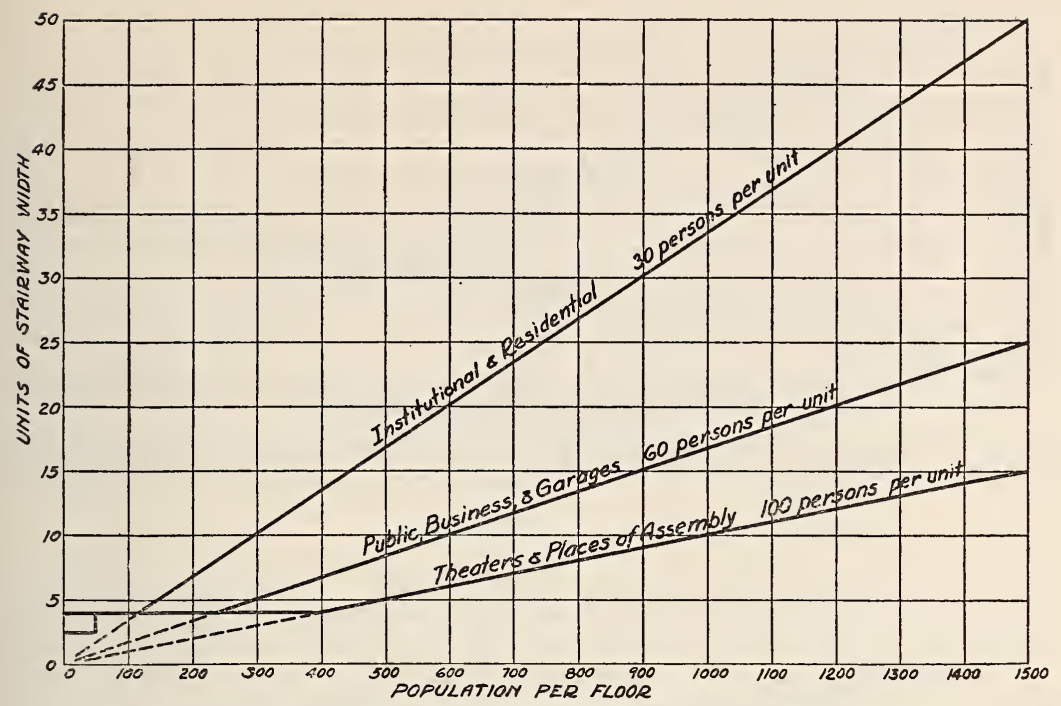

FIgURE 6.-Relation between exit width and population per floor.

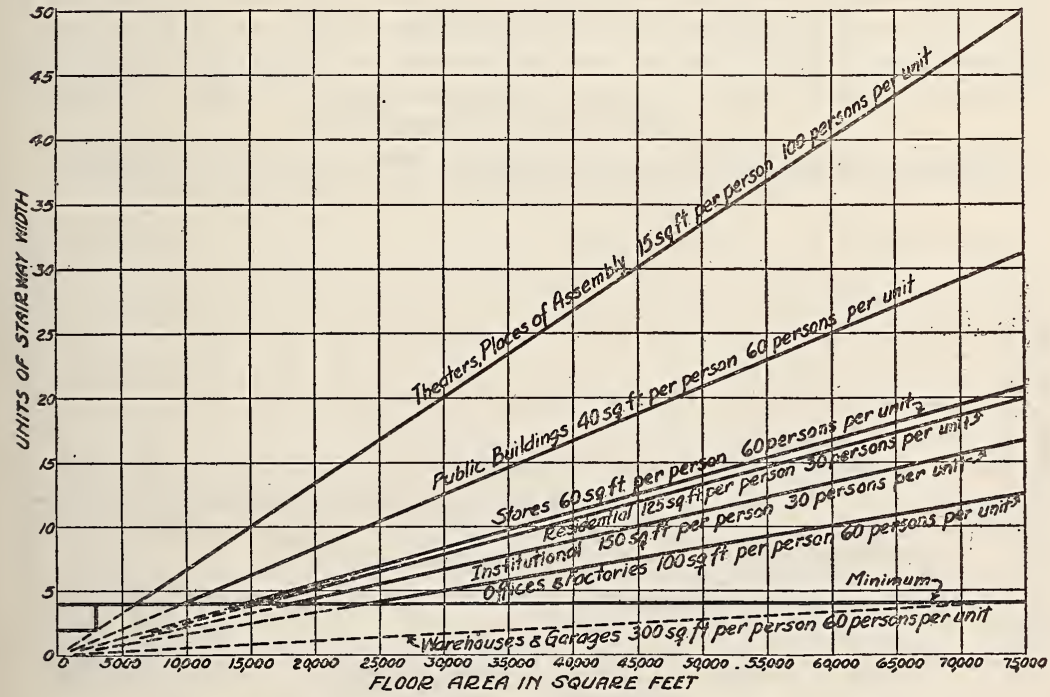

FigURe 7.-Relation between exit width and floor area. 


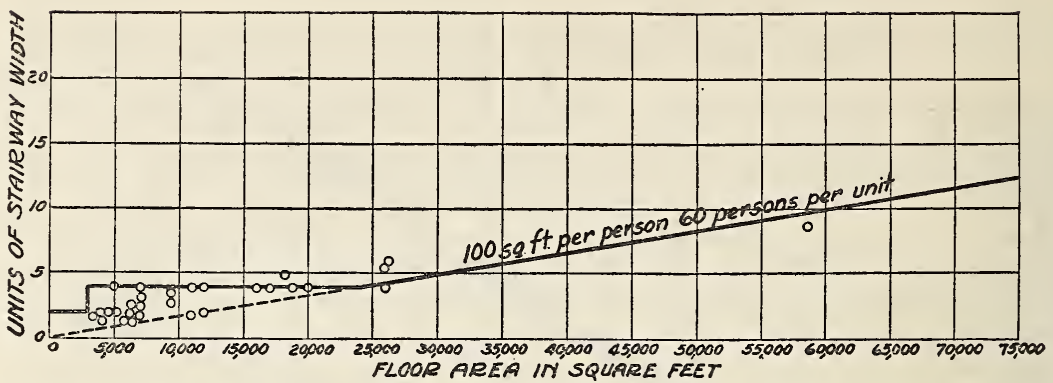

FIGURE 8.-Results of exits survey compared with curve adopted for office buildings.

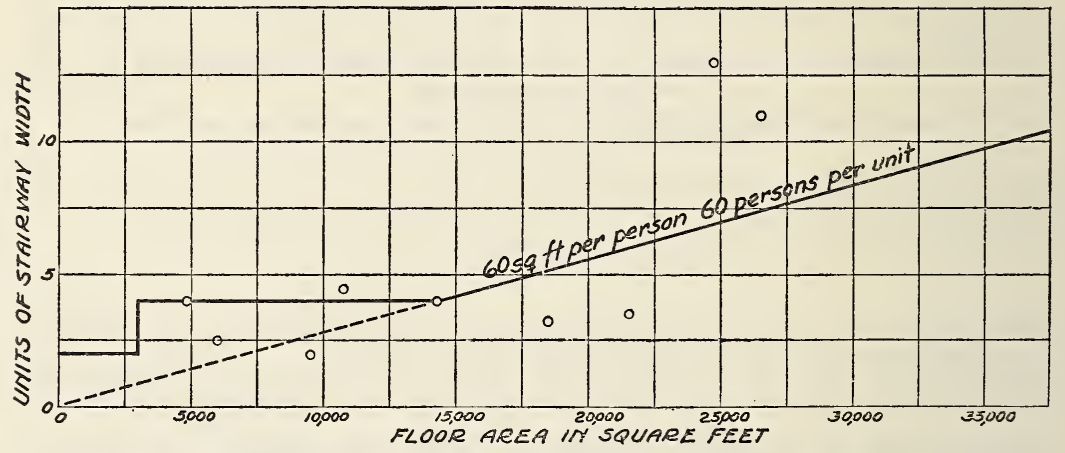

FIGURE 9.-Results of exits survey compared with curve adopted for stores.

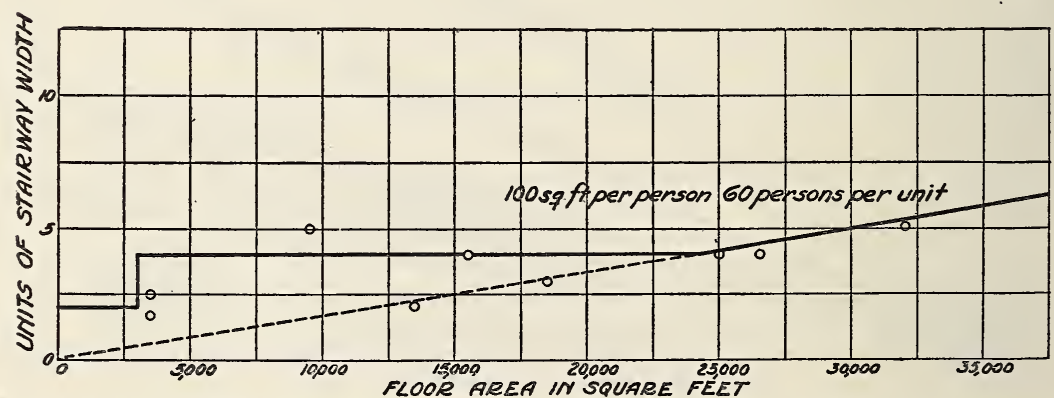

FIGURE 10.-Results of exits survey compared with curve adopted for factories. 


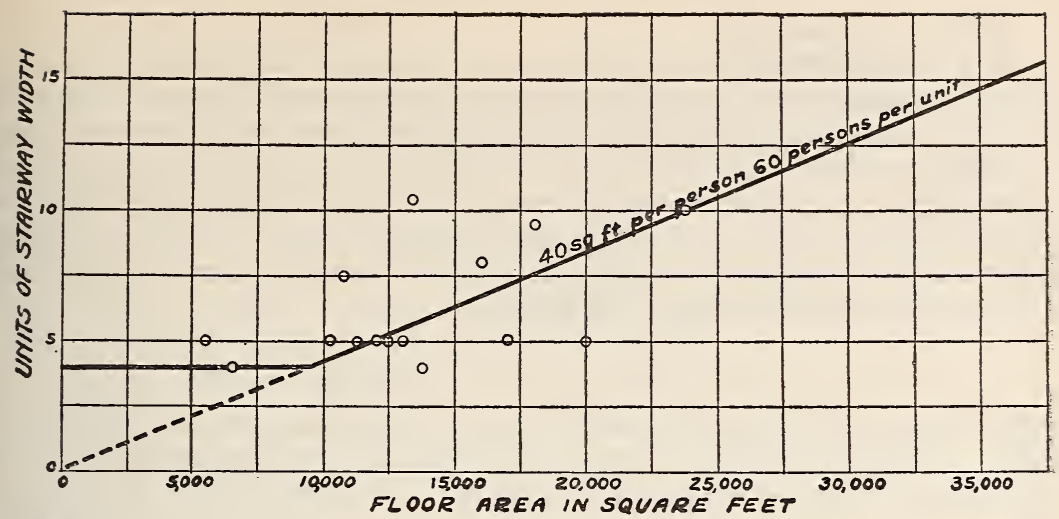

FIGURE 11.-Results of exits survey compared with curve adopted for schools.

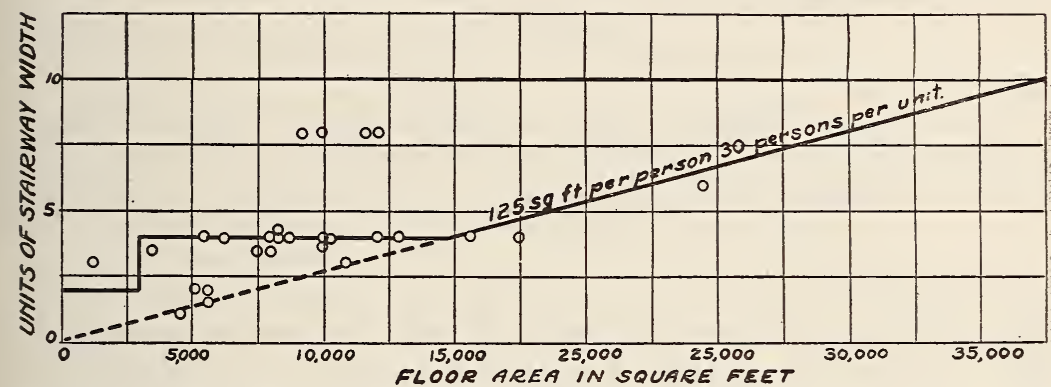

FIGURE 12.-Results of exits survey compared with curve adopted for apartments.

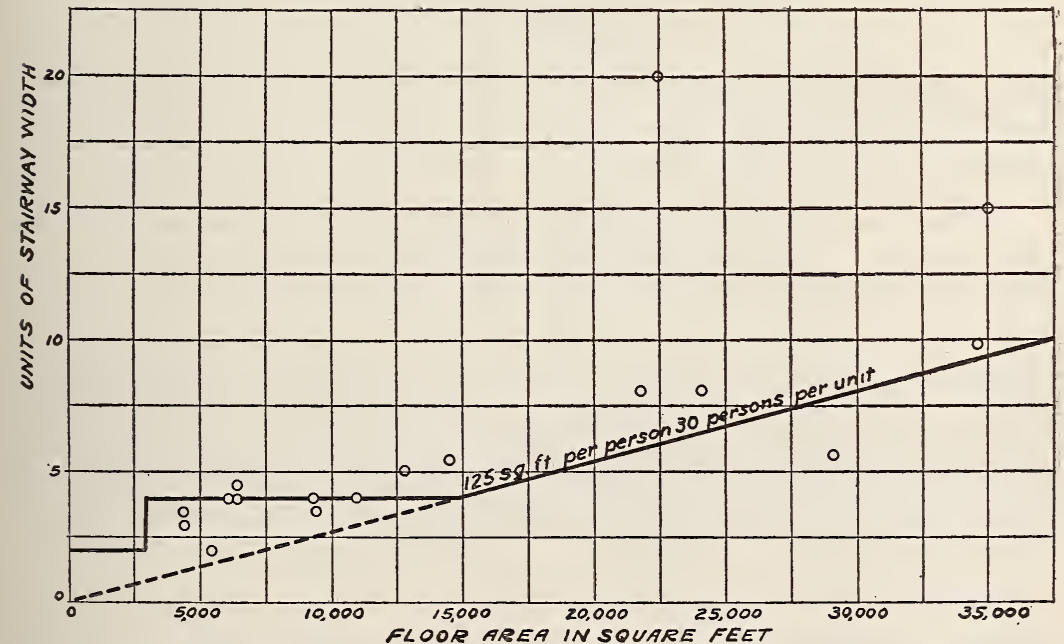

FIGURE 13.-Results of exits survey compared with curve adopted for hotels and dormitories. 
7-6-2. Construction.

7-6-2-1. Materials. ${ }^{47}$

Stairs and landings of exit stairways shall be constructed of incombustible materials; provided, that combustible materials may be used for stairs and landings of interior exit stairways in buildings of type 3 , heavy-timber construction not over 4 stories in height, in buildings of type 4, masonry-wall and joist construction, and of interior and exterior exit stairways for buildings of type 5, wood-frame construction. Exit stairways shall have solid treads.

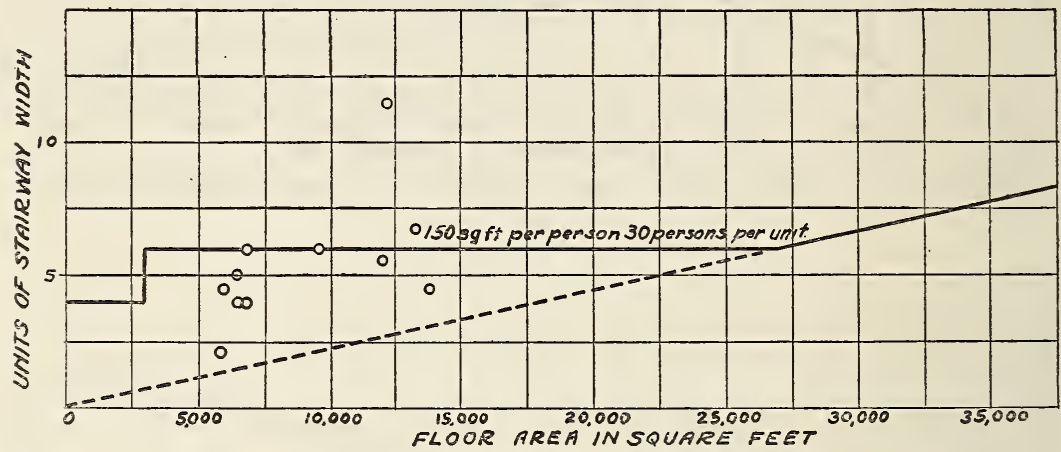

FIGURE 14.-Results of exits survey compared with curve adopted for hospitals and institutions.

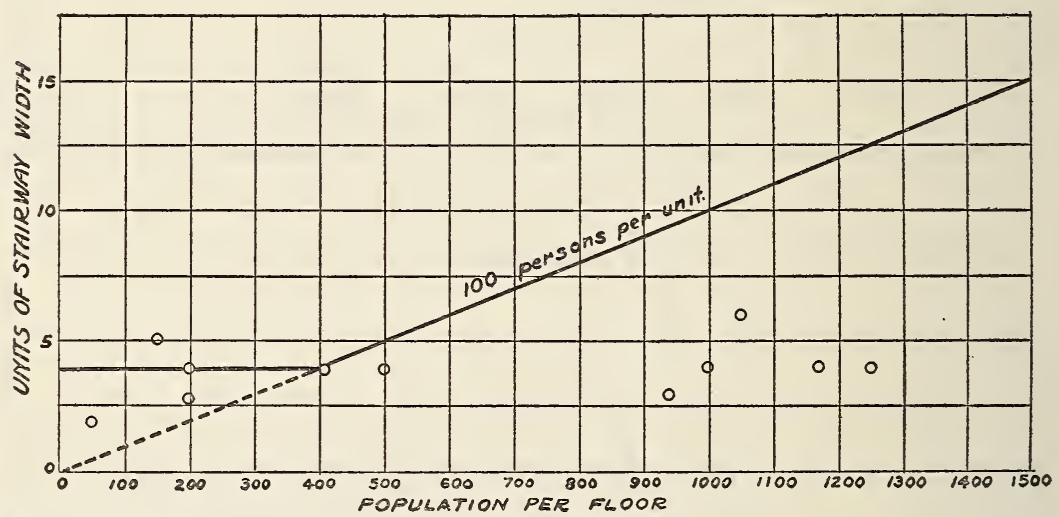

FIGURE 15.-Results of exits survey compared with curve adopted for places of assembly.

${ }^{47}$ In view of the fact that stairways are required to be enclosed in partitions of incombustible materials, it was considered consistent to keep the materials of the stairways themselves in harmony with the rest of the building. There is a point, based on judgment, where combustible materials should be allowed, and a natural point is that of the height of type 4, masonry-wall and joist construction. Accordingly, combustible materials were allowed for stairs and landings of interior exit stairways in buildings of type 3 , heavy-timber construction, not over 4 stories in height, in buildings of type 4, masonry-wall and joist construction, and of interior and exterior exit stairways in buildings of type 5, wood-frame construction. It should be remembered that interior exit stairways are required to be enclosed in fire-resistive partitions as provided in section $7-6-3-1$. Handrails are not required to be of fire-resistive material. 
7-6-2-2. Treads and Risers. ${ }^{43}$

Treads and risers of stairs in exit stairways shall be so proportioned that the sum of the height of 2 risers, in inches, and the width of 1 tread, in inches, is not less than 24 nor more than 25 ; that no riser shall be greater than $7 \frac{3}{4}$ inches in height and no tread less than 9 inches in width, exclusive of nosing. Treads shall be not less than 12 inches in width where flights of less than 3 risers are permitted. Treads less than 10 inches wide ${ }^{49}$ shall have nosings. Treads shall be of uniform width and risers of uniform height in any 1 flight.

Winders shall not be used in exit stairways.

7-6-2-3. Required Landings. ${ }^{50}$

No flight of stairs shall have a vertical rise of more than 12 feet between floors or landings; provided, that in exit stairways in buildings whose occupancy comes under class 1 , public, such vertical rise shall not exceed 8 feet.

The length and width of landings shall be not less than the width of exit stairways in which they occur; provided, in straight runs the minimum distance between risers on landings and platforms shall not be required to be more than 44 inches.

7-6-2-4. Changes in Floor Level.51

In buildings whose occupancy comes under class 1 , public, flights of less than 3 risers shall not be used at entrances or elsewhere in connection with required exits. To overcome lesser differences in level, gradients not exceeding 1 foot in 10 feet shall be used.

7-6-2-5. Handrails. ${ }^{52}$

Exit stairways shall have enclosing walls or well-secured balustrades or guards on both sides; when less than 44 inches in width they shall have handrails on at least 1 side; when 44 inches or more in width, they shall have handrails on both sides.

48 Of the several rules in use for proportioning treads and risers, the one given in this section seems to give results more nearly in agreement with current practice. The matter of the slope of stairs seems to be a very important point, affecting as it does, the comfort and safety of the use of the stairs. A high riser and narrow tread make a steep stair which may become very hazardous under fire conditions. On the other hand, a very low riser and wide tread make travel slow and may render the stair as unsafe as risers and treads of the other extreme. The possibility of the risers being made too high or too low has been overcome by fixing a maximum for the riser height and a minimum for the tread width.

Some recent studies have been made on the relation of tread width to riser height and other features affect ing the use of stairways. Curves plotted for the three well-known rules for proportioning treads and risers of stairways and one or two suggested curves indicate that in the range of riser heights ordinarily found in buildings the tread widths vary only slightly. However, further study of this phase of stairway design appears advisable. For further discussion of the subject, consult articles in the November and December 1933 issues of Architecture entitled "Rake, Riser, and Tread"; and "More Anent the Stair Rule", and "More Anent Stairway Design", in the January and February 1931 issues of Pencil Points.

Stairways which wind as they descend thus causing a difference in width between their inner and outer ends are also hazardous, because there is no uniform width of tread in any one step. As a consequence the user must feel his way carefully and the usual rate of descent is slowed up. There is also an ever-present possibility of tripping because of the varying footing. Winders are frenuently graceful in appearance and it is often desirable to make use of them from an artistic standpoint, particularly in dwellings and monumental buildings. The requirement given does not prohibit their use on monumental stairs, but does exclude their use in exit stairways.

49 The measurement of tread width under this requirement means the run as measured horizontally from the face of 1 riser to the face of the next.

${ }_{50} \mathrm{An}$ unbroken length of stairway extending for some distance creates an effect of steepness that is disconcerting to many people and offers no relief from the fatigue imposed in descending. By breaking up the length of travel through the use of landings, a desirable effect is produced both as regards the appearance of steepness and in providing welcome change from steady descent. The provisions of this section are intended to accomplish these purposes. The vertical height permitted between landings has been decreased in tho case of public buildings because of a greater number of people to be accommodated and the greater possibilities of panic in public gatherings.

51 Short flights of stairs are particularly objectionable and flights of less than 3 risers should not be permitted in public buildings. When the exits are crowded, the stairs are not readily visible and tripping or stumbling is likely to occur. Ramps are much more suitable for such buildings provided the gradient is kept low enough for safe travel.

${ }_{52}$ Handrails are essential in stairways to provide support for persons descending and it is desirable that each filo of persons should have its own support.

Rails also serve as guides to indicate changes from flight to landing, change of direction, and proportion of rise to tread in locations where visibility is poor, or where attention has been diverted to other than travel on the stair. 
When the width of an exit stairway is 88 inches or more there shall be an intermediate handrail continuous between landings; provided, that the number and positions of intermediate handrails shall be such that there shall be not more than 66 inches between adjacent handrails; and provided further, that in schools, there shall be an intermediate handrail when the width of the exit stairway exceeds 66 . inches.

\section{7-6-3. Enclosures.}

7-6-3-1. Construction. 53

Exit stairways in buildings whose occupancies come under class 1, public, class 2 , institutional, class 4 , business, or class 5 , garages, hangars, barns, shall be enclosed with walls or partitions having an ultimate fire resistance of at least 2 hours, and in buildings whose occupancies come under class 3, residential, shall be enclosed with walls or partitions having an ultimate fire resistance of at least 1 hour; provided, that portions of the enclosure outside the walls of the building shall have an ultimate fire resistance of at least 1 hour. On buildings not over 45 feet in height the building official may waive the requirement for enclosure of portions of such stairway outside of the building walls if all openings in the building walls below or within 10 feet horizontally of such stairways are protected by approved fire: doors or stationary fire windows.

Whenever an exit stairway is so constructed that the several flights are not directly above one another, the necessary connecting. hallways shall be enclosed in partitions, floors, and ceilings of the same ultimate fire resistance as required for the type of construction of the building in which they occur but not less than 1 hour in any case, and openings into such hallways shall be provided with approved. fire doors.

7-6-3-2. Openings. ${ }^{54}$

No openings except the necessary doorways, and windows opening: to the exterior of the building, shall be permitted in exit-stairway enclosures. Doorways opening into exit stairways shall be equipped with approved self-closing fire doors; provided, that in schools and institutional buildings approved automatic fire doors so arranged that they can be readily closed may be permitted in lieu of self-closing

\footnotetext{
53 The enclosure of the stairway serves several purposes. It provides a safe line of travel by medns of which the occupants may proceed protected from the flames; it serves as a barrier to upward spread of flames; it prevents smoke from rising to floors above and obstructing egress; and it affords firemen access. to the building for rescue of the occupants or for fighting the fire. In order that these four objectives. may be accomplished it is essential that the partitions forming the enclosures have a substantial degree of fire resistance. One hour fire resistance has been fixed as the minimum. Unless the occupants are removed within that period, the possibility of their eventual removal, if necessary, is extremely remote. The requirements of fire resistance of enclosures varies also with the class of occupancy, being somewhat more severe in those buildings in which large crowds assemble or in which the combustible content is high. ${ }_{54}$ Any opening in a stairway enclosure is admittedly a point of weakness which decreases its efficiency. Good strategy requires that such points of weakness in a defense erected against fire should be made as: few, as small, and as well protected as practicable. This is the intent of the requirements of this section. Self-closing fire doors are required as a general rule in all doorways of stair enclosures except for those. doors which open directly to the exterior or into a protected passageway. In schools and institutional; buildings in which the stairways are used extensively as service stairways, automatic fire doors are permitted in order that these doors may stand open to permit traffic to pass easily. However, as a safety provision it is required that these doors be arranged so that they may be easily closed in an emergency. It is: contemplated that fusible links and weights or checks controlled by a fusible link will be employed to. close these doors in the event of fire. Anticipating that these devices may fail to function, it is further required that evidence be submitted to the building official that other suitable means are provided to close. the doors. For example, smoke may rise from a fire and penetrate the stairway to such an extent that the. stairway becomes impassable and yet sufficient heat may not be generated to melt the fusible link and automatically close the door. Therefore, certain persons must be designated as a part of the fire drills of ${ }^{*}$ the buildings to insure these doors being closed, manually, if necessary, and evidence must be furnisheds the building official that such means are maintained and not simply designated.
} 
fire doors when satisfactory evidence is furnished the building official that adequate devices are installed and maintained for closing such doors in case of fire; and provided, further, that in buildings not over three stories in height whose occupancy comes under class 3 , residential, approved self-closing wood-slab doors of a minimum thickness of $1 \frac{3}{8}$ inches may be permitted.

\section{7-6-4. Moving Stairs. ${ }^{55}$}

Moving stairs which operate normally in the direction of exit travel may be given credit as exit stairways provided they conform to all requirements of this chapter that are applicable.

\section{Section 7-7. Ramps. ${ }^{56}$}

Ramps serving as exits shall not exceed in slope 1 foot in 10 feet.

Ramps may be substituted for exit stairways. Ramps serving as exits shall comply with all the requirements for exit stairways that are applicable. When a doorway opens into a ramp the floor of the ramp shall comply with the requirements for inclined exit passageways given in this chapter.

Ramps shall be provided with an approved nonslip surface.

\section{Section 7-8. Doorways.}

\section{7-8-1. Width. ${ }^{57}$}

No exit doorway shall have a width of less than 36 inches; provided, that in institutional occupancies doorways serving as exits for bedridden patients shall be not less than 48 inches in width.

The aggregate width of exit doorways on any floor serving more than 100 persons shall be not less than at the rate of 22 inches for each 100 persons on that floor.

65 The increasing use of moving stairs in department stores and even in office buildings requires some recognition of these devices as means of egress. They are, however, required to conform to all of the provisions of this chapter that apply to width, enclosure, and hand rails, if they are to receive credit as required stairs. Obviously the requirement for landings between stories of more than a given height as contained in section 7-6-2-3 does not apply. All moving stairs for which credit is given as constituting required means of egress should be of the horizontal tread type. The cleat type is not recognized as a required means of egress.

${ }_{66}$ Ramps are recognized as equal in all respects to a stairway as a means of egress when meeting the requirements of stairways pertaining to width and enclosure. For certain occupancies, such as schools and institutions, they are believed to be more satisfactory and their use in these buildings is recommended. The slope of the ramp and the character of the walkway surface are important points in the construction which should be checked carefully by the building official. As will be evident from a consideration of figures on page 37, ramps have a rate of discharge between that of stairways and level passageways. While this is an added recommendation in their favor as compared with stairways, it has been considered unwise further to complicate the requirements by giving them a special rating.

57 Extensive studies summarized on page 38, were made on rates of flow through doorways with the object of determining an average rate which could be used in calculating the required width of doorways. The studies were made under sufficiently varying conditions and included enough different classes of occupancy to give results which represented a fair average.

Consistent with the requirements for stairway width, the aggregate width of doorways has been expressed in terms of units of 22 inches. This is regarded as a proper basis of computation since it permits one file of persons for each unit of width. Although the studies of flow through doorways revealed that travel was seldom, if ever, in files, yet in buildings in which fire drills are maintained it is essential that the width of doorways be made to accommodate such methods of egress, and in other buildings it serves as a factor of safety.

In speaking of width of doorways, the clear width between jambs is intended. In other words, when a doorway containing 2 doors has 2 separate openings each would be measured separately while if these doors merely meet at the center without the intervention of a mullion the opening would be measured as a whole.

The conclusion from the studies made by other agencies and confirmed by the committee's studies was that rate of travel through doorways with doors fastened open could be maintained at the rate of 60 persons per minute per 22-inch width. This rate was found to be constant up to a width of about 6 feet, beyond which the rate diminished as the doorway became wider, indicating that 6 feet is about the maximum efficient width. Beyond this width it would seem more desirable to introduce additional doors.

Exit-doorway widths for ground-floor areas into which no population from upper floors is discharged are readily computed. However, when a portion or all of the upper-floor population must find its way out from the bottom of a stairway through aisles in the floor area as in department stores, or through lobbies, hallways, or passageways as in office buildings, allowance must be made for this condition.

In sketch 1, figure 16, since none of the population of the upper floors passes through the ground-flocr area, the exit-doorway width for the ground-floor area is figured simply at the rate of 100 persons per 22 inches 
Credit of 50 percent of a unit shall be allowed for 12 inches or more of width added to 1 or more full 22 -inch units of doorway width.

The aggregate width of exit doorways to the outside of a building from aisles, lobbies, hallways, or passageways in which a single exit stairway discharges shall be at least equal to the width of the exit stairway. If there is more than one such exit stairway, the exit doorways to the outside shall be at least equal in aggregate width to three-fourths the combined width of the exit stairways. The aggregate width of the exit doorways shall be further increased at the rate of 22 inches per 100 persons for any additional persons on the floor served by such exit doorways.

of exit-doorway width. This would result in a total required width of 2 units or 44 inches in the case shown. However, because the minimum number of doorways required by saction 7-3-2 would be 2 and because each doorway must be at least 36 inches wide, two 36-inch doorways must be provided.

In sketch 2, figure 16, 1 stairway discharges into a passageway at the ground-floor level and the persons coming down the stairway must find their way out through this passageway to the street. The width of the doorway leading from this passageway must, then, under the requirement, equal the width of the stairway plus an increment of width sufficient to accommodate the portion of the ground-floor population served by the passageway. The determination of what part of the ground-floor population is served by the passageway is a matter for the individual designer, subject to the approval of the building official. In the case shown it is assumed that one-half of the ground-floor population would leave through the passageway, which would make it necessary to add 1 unit of exit width to the width of the stairway, giving a total of 66 inches as the required width of the doorway leading from the passageway. The other door serving the ground-floor population would have to be at least 1 unit wide by calculation, but would be further governed by the requirement of 36 inches minimum width.

In sketch 3 , figure 16, 2 stairways discharge into a passageway which also serves a portion of the groundfloor population. Under the requirement the doorway width leading from the passageway would be $3 / 4$ $(44+44)$ plus 22 inches for the portion of the ground-floor population served, as explained in the previous example. This would result in a total of 88 inches, which would be satisfied by two 44 -inch doorways. The' other doorway serving the ground-floor population would be 36 inches wide as before.

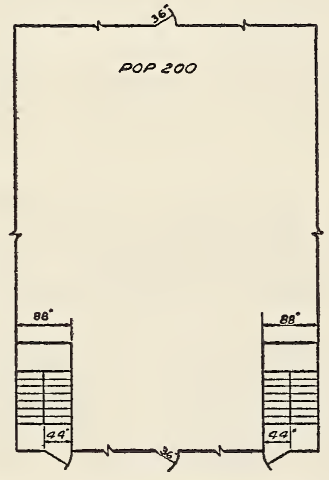

子

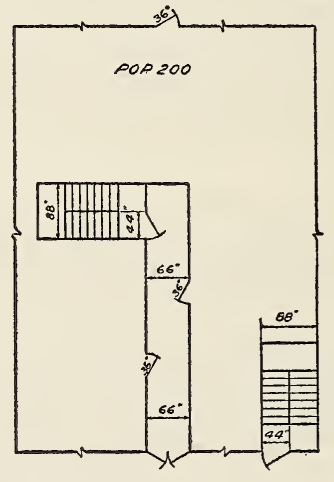

2

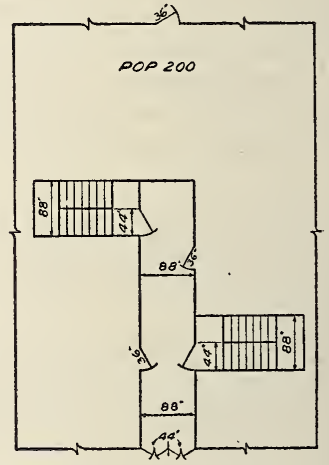

3

FigdRe 16.-Example for computation of doorway widths.

The permission for several stairways to discharge into a passageway only three-quarters the combined width of these stairways is an apparent variation of the rule that the exit width should never diminish in the direction of exit travel. Actually, in terms of potential-fiow capacity there is no change, since the passageway can discharge at a rate four-thirds as fast as the stairways. In the case of 1 stairway, the reduction is not necessary because ordinary design would require a passageway as wide as the stairway whether this width were needed for exit purposes or not. In the case of several stairways, however, the sum of their width would create an unreasonable and unnecesary width of passageway.

In the above examples, occupants have been provided with means of escape involving a combination of doorways, passageways, and stairways. The width of stairways is determined by the population of upper floors as set forth in section 7-6-1. The width of the doorways leading from the building is determined in the manner just explained. The width of the passageways connecting these doorways with the base of the stairways is governed by the width of the doorways as set forth in section 7-9-1. The width of doorways. entering stairways at any given floor may vary with the population on that floor.

It was noted at the fire drill of a large building in which the stairway from the upper floors discharged into the hallways serving the ground floor, that a stoppage occurred at the ground-floor exit door due to the joining of the streams of traffic from the stairway and the ground floor indicating that, although the exit doorway was wide enough for the ground-floor population, its width had not been increased to care for the discharge from the stairway. The stoppage was sufficient to back up the stream of traffic to such an extent that the occupants of the stairway were compelled to remain stationary until the doorway had been cleared and the forward movement down the stairs could be resumed. Panic spreads quickly under such conditions and a jam with consequent blocking of the stairway would seem almost inevitable in case of actual fire. 
The width of exit doorways at the foot of exit stairways or at the head of exit stairways serving basements shall be at the rate of at least 20 inches ${ }^{58}$ for each unit of exit stairway served.

\section{7-8-2. Hanging of Doors. ${ }^{59}$}

The doors of exit doorways shall swing in the direction of exit travel and shall be so hung and arranged that they shall not obstruct the travel along an exit passageway, stairway, or other required exit; provided, that a door swung flat against a wall is not considered an obstruction; and provided, further, that no door shall at any point in its swing reduce the width of an exit stairway by more than 18 inches.

Except in occupancies coming under class 3, residential, exit doorways to a street or an exterior open space leading to a street, shall have the doors, including the doors of vestibules, so hung as to swing outwardly when opening; but this requirement shall not be construed to prohibit the use of doors swinging both inwardly and outwardly or of doors sliding horizontally when used in shipping and receiving rooms in occupancies coming under class 4 , business, nor in class 5, garages, hangars, barns, nor of sliding doors when used in connection with a horizontal exit.

Doors leading from rooms occupied by 50 or more persons shall be hung to swing in the direction of exit travel.

No door of an exit doorway shall open immediately on a flight of stairs, but a landing at least the width of the door shall be provided between such door and such stairs.

\section{7-8-3. Revolving Doors. ${ }^{60}$}

Revolving doors may be used as doors in exit doorways, except in places of assembly, in schools, and in occupancies coming under class 2 , institutional.

58 In most cases the doorways at the foot of stairways can be made the same width as the stairways and where possible this should be done. It has been recognized that in straight run flights of stairs some practical difficulty would be encountered in making the doorway the same width as the stairway, and for that reason the doorway width has been reduced by a maxmum of 2 inches for each unit of stairway width.

59 It will be noted that the doors of exit doorways and doors leading from rooms occupied by 50 or more persons are required to swing in the direction of exit travel. Exit doorways are those required by the proleading to the exterior of the building which are also classified as "exits", and doorways opening into exit passageways.

This permits the doors of classrooms containing less than 50 persons to swing in either direction at the option of the architect. An inwardly swinging door is regarded by some school authorities as giving the classroom teacher better control over the pupils in case of fire.

Residential buildings are exempted from the requirement that all exterior exit doors shall swing outwardly. While this may represent a possible relaxation in the requirements, in view of current practice it seems to be a reasonable one. It takes into account the probability that the occupants will not arrive at the exit doors in a crowd, but that opportunity will be afforded for opening the doors before the maximum use of the doorway is necessary.

60 Revolving doors are given credit as a means of egress in buildings of certain occupancies when limited in use as required by the provisions of section 7-8-3. Certain advantages are claimed over the swinging door in ease of operation and protection against the elements. Considered solely as a means of egress, however, the revolving door has not been given the same credit as the swinging door. Mechanical operation may not be sure and rate of discharge is generally slower, particularly when large crowds of people must be accommodated, and while these doors may possess collapsible features, investigation has shown that unless properly maintained the probability of collapse at the time when needed is uncertain. For these reasons, revolving doors have not been recognized as exits in places of assembly, in schools, in institutional buildings, and at the base of required stairways in all buildings, but their use has not been prohibited for other than exit purposes.

The studies of rate of flow through doorways did not indicate that an increase in width of revolving doors increased the flow through them to any appreciable extent. The revolving door in actual practice is a 1 . line door, i. e., accommodates but 1 file of persons. At the normal revolving speed 1 person can be accommodated in the space between each 2 leaves of the door, but observations made on these doors in actual use indicate that this flow is not steady. Also, unless properly maintained, as the doors become worn from use, the revolving speed is likely to increase, thus hampering a normal flow of persons through the doorway. These considerations led to the decision that only part credit should be given revolving doors as means of egress.

To insure safe egress it was decided to limit the total number of revolving doors that might be used to 50 percent of the required exit width, and to guard against the possibility of the revolving door failing to function, due either to mechanical faults or to the pressure of a crowd against the door, it is required that revolving doors be supplemented by swinging doors. 
Credit for revolving doors serving exit doorways shall be made only at the rate of one-half unit of exit width for each door. Such doors shall not be located inmediately at the foot of exit stairways. Such doors shall not exceed 50 percent of the required width of exit doors and there shall be at least one swinging door for each revolving door in the same general exit opening.

\section{7-8-4. Door Fastenings. ${ }^{61}$}

Fastenings on doors serving exit doorways shall be such that the doors may be readily opened from the inside without the use of keys during the time when the building is occupied, but this requirement shall not apply to the doors of rooms where persons are under legal restraint.

\section{Section 7-9. Exit Passageways. ${ }^{62}$}

7-9-1. Width.

The clear width of exit passageways shall be at least equal to the width of the exit doorways leading from them to the exterior of the building.

\section{7-9-2. Enclosures.}

7-9-2-1. Construction. 63

The walls of exit passageways shall have an ultimate fire resistance of not less than 2 hours.

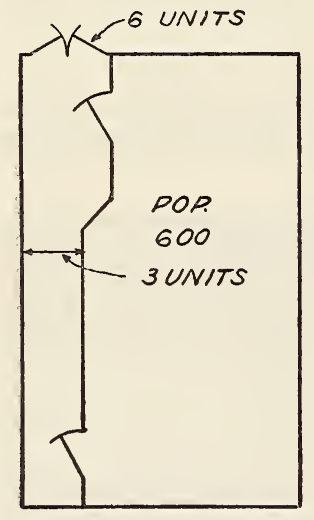

l

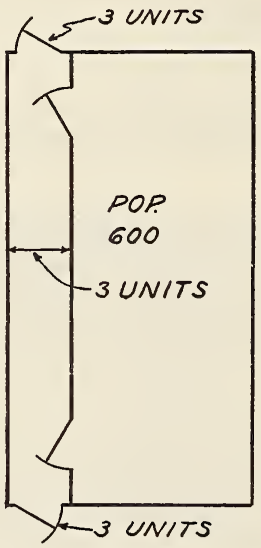

2

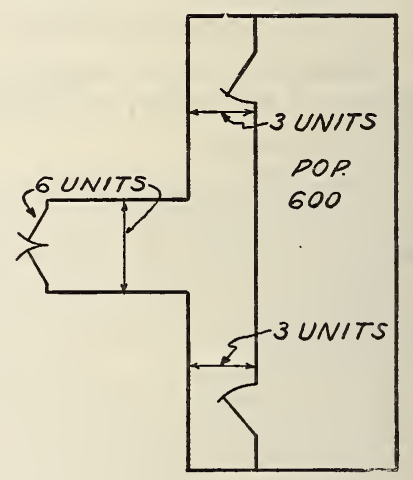

3

FIGURE 17.-Example for computation of exit passageway widths.

${ }_{61}$ The survey of exit facilities in buildings revealed that many exit doors are kept locked during the time when the buildings are occupied, and testimony of building officials indicates that this practice is extremely difficult to prevent. Nevertheless, the necessity of detecting such violations is of primary importance. Doorways, passageways, and stairways may be of ample size and properly designed and distributed to accommodate the population, yet one padlocked exit door may be sufficient to defeat every effort to secure safe and prompt egress. Exit doors are not usually locked in an effort to invite calamity; they are locked as a matter of operating convenience or because of poor maintenance, and it is only by conscientious inspection and the exercise of vigilance on the part of building inspectors and fire marshals, reinforced by severe penalties for violations, that such practices can be abolished.

62 In renuiring the width of exit passageways to be at least equal to the width of exit doorways leading from thom to the exterior of the building, an attempt was made to simplify the method of design and eliminate any unnecessary computations. It is obvious that there is no advantage in making the passageway any wider than the door or doors at the ends and hence, once the exit doorway width has been established, all that is required is that the passageway shall have the same width.

63 The passageway must provide protection to the occupants for an interval adequate to evacuate the space served by the passageway. To do this, the enclosure must have sufficient fire resistance to withstand flame and smoke penetration for at least the time required to complete the evacuation with some margin of safety to allow for an interval between the start of the fire and the sounding of the alarm. This section, which is taken from the Building Code Committee's report entitled " Recommended Minimum Requirements for Fire Resistance in Buildings", is intended to provide this protection. 
The floors and ceilings of exit passageways shall have an ultimate fire resistance at least equal to that required for the type of construction of the building in which they occur, but not less than $1 \frac{1}{2}$ hours.

\section{7-9-2-2. Openings. 64}

No openings other than the exit doorways leading into or out of an exit passageway, and windows to the outer air, shall be permitted. Exit doorways, except those from enclosed stairways discharging into exit passageways and those to the exterior of the building, shall be equipped with approved self-closing fire doors.

\section{7-9-3. Inclined Exit Passageways. ${ }^{65}$}

To overcome differences in level within exit passageways gradients of not more than 1 foot in 10 feet or flights of stairs having not less than 3 risers shall be used; provided, that at a doorway leading into an exit passageway or at the foot of an exit stairway, the floor shall be level across the entire width of such passageway and along its length in the case of the doorway for a distance of not less than 12 inches on each side of the doorway, and in the case of an exit stairway for a distance of not less than 25 inches at the foot of such stairway.

\section{Section 7-10. Hallways.}

The width ${ }^{66}$ of a hallway shall be at least equal to the width of the exit doorway to which it leads.

${ }^{64}$ As in the stairway enclosure, it is necessary that the opcnings in the passageway be kept at a minimum. An exception to the requirement might be made in the case of doors to toilet rooms or service closets.

65 From the very nature of the passageway it is frequently necessary that difference of elevation be overcome, as in the case of a passageway leading occupants of the orchestra floor of a theater to grade level. Flights of stairs are objectionable for obvious reasons. Ramps, on the other hand, are very desirable, if space permits and the slope can be kept within reasonable limits. In order to make the walkway safe and to avoid tripping or falling at doorways or at the foot of stairways, certain level landings are required by this section as illustrated in figure 18.

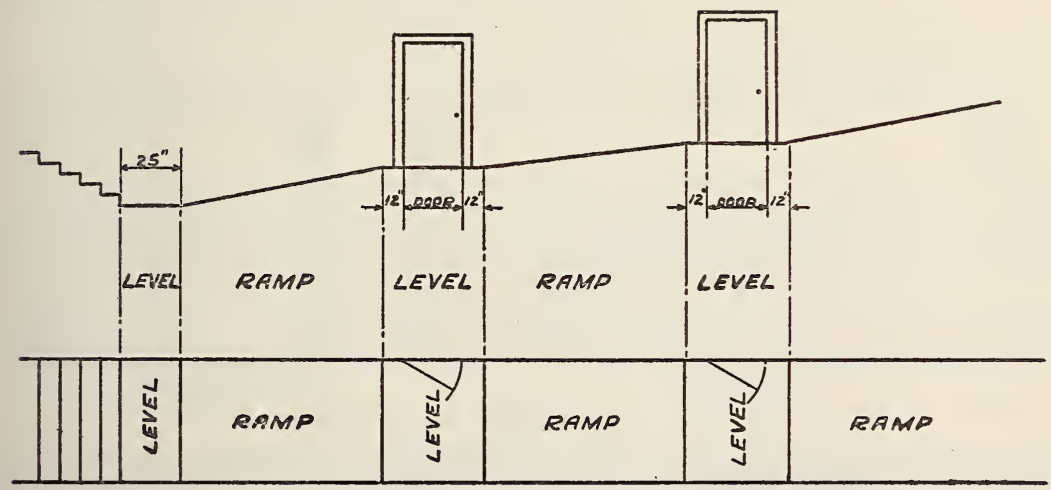

FIGURE 18.-Level landings required on inclined passageways.

${ }_{60}$ The required width of exit doorways which controls hallway width is given in section 7-8-1. 
Section 7-11. Horizontal Exits. ${ }^{67}$

The width ${ }^{68}$ of horizontal exits shall be determined in the same manner as the width of exit doorways.

Horizontal exits shall be equipped with at least one approved fire door; provided, that when located in fire walls or party walls there shall be an approved fire door on each side of such walls, one of which shall be a swinging, self-closing fire door. ${ }^{69}$

The floor area on either side of a horizontal exit shall be sufficient to hold the occupants of both floor areas, allowing not less than 3 square feet net clear area per person.

There shall be at least one exit accessible to or from the space on each side of a horizontal exit.

${ }_{67}$ Horizontal exits are considered to be a very effective means of egress, particularly for those portions of institutional occupancies where, in case of emergency, bedridden patients must be removed from the floor area exposed to fire.

The horizontal exit is a most practical device for providing means of egress from one floor area of a building to an adjoining one, or from one building to a connecting building. Equipped with self-closing or automatic fire doors the space on the far side of the exit becomes a place of refuge having sufficient fire resistance to enable the occupants to make their escape in an orderly manner.

Some examples of horizontal exits are given in figure 19.

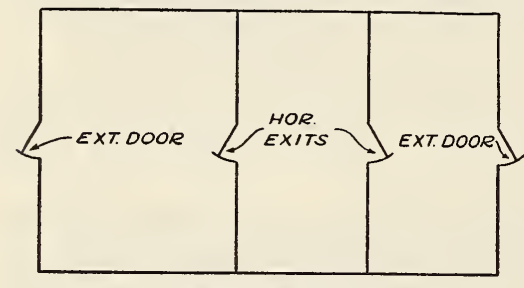

GROUND FLOOR

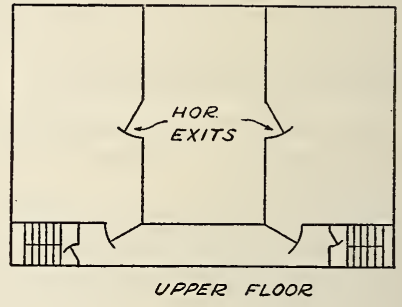

UPPER FLOOR

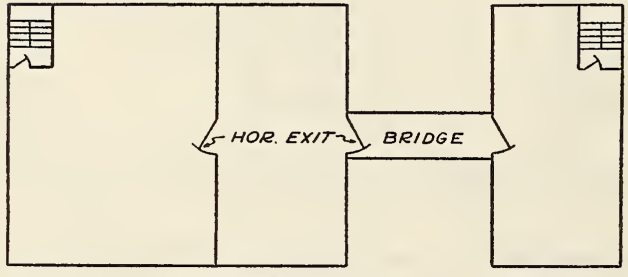

UPPER FLOOR

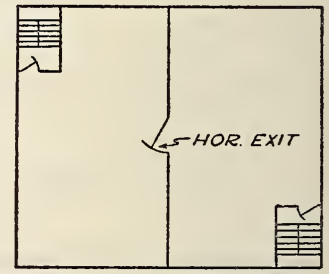

UPPER FLOOR

Figure 19.-Various types of horizontal exits.

If all of the effectiveness of the horizontal exit is to be utilized, it is necessary that sufficient clear space be provided on each side to hold all of the occupants of the areas on both sides. This space may consist of aisles or open spaces providing at least 3 square feet of standing room per person. This is the minimum space which will permit movement; more is desirable if possible, but the minimum will serve the purpose of a place of refuge. Elevator lobbies are frequently so constructed with fire-resistive walls and fire doors that they may serve as places of refuge. These are practically all clear space.

Having reached the place of refuge on the safe side of a horizontal exit it is not contemplated that the occupants remain there indefinitely, although to do so may be safe. Access must be provided to additional exits which lead to the street as the place of ultimate safety. Such additional exits may consist of doorways or other horizontal exits leading to the exterior or to hallways communicating with a stairway, or to horizontal exits leading to a connecting building, or stairways leading to the street may be provided on each side of the horizontal exit. Whatever the method employed access must finally be had to a stairway or ramp leading to the street.

68 The minimum and aggregate width of horizontal exits is determined in the same manner as that for exit doorways given in section 7-8-1.

${ }^{69}$ From an exit standpoint, provision for a door on each side of a fire wall may prove to be awkward. Two doors are, however, necessary to meet fire-resistance requirements. A desirable arrangement would provide a vestibule on one side of the wall so that the occupants will not be confronted with the problem of opening two doors at almost the same instant. 
Horizontal exits complying with the requirements of this section may be substituted for stairways or other exits. ${ }^{70}$

Vestibules, open-air balconies, or bridges serving as horizontal exits shall be constructed of incombustible materials and their clear width shall be at least equal to the width of the exit doorway opening into them.

Doorways or windows opening on, below, or within 10 feet of such vestibules, balconies, or bridges shall be equipped with approved self-closing fire doors or approved stationary fire windows.

Where there is a difference in level between the connected floor areas, gradients of not more than 1 foot in 10 feet shall be provided. No stairs or steps shall be used in a horizontal exit. ${ }^{71}$

\section{Section 7-12. Modifications in Required Exit Widths. ${ }^{72}$}

There shall be no reduction in required width along the line of exit travel, except as specifically permitted in this chapter.

\section{Section 7-13. Exit Designation. ${ }^{73}$}

\section{7-13-1. Exit Signs.}

Exits shall be indicated by suitable signs or lights at all times when the building is occupied. In places of assembly accommodating more than 100 persons exits shall be plainly marked by approved signs, sufficiently illuminated when such places are occupied, to be readily distinguished.

In places of assembly exit lights and lights used for the illumination of exit signs and lights for the lighting of halls, corridors, and any other parts of places of assembly used by the audience, except the general auditorium lighting, shall be fed independently of the stage lighting, and shall be controlled only from the lobby or other convenient place in the front of the house.

In buildings where exit lights or signs or the exits themselves are not visible from every point in a hallway or undivided floor area, suitable directional signs indicating the location of the exit shall be provided.

70 This provision is intended to prevent the substitution of a horizontal exit on a single floor for a stairway running through the entire height of the building. Its effect would be to provide a horizontal exit on each floor served by the stairway allowed to be eliminated. Such an arrangement may sometimes be advantageous as is shown in the following example: A factory containing 3 floors of 60,000 square feet each has a fire wall extending up through the building dividing it into 2 approximately equal sections each of which contains 2 stairways. By providing a horizontal exit of suitable size in the wall, 1 stairway can be eliminated on each side of the wall, reducing the total number of stairways in the building from 4 to 2 .

71 Where the bridge or balcony is not enclosed and the climate such as to involve the possible blocking of the doors by snow or ice, it is desirable to place the level of the bridge floor below the level of the building floor by the height of an ordinary riser-73/4 inches. Otherwise the building-floor level and the balcony or bridge-floor level may be the same.

72 Concerning reduction in doorway width where the population from 2 or more stairways merges, see section 7-8-1.

73 Adequate exit marking, although often neglected, is an essential feature to secure safe egress. This is particularly true in those buildings frequented by transients, who cannot be expected to be familiar with the location of exits.

In many codes, places of assembly for religious gatherings are exempted from the provisions of this section. There seemed no more reason for exempting such assemblies than for assembly rooms used for a political gathering. The hazard appears equal in either case and fire records testify that churches are not more immune to the dangers of fire than many other buildings in which nonreligious gatherings are held. Properly designed and placed exit signs should not detract from the beauty of the interior of a church and there can be no question as to their value in promoting safe egress should a fire occur.

The requirements of section 7-13-1 are based on the recommendations of the National Electrical Safety Code.

The reasonableness of the requirements for exit designation would seem to be so obvious as to make their incorporation in a code unnecessary. Yet the most casual observation will reveal how infrequently the provisions are carried out. In these days of high-speed elevators the tenant of the average office building, hotel, or apartment house may not even know the location of the stairway and certainly has but small occasion to use it to the extent of becoming familiar with it at different floor levels. This fact emphasizes the importance of marking the street-level door of the stairway so that there can be no mistaking when that level has been reached. In the confusion attending a fire the occupants might easily follow the stairway down into the basement and lose valuable time in seeking egress to the street unless the street level was clearly marked. 
Exit stairways shall be so arranged or marked as clearly to indicate the level at which there is direct exit to a street or to an exterior open space leading to a street.

\section{7-13-2. Lighting.}

Exits and hallways leading to them shall be kept adequately lighted at all times when the building is occupied.

Artificial light shall be provided whenever natural light is inadequate.

In buildings whose occupancy comes under class 1, public, or class 2 , institutional, the artificial lighting required by this subsection shall be separate and independent from that serving other parts of the building.

\section{Section 7-14. Maintenance. ${ }^{74}$}

Exits, and other means of escape when permitted, shall at all times be maintained in good, safe, usable condition, and shall at all times be kept free and clear of obstructions and shall be readily accessible. Exits shall be kept free from combustible material or decorations. No part of an exit shall be used for storage. The space under stairs shall be kept clear and free. No fire-extinguishing apparatus, radiator, steam or other riser shall be placed in an exit or in a hallway leading to it, nor in an aisle of a floor area in which seating accommodation is provided, unless placed in such a manner as not to interfere with free travel, and unless heating apparatus is guarded by substantial metal screens.

\footnotetext{
${ }^{74}$ It is the intent of this section that exits shall at all times be kept in an unobstructed condition and free from combustible materials, including decorations which may be hung in stairways or hallways and provide a possible fire hazard. There is at least one instance on record in which such decorations in a stairway were ignited and not only rendered the stairway impassable but communicated the fire to other portions of the building.

Maintenance of exit facilities is one of the most difficult provisions of building regulations to enforco according to building officials. Exit doors are locked; self-closing fire doors are werged in the open position; stairways and passageways are utilized for the storage of materials, combustible as well as incom. bustible; fire escapes are blocked and the lower swinging portion is permitted to rust and become unusable; to mention only a few of the violations of maintenance provisions.

During the survey of exit facilities made in connection with the preparation of egress requirements, the condition of the exits was investigated carefully to determine how closely the maintenance provisions were being carried out. The conditions were most deplnrable. Scarcely a building was inspected which drd not show a violation in one form or another, the most common being the wedging of self-closing fire doors and the utilization of stairways and hallways as storage space for combustible materials. It would scem that unless frequent and thorough inspections necessary to secure proper administration of code maintenance provisions were carried out, coupled with sufficiently severe penalties for infraction of rules, much of the effort and careful planning necessary to provide proper exit facilities would be at least partially neutralized by inadequate maintenance.
} 


\section{INDEX TO RECOMMENDATIONS}

A Page

Aisle width

Application of chapter VI

Approved, definition of

Areas:

Assumed per person

For various occupancies

57

46

Areas:

Below grade

Stairways serving in types 1 and 2 buildings_. 53

In other types of construction............... 53

Alterations involving:

Changes of occupancy

Physical changes

Automatic fire doors:

Definition

Required. $66,71,72$

B

Balconies:

Horizontal exits.

Population of

Separate stairways for

Basements:

Population of

Stairways from

Boiler-room exits.......... 54

Bridges as horizontal exits.................... 47,73

Buildings:

Fixisting

New

D

Definitions

46

Department stores

Aisles.

Aggregate exit widths

Location of exits

Minimum number of exits--

Minimum winth of exits

Stairways ending in first-floor area......... 57

Distance to an exit:

Maximum permitted.................... 55

Special limitations....... 55

Doors:

Automatic fire-_...

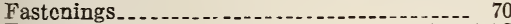

Firc

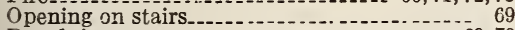

Revolving

Swing not to create obstruction.--.........-. 69

Hanging

Doorways:

Aggregate width

Minimum number............................. 51,52

Minimum width

Dwellings excepted from requirements.--..--- 50

Enclosures:

\section{$\mathbf{E}$}

Of lobbies

Of stairways.-...... 66

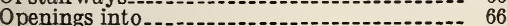

Existing buildings:

Dwellings excepted

Inadequate exit facilities........... 50

Exit:

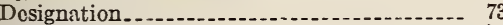

Lighting -

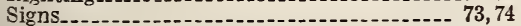

Exits:

Aggregate width of

Distribution of ...... 55,56

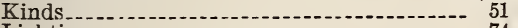

Lighting-(-.-..... 74

Location-1-... 55

Minimum number.-.-........... 51, 52, 53,54

Modifications in required width

Relation of population to............. 57

Signs.
Factory exits:

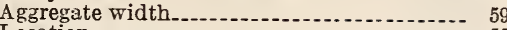

Location . - . .

Minimum number.................. 51, 52, 53

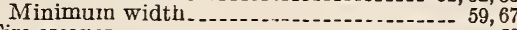

Fire escapes.

Fire doors:

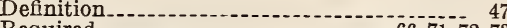

Required

Fire walls, definition of

Fire window:

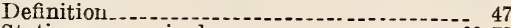

Stationary required................ 66,73

Floor are:

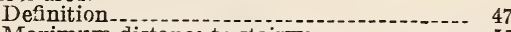

Maximum distance to stairway

Minimum number of stairways......... $52,53,54$

Floor exits:

Aggregate width

Distribution-...- 55, 56

Minimum number of, exceptions......... 53

Minimum width

Floor level, changes in

Fractions:

How treated when computing.............. 60

Aggregate stairway width ......... 60

Grade:

$\mathbf{G}$

Definition

Stairways serving areas below in types 1 and 2

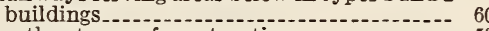

In other types of construction..... 53

Gradients:

Maximum permitted

67,71

Stairs in connection with

Ground-floor exits:

Aggregate width

Distribution

Minimum number.............-... 53

Minimum width...... 67

Hallways:

Openings into

Width

Handrails required

Horizontal exits:

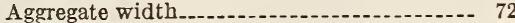

Definition -.........-. 47

Differences in level...-.... 73

Doors in connection with.-. 72

Exits on each side of

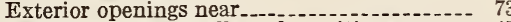

Fire resistance of walls and partitions........ 47

Floor area on each side of

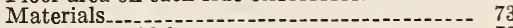

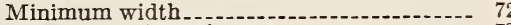

Substitution for stairways

Hospitals. See: Institutional occupancies.

I

Institutional occupancies:

Aggregate width of exits.

Distribution of exits................. 55

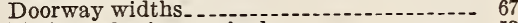

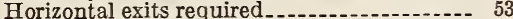

Minimum number of exits.....-...-..-..- 51

Minimum width of exits.......... 59,67

Stairways to outside............ 56

Kinds of exits:

$\mathbf{K}$

Doorways.

Horizontal exits.-...- 72

Passageways.......... 70

Ramps

Recognized as required exits............-..- 51

Stairways.............. 59 
Landings:

$\mathbf{L}$

Page

Length

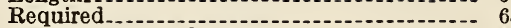

Vertical distance between

Width

Lighting of:

Stairways.

Passageways, etc.

Exit signs

Lobbies:

Clear space when served by horizontal exits_. 72

Enclosure when stairways terminate in.....- 56

Location of exits:

Distribution

Maximum distance to exits......... 55

Outlets from exits

Maintenance:

\section{M}

Combustible material

Space under stairs

Storage.

Materials for:

Stairs.

Stairway enclosures

Walls and partitions

Maximum distance to an exit

(1) 55

Minimum number of exits

Minimum width of exits................. 59,67

Modifications in exit width

Moving stairs, requirements for

New buildings:

Application of chapter to

D wellings excepted.... 50

Number of exits:

For boiler rooms

For rooms

For ground-floor areas

For other floor areas........... 53

For institutional occupancies...-_...-...-... 53

For places of assembly ........

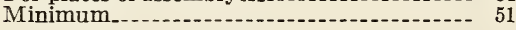

Office buildings:

\section{O}

Aggregate exit width.

59,67

Location of exits

59,67

Minimum number of exits

Minimum width of exits.-.-..- 59, 67

Outlets from exits . .

Passageways:

Agrregate width

Definition of exit passageway...... 46

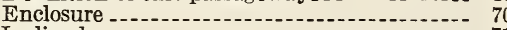

Inclined.

Minimum width

Openings in enclosure

Places of assembly:

Aggregate width of exits..._._._._._._._. 59,67

Definition

Marking of exits...-...-. 73

Minimum number of exits......... 54

Minimum width of exits.-.-...- 59,67

Theater stairways to be separate...-...- 54

Population:

Determination of

Limited by requirements..-.

Relation of exits to.....
Ramps:

$\mathbf{R}$

Page

Maximum slope

Requirements for............................ 67

Substituted for stairways............-. 67

Risers. See: Treads and risers.

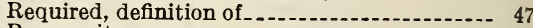

Room exits........

Schools:

$\mathbf{S}$

Aggregate exit width

Assembly halls in

Doors into stairways -............ 66

Location of exits

Minimum number of exits

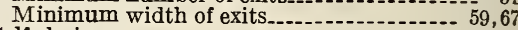
Self-closing:

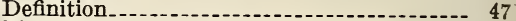

Fire doors required......... $66,71,72,73$

Signs:

At street level in stairways.................... 73

Directional-1.-

Lighting of -

Location of - 73

When required.....

Sprinklers:

Affecting minimum distance to an exit_...-- 55

Affecting minimum number of stairways.... 53

Definition

Stairways:

Aggregate width

Changes in floor level

Construction of enclosures......... 66

Definition............. 47

Distribution of

Exterior

Handrails. - 65

Lighting

Location of

Materials_-......... 64

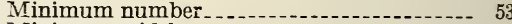

Minimum width

Moving ........... 67

Not continuous.-1..- 66

Openings-o..- 66

Outlet from. . .

Treads and risers..... 65

Street, definition of

Theaters: $\quad \mathbf{T}$

Aggregate width of exits..._._. 59

Definition

Minimum number of exits

Minimum width of exits.-.- 59,67

Population

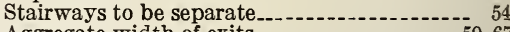

Aggregate width of exits

Tier, stairways for

Treads and risers, rule for width and height.-. 65

$\mathbf{U}$

Ultimate fire resistance, definition of

Unit:

Definition............ 59

Width of

$\mathbf{v}$

Vestibules as part of horizontal exits............ 73

\section{$\mathbf{w}$}

Winders prohibited

Windows:

Permitted in exit enclosures..................... 66

Protected where near exits........................... 73 

